\title{
Fetal death
}

\section{Population-based studies of pregnancies in Norway}

\author{
Ashi Sarfraz Ahmad \\ Department of Obstetrics and Gynecology \\ Akershus University Hospital \\ Institute of Clinical Medicine, \\ Akershus University Hospital \\ Faculty of Medicine \\ University of Oslo \\ Norway 2014
}

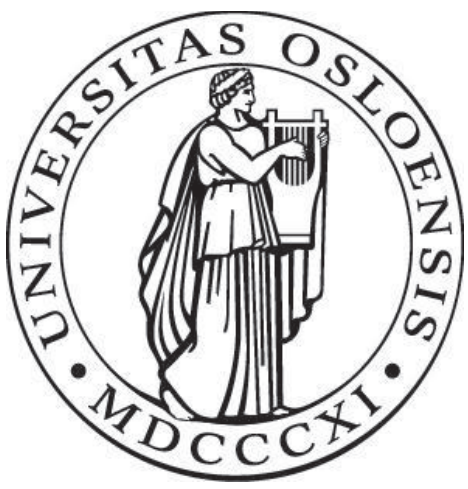


(C) Ashi Sarfraz Ahmad, 2014

Series of dissertations submitted to the Faculty of Medicine, University of Oslo No. 1863

ISBN 978-82-8264-771-0

All rights reserved. No part of this publication may be reproduced or transmitted, in any form or by any means, without permission.

Cover: Hanne Baadsgaard Utigard.

Printed in Norway: AIT Oslo AS.

Produced in co-operation with Akademika Publishing.

The thesis is produced by Akademika Publishing merely in connection with the thesis defence. Kindly direct all inquiries regarding the thesis to the copyright holder or the unit which grants the doctorate. 


\section{TABLE OF CONTENTS}

ACKNOWLEDGEMENTS

PAPERS INCLUDED IN THIS THESIS

DEFINITIONS AND ABBREVIATIONS 8

1. INTRODUCTION 11

1.1 Definition of fetal death/stillbirth 12

$\begin{array}{ll}1.2 \text { Scope of fetal death/stillbirth } & 15\end{array}$

2. SYSTEMATIC REVIEW OF THE LITERATURE ON RISK FACTORS FOR STILLBIRTH

2.1 Maternal age 20

$\begin{array}{lll}2.2 & \text { Parity } 21\end{array}$

2.3 Maternal weight 21

2.4 Medical conditions 23

$\begin{array}{lll}2.5 & \text { Smoking } 25\end{array}$

2.6 Alcohol and coffee consumption 26

$\begin{array}{lll}2.7 & \text { Social disparities and race/ethnicity } 27\end{array}$

2.8 Intrauterine growth restriction 29

2.9 Gestational age 30

$\begin{array}{ll}2.10 \text { Previous stillbirth } & 30\end{array}$

3. CAUSES AND CONSEQUENCES OF STILLBIRTH

4. CONCERNS AND GAPS RELATED TO STUDIES OF STILLBIRTH 47

5. AIMS OF THE THESIS

6. MATERIALS AND METHODS 53

6.1 Toxoplasmosis study 53

6.1.1 Study design and population 53

6.1.2 Blood sampling and analysis 53

6.1.3 Variables 54

6.1.4 Statistical analysis $\quad 55$

6.1.5 Ethical aspects $\quad 56$

6.2 The Medical Birth Registry of Norway 56 
6.2.1 Study design and population $\quad 57$

6.2.2 Variables 58

6.2.3 Data preparation 61

6.2.4 Theoretical basis of the statistical analysis 61

6.2.5 Statistical analysis 62

6.2.6 Ethical aspects $\quad 65$

7. MAIN RESULTS (summary of Papers I-IV) 66

$\begin{array}{ll}7.1 \text { Paper I } & 66\end{array}$

$\begin{array}{ll}7.2 \text { Paper II } & 67\end{array}$

$\begin{array}{ll}7.3 \text { Paper III } & 68\end{array}$

$\begin{array}{ll}7.4 \text { Paper IV } & 69\end{array}$

8. DISCUSSION 70

8.1 Methodological considerations $\quad 70$

$\begin{array}{ll}8.2 \text { Interpretations of the results } & 78\end{array}$

8.2.1 Maternal parvovirus B19 infection and risk of fetal death 78

8.2.2 Trends in fetal death in Norway 81

8.2.3 The impact of maternal age and fetal death 84

8.2.4 Hypertensive disorders in pregnancy and risk of fetal death 87

9. CLINICAL IMPLICATIONS AND FUTURE CHALLENGES 90

10. REFERENCES 92

$\begin{array}{ll}\text { Appendix I } & 117\end{array}$

PAPERS I-IV

APPENDICES

Medical Birth Registry Form 1967-1998

Medical Birth Registry Form 1999-present 


\section{ACKNOWLEDGEMENTS}

The present work was carried out at the Department of Obstetrics and Gynecology at Akershus University Hospital and The Institute of Clinical Medicine Faculty Division of Akershus University Hospital, University of Oslo with grants from the Norwegian Extrafoundation for Health and Rehabilitation, for which I am very grateful.

First of all I would like to thank my two wonderful and knowledgeable supervisors Professor Sven Ove Samuelsen and Professor Dr. Jeanette Magnus. I would like to express my deepest gratitude to Jeanette for stepping in as my supervisor, for guiding me, encouraging me and for believing in me. Your high scientific standards and professionalism are really admirable! I am so grateful to have had the chance to work with you.

I would also like to thank Professor Sven Ove Samuelsen, for his knowledge and genuine, continuous support throughout the years. I am really impressed by your knowledge; you always seem to have the answer to any complicated mathematical challenge. Thank you for always being available for questions and conversations, but not too early in the morning.

I would also like to thank former head of department Dr. Arne Urnes and Dr. Runar Eraker for having created a wonderful working place and for your support and conversations in difficult times. Thanks to Dr. Pernille Schjønsby and Dr. Hege Lundring who have taken over the baton of leadership and managed to preserve the unique milieu at KK. Dr. Renate Häger my clinical supervisor for sharing your clinical wisdom with me and being an inspiring role model. Thanks to all my colleagues at the Department of Gynecology and Obstetrics at Akershus University Hospital, for working so hard, almost never complaining and for creating the best working environment in the world. I also thank Professor Anne Eskild for her guidance when writing the papers.

All the cool researchers at the "Villa", for good conversations and meetings and for being who you are. Especially Dr. Camilla Haavaldsen, my good friend and co- 
author, it has been a pleasure to work and travel with you, and to share ups and downs with you. And I am looking forward to working in the clinic with you in the future.

My deep thanks Dr. Drude Fugelseth, Karin Vassbakk and Andrè Øyen of the Faculty of Medicine.

I have been privileged to have such excellent researchers as Dr. Fredrik Frøen Professor Leif Bakketeig and Dr. Vasilis Sitras reading my thesis and giving highly valued constructive comments.

The Medical Birth Registry of Norway for providing data for this work, and my thoughts goes out to all the women who lost their child.

My family and friends for supporting and helping me. Especially my parents for always believing in me and for being such good role models. My good friends "Verksted-jentene" your support, good spirit and excellent food has been invaluable during the years.

My children Mariam, Adam and Maria you mean everything to me and always remind me of what really matters in life. And finally my dear husband Tuqeer, thank you for your support, I could not have done this without your encouragement. Thank you for believing in me!

Lørenskog, October 2014

Ashi Sarfraz Ahmad 


\section{PAPERS INCLUDED IN THIS THESIS}

\section{Paper I.}

Sarfraz AA, Samuelsen SO, Bruu AL, Jenum PA, Eskild A. Maternal human parvovirus B19 infection and the risk of fetal death and low birthweight: a casecontrol study within 35940 pregnant women. BJOG 2009;116:1492-1498.

Paper II.

Sarfraz AA, Samuelsen SO, Eskild A. Changes in fetal death risk during $\mathbf{4 0}$ years - different trends for different gestational ages: a population-based study in Norway. BJOG 2011;118:488-494.

Paper III.

Haavaldsen C, Sarfraz AA, Samuelsen SO, Eskild A. The impact of maternal age on fetal death: does length of gestation matter? Am J Obstet Gynecol 2010;203:554.e1-8.

Paper IV.

Ahmad AS, Samuelsen SO. Hypertensive disorders in pregnancy and fetal death at different gestational lengths: a population-based study of $2,121,371$ pregnancies. BJOG 2012;119:1521-1528. 


\section{DEFINITIONS AND ABBREVIATIONS}

\section{DEFINITIONS}

Antepartum:

An event happening before labor.

Chronic hypertension: Pre-pregnancy blood pressure of $\geq 140 \mathrm{mmHg}$ systolic or $\geq 90 \mathrm{mmHg}$ diastolic or increased blood pressure diagnosed before 20 weeks of gestation.

Early neonatal mortality: Neonatal death within 7 days of birth.

Eclampsia:

Preeclampsia with seizures.

Fetal death, Papers I-III: Birth of a dead fetus $\geq 16$ weeks of gestation.

Fetal death, Paper IV: $\quad$ Birth of a dead fetus $\geq 20$ weeks of gestation.

Gestational hypertension: Increase in maternal blood pressure to $\geq 140 / 90 \mathrm{mmHg}$ after completed 20 weeks of gestation.

Intrapartum: An event happening during labor.

Perinatal mortality rate,

Papers II and IV:

Sum of infant deaths in pregnancies lasting $\geq 22$ weeks (154 days) and within 7 days of birth, per 1000 births.

Pre-eclampsia: Increase in maternal blood pressure of $\geq 140 / 90 \mathrm{mmHg}$ combined with proteinuria after completed 20 weeks of gestation, measured on at least two occasions 6 hours apart.

Stillbirth, Paper II: $\quad$ Birth of a dead fetus $\geq 22$ weeks of gestation. 


\section{ABBREVIATIONS}

\begin{tabular}{ll} 
BMI & Body mass index \\
CASP & Critical Appraisal Skills Programme \\
CI & Confidence interval \\
HR & Hazard ratio \\
ICD-10 & International Classification of Diseases Revision 10 \\
IgM & Immunoglobulin M \\
IgG & Immunoglobulin G \\
IUGR & Intrauterine growth restriction \\
LMP & Last menstrual period \\
MBRN & The Medical Birth Registry of Norway \\
OR & Odds ratio \\
PCR & Polymerase chain reaction \\
PVB & Human parvovirus B19 \\
PMR & Perinatal mortality rate \\
RCT & Randomized controlled trial \\
RR & Relative risk (risk ratio in Paper IV) \\
SES & Socioeconomic status \\
SGA & Small for gestational age \\
SPSS & Statistical Package for the Social Sciences \\
T. gondii & Toxoplasma gondii \\
WHO & Health Organization \\
\hline &
\end{tabular}




\section{INTRODUCTION}

In Norway more than 200 infants $\geq 22$ weeks of gestation are stillborn each year. ${ }^{1}$ The global health impact of stillbirth is large, it is estimated that there are more than 2 million stillbirths annually. However, the true number is probably higher, as underreporting is common. ${ }^{2 ; 3}$ During the last 50 years stillbirth rates have declined in high-income countries, and the majority of cases (>98\%) now happen in low- to middle-income countries. ${ }^{4}$ This reduction can be attributed to improvements in public health, and in medical and antenatal care.

In Norway the late fetal mortality rate ( $\geq 28$ weeks of gestation) dropped from around 40 per 1000 births in 1850 to 2 per 1000 births in 2012. ${ }^{1: 5}$ Most of this decline happened between 1950 and 1980, but recently it has slowed. ${ }^{6 ; 7}$ In high-income countries fetal mortality rates have stagnated, and sometimes risen, ${ }^{8 ; 9}$ though these phenomena seem to be region-specific. In some regions this may be due to an increased prevalence of certain risk factors (i.e. advanced maternal age, obesity, multiple pregnancies) for fetal death in women of childbearing age,$^{10}$ while in others the availability of prenatal diagnostics and induced termination of pregnancies may be the explanation. ${ }^{11}$

Causes of fetal death are complex and incompletely understood. Etiological studies reported that between $9 \%$ and $60 \%$ of fetal deaths are unexplained, that is, no maternal, fetal, placental or obstetric cause could be found. ${ }^{12-17}$ Norwegian studies reported between $19 \%$ and $43 \%$ of stillbirths as unexplained. ${ }^{16 ; 18 ; 19}$ Differences in the proportion of stillbirths classified as unexplained are due to variations in the extent of the investigations performed after fetal death, but are also dependent on the classification system applied. ${ }^{10 ; 20}$ In order to prevent fetal death, it is imperative to achieve a better understanding of its causes and risk factors. In order to inform preventive initiatives, caregivers and governments are reliant on relevant studies.

Nearly 30 years ago, Yudkin and colleagues reported that the risk of fetal death varied by gestational age, increasing gradually with increasing gestational age. ${ }^{21}$ Recent studies have reported that the causes of fetal death also vary by gestational age ${ }^{13 ; 22}$ As distribution of causes vary by gestational age, risk factors may also 
contribute differently to risk of fetal death depending on gestational age. Interaction between certain risk factors for fetal death such as maternal age ${ }^{23}$ racial disparity, ${ }^{24}$ and educational level ${ }^{25}$ and gestational age has been implied, but needs to be further explored.

Furthermore, it is widely accepted that stillbirths may be prevented by selective, timely elective delivery of fetuses at risk of death, however, the outcome of this intervention is dependent on gestational age. This concept has contributed to a leftshift in the population distribution of gestational age at birth by increasing the number of iatrogenic premature births, ${ }^{26}$ but at the same time decreasing the stillbirth rate. The timing of delivery in pregnancies with increased risk of stillbirth is thus challenged by the competing risks of neonatal morbidity (neurodevelopmental impairments, respiratory distress, and gastrointestinal complications) associated with preterm birth. $^{27}$

In addition, studies of gestational-age-specific risk may guide clinicians on when to initiate antenatal care, and add to the knowledge on the pathological processes leading to stillbirth.

The overall aims of this thesis were to study how the fetal mortality rate varies across gestation and over time in the Norwegian population. The findings should advance the understanding of fetal death, and at the same time evaluate the Norwegian healthcare system.

In the following sections a definition of fetal death/stillbirth is given followed by a comprehensive review of the literature on certain risk factors for stillbirth and a brief overview of causes and consequences of stillbirth.

\subsection{Definition of fetal death/stillbirth}

The World Health Organization (WHO) in its International Classification of Diseases Revision 10 (ICD-10) defines fetal death as:

"Death prior to the complete expulsion or extraction from its mother of a product of conception, irrespective of the duration of pregnancy, the death is indicated by the 
fact that after such separation the fetus does not breathe or show any other evidence of life, such as beating of the heart, pulsation of the umbilical cord, or definite movement of voluntary muscles". ${ }^{28}$

The WHO further distinguishes between early fetal deaths/stillbirths (death of a fetus with a birth weight $\geq 500 \mathrm{~g}$, if birth weight not available gestational age $\geq 22$ weeks or crown-heel length $\geq 25 \mathrm{~cm}$ ) and late fetal deaths/stillbirths (death of a fetus with a birth weight $\geq 1000 \mathrm{~g}$, if birth weight not available gestational age $\geq 28$ weeks or crown-heel length $\geq 35 \mathrm{~cm}$ ) (Figure 1).

In the United States and Canada fetal death are categorized into early fetal death (20-27 weeks of gestation) and late fetal death ( $\geq 28$ weeks of gestation). Stillbirth categorization may also be based on timing of death in relation to labor; antepartum (prior to onset of labor) and intrapartum (during labor). The majority of stillbirths in high-income countries are antepartum. ${ }^{29}$

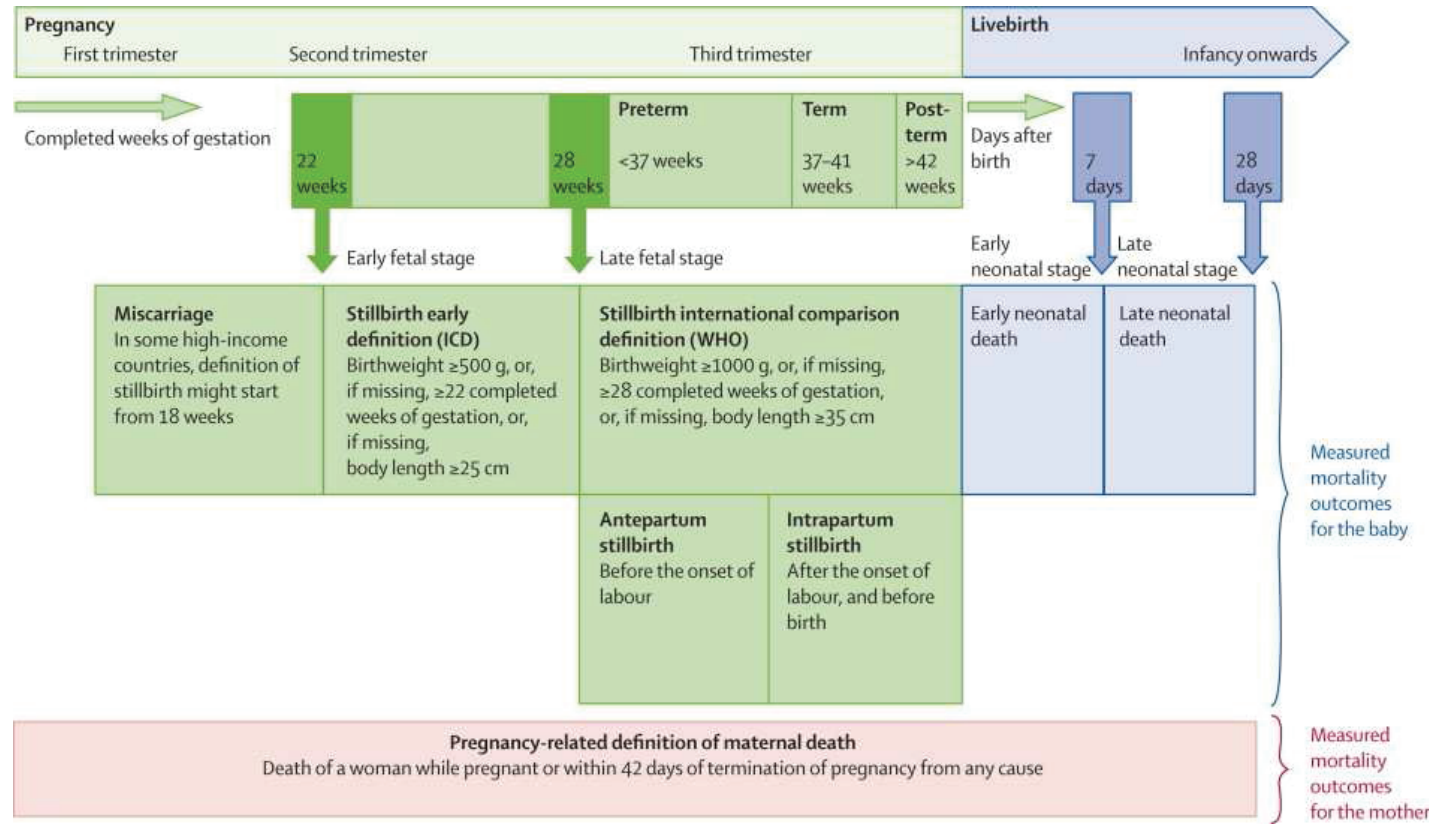

Figure 1. Defining stillbirths and associated pregnancy outcomes.

Reprinted from The Lancet 2011;377 (9775):1448-63. ${ }^{29}$

Copyright (2011), with permission from Elsevier. 
Stillbirth is the informal term that covers both early and late fetal deaths. ${ }^{30}$ The term "stillbirth" originates from the eighteenth century, and was applied to fetuses born without movement (still, but not necessarily lifeless). During the early twentieth century, the definition was further refined to "stillbirth is birth of a viable fetus born dead", and 28 weeks of gestation was set as the limit of viability. ${ }^{31}$ The fetal period begins at 10 weeks of gestation, and therefore fetal deaths comprises some miscarriages as well, whereas the term stillbirth is more commonly applied to fetal death occurring at $\geq 22$ weeks of gestation. ${ }^{32}$

The WHO recommends that late fetal deaths ( $\geq 28$ weeks) should be reported to assure global comparability, as countries where most fetal deaths occur do not have reliable data on early fetal deaths, and the chance for survival prior to 30 weeks of gestation in these countries is very limited. ${ }^{33 ; 34}$ Whereas, in high-income countries the gestational age for neonatal survival has greatly decreased, as fetuses delivered as early as gestational week 22 may survive, and therefore in these countries early fetal deaths are more commonly registered. ${ }^{35}$ However, as can be seen in Table 1 , the gestational age threshold applied for reporting fetal death in high-income countries varies, making international comparison challenging. ${ }^{36}$ The quality of the data in national vital registries also varies due to local legal definitions, and varying social, economic and cultural factors. ${ }^{37}$

In Norway, as per legal requirements passed in 1999, all fetal deaths occurring at $\geq 12$ weeks of gestation are to be reported to the Medical Birth Registry of Norway (MBRN). The Norwegian Institute of Public Health publishes both early (gestational age 22-27 weeks) and late (gestational age $\geq 28$ weeks) fetal death statistics. ${ }^{1}$

In the present thesis the terms fetal death and stillbirth will be applied interchangeably, and this thesis will only focus on fetal death $\geq 16$ weeks of gestation. 
Table 1. Reporting requirements for fetal death in different countries. ${ }^{37-39}$

\begin{tabular}{|c|c|c|c|c|}
\hline $\begin{array}{c}\text { Lower } \\
\text { gestational } \\
\text { week }\end{array}$ & $\begin{array}{l}\text { Body } \\
\text { length }\end{array}$ & Birthweight & Country & Year \\
\hline$\geq 28$ & $\geq 35 \mathrm{~cm}$ & & League of Nations* & 1925 \\
\hline$\geq 28$ & $\geq 35 \mathrm{~cm}$ & $\geq 1000 \mathrm{~g}$ & WHO & 1950 \\
\hline$\geq 28$ & & & United Kingdom & 1926-1992 \\
\hline$\geq 28$ & & & $\begin{array}{l}\text { Sweden, Luxembourg } \\
\text { Greece, Iceland } \\
\text { Denmark }\end{array}$ & -2003 \\
\hline$\geq 26$ & & & Italy, Spain & \\
\hline$\geq 24$ & & & $\begin{array}{l}\text { United Kingdom, Hungary } \\
\text { Scotland, Portugal, Ireland }\end{array}$ & \\
\hline$\geq 22$ & $\geq 25 \mathrm{~cm}$ & $\geq 500 \mathrm{~g}$ & ICD-9 & 1975 \\
\hline$\geq 22$ & & $\geq 500 \mathrm{~g}$ & $\begin{array}{l}\text { ICD-10 } \\
\text { Denmark, } \\
\text { Latvia, Lithuania, France } \\
\text { Finland, Switzerland }\end{array}$ & $\begin{array}{l}1992 \\
2004\end{array}$ \\
\hline$\geq 20$ & & $\geq 350 \mathrm{~g}$ & $\begin{array}{l}\text { United States }{ }^{* *} \\
\text { Canada }\end{array}$ & 1959 \\
\hline$\geq 20$ & & $\geq 400 \mathrm{~g}$ & $\begin{array}{l}\text { Australia } \\
\text { New Zealand } \\
\end{array}$ & \\
\hline & & $\geq 500 \mathrm{~g}$ & $\begin{array}{l}\text { Belgium, Germany, } \\
\text { Poland, Austria, Slovenia }\end{array}$ & \\
\hline$\geq 16$ & & & Norway & $1967-1998$ \\
\hline$\geq 12$ & & & Norway & 1999 \\
\hline
\end{tabular}

* Precursor to the United Nations 1919-1947.

** Most States

Abbreviations: ICD-9. International Classification of Diseases Revision 9: ICD-10. International Classification of Disease Revision 10

\subsection{Scope of fetal death}

The WHO reported global stillbirth ( $\geq 28$ weeks) estimates of approximately 4.3 million in 1995 (stillbirth rate 29 per 1000 births). ${ }^{40} \mathrm{~A}$ declining global trend has been reported with 3.3 million stillbirths in 2000 (stillbirth rate 24 per 1000 births), and 3 million in 2004 (stillbirth rate 22 per 1000). ${ }^{41 ; 42}$ Stanton and colleagues reported similar estimates for the year 2000 with 3.2 million (95\% confidence interval [CI] 2.54.1) stillbirths at $\geq 28$ weeks of gestation, corresponding to a stillbirth rate of 23.9 stillbirths per 1000 births (18.8-30.5). ${ }^{4}$ The latest global estimate of 2.6 million stillbirths in 2009 (stillbirth rate 18.9 per 1000) shows that there has been a continuing gradual decline in the number of stillbirth. ${ }^{2}$ 
However, as can be seen in Figure 2, large global differences in the stillbirth rate prevail. Even across high-income countries the stillbirth rate ( $\geq 28$ weeks of gestation) differs and has been reported to range between 1.7 per 1000 births in Slovak Republic to 4.9 per 1000 births in France in 2004, ${ }^{43}$ and in 2009 between 1.5 per 1000 births in Czech Republic and 4.3 per 1000 in France. ${ }^{44}$ When lower gestational age stillbirths ( $<28$ weeks of gestation) are included in the estimates the inter-country differences increases from less than 4 to more than 8 stillbirths per 1000 births (some of the difference is due to registration of terminations of pregnancy as stillbirth in some countries). Also intra-country differences in stillbirth rates are reported and have been linked to accumulation of risk factors in deprived neighborhoods. ${ }^{45}$ Although the stillbirth rate has declined the above described inequalities in the incidence indicates that further improvement is achievable. ${ }^{14}$ 


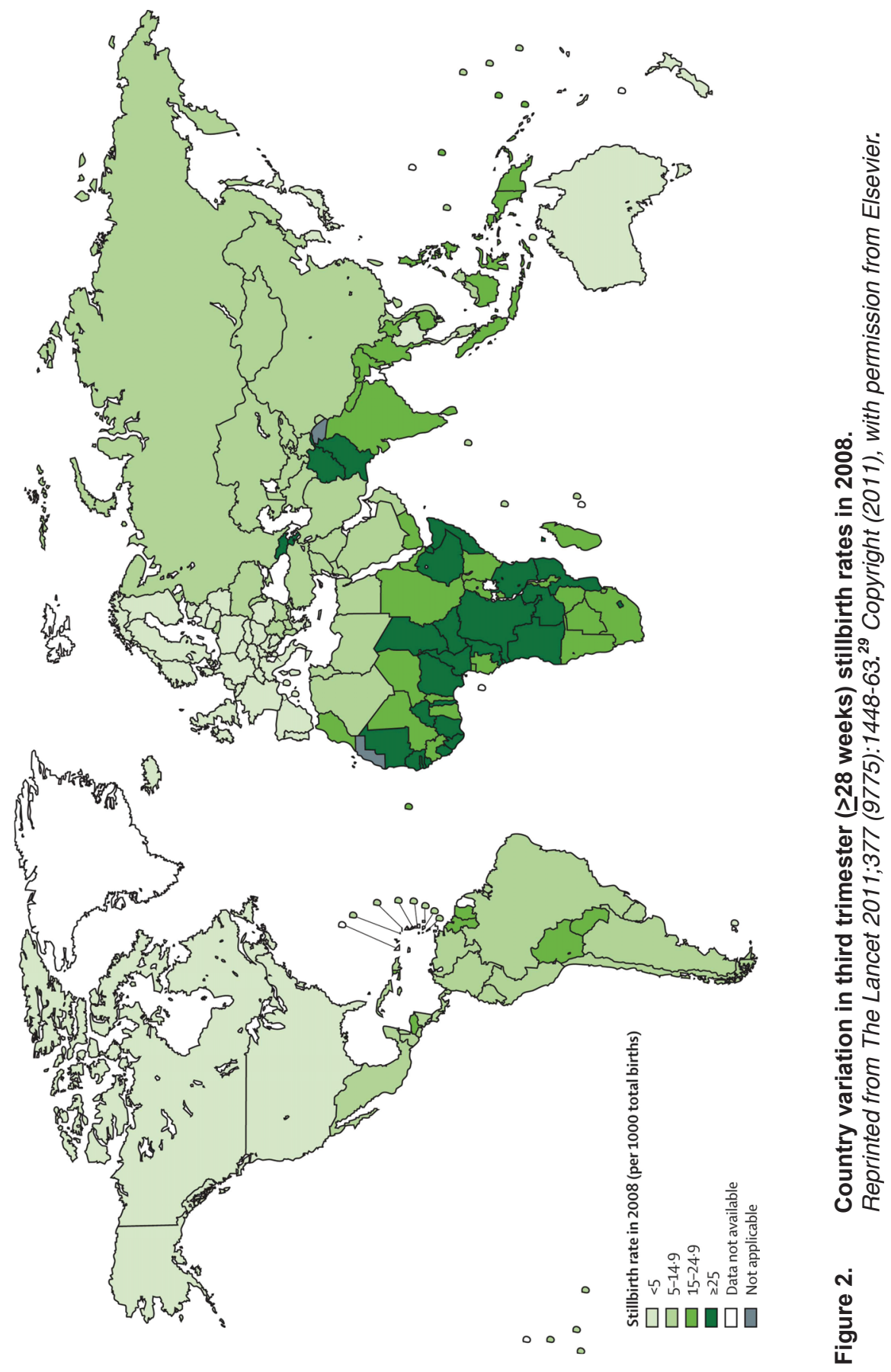




\section{SYSTEMATIC REVIEW OF THE LITERATURE ON RISK FACTORS FOR STILLBIRTH}

In this section a systematic review of observational studies was conducted, to explore the association between the most frequently reported risk factors in relation to stillbirth.

\section{Literature search}

Relevant studies were identified by a systematic search of the peer-reviewed literature covering the period January 1990 to December 2013. A literature search using Medline (Ovid and PubMed) was undertaken using the following terms: "stillbirth" or "fetal death" or "fetal mortality" or "pregnancy outcome", during the period 2003-2007, using a sensitive filter for the detection of etiological studies. For the period 1990-2002 and 2008-2013, a literature search using the Clinical Queries feature in PubMed for the terms "stillbirth" or "fetal death" was conducted, using a sensitive/broad filter for etiological studies. The reference lists of the obtained literature and current reviews were scrutinized for additional relevant publications.

\section{Study inclusion and exclusion criteria}

Studies that fulfilled the following requirements were included: the main focus of the study was stillbirth ( $\geq 20$ weeks of gestation), at least one risk factor for stillbirth was assessed and the study was conducted in high-income countries (defined for the purpose of this review according to the Word Bank country classification: highincome members of the Organization for Economic Co-operation and Development). ${ }^{46}$ The search was limited to publications in the English language and concerning human studies.

The review was limited to the following risk factors associated with stillbirth: maternal demographic factors (maternal age, parity, socioeconomic status (SES), race/ethnicity), maternal lifestyle/behavioral factors (maternal weight, smoking, alcohol and coffee consumption), maternal medical disorders (hypertensive disorders, diabetes), pregnancy-related factors (intrauterine growth restriction (IUGR), gestational age, previous stillbirth).

Studies were excluded if: a) stillbirth was not the main focus, b) the study only reported on intrapartum deaths, c) the study reported only perinatal deaths 
and stillbirths were not reported separately, d) the study was assessed to have low quality. The quality of the papers was assessed by applying the Critical Appraisal Skills Programme (CASP) checklist for observational studies available at the CASP UK website. ${ }^{47}$ The checklist is comprised of 12 questions enabling assessment of the methods used, validity of results, possible bias, confounding factors and generalizability.

\section{Results}

A total of 10,910 publications were initially identified (Figure 3). After the review a total of 150 papers met the inclusion criteria; 128 cohort studies (22 prospective and 106 retrospective), 19 case-control studies and three cross-sectional studies. In the following sections the results of the review is presented (Table 3 ).

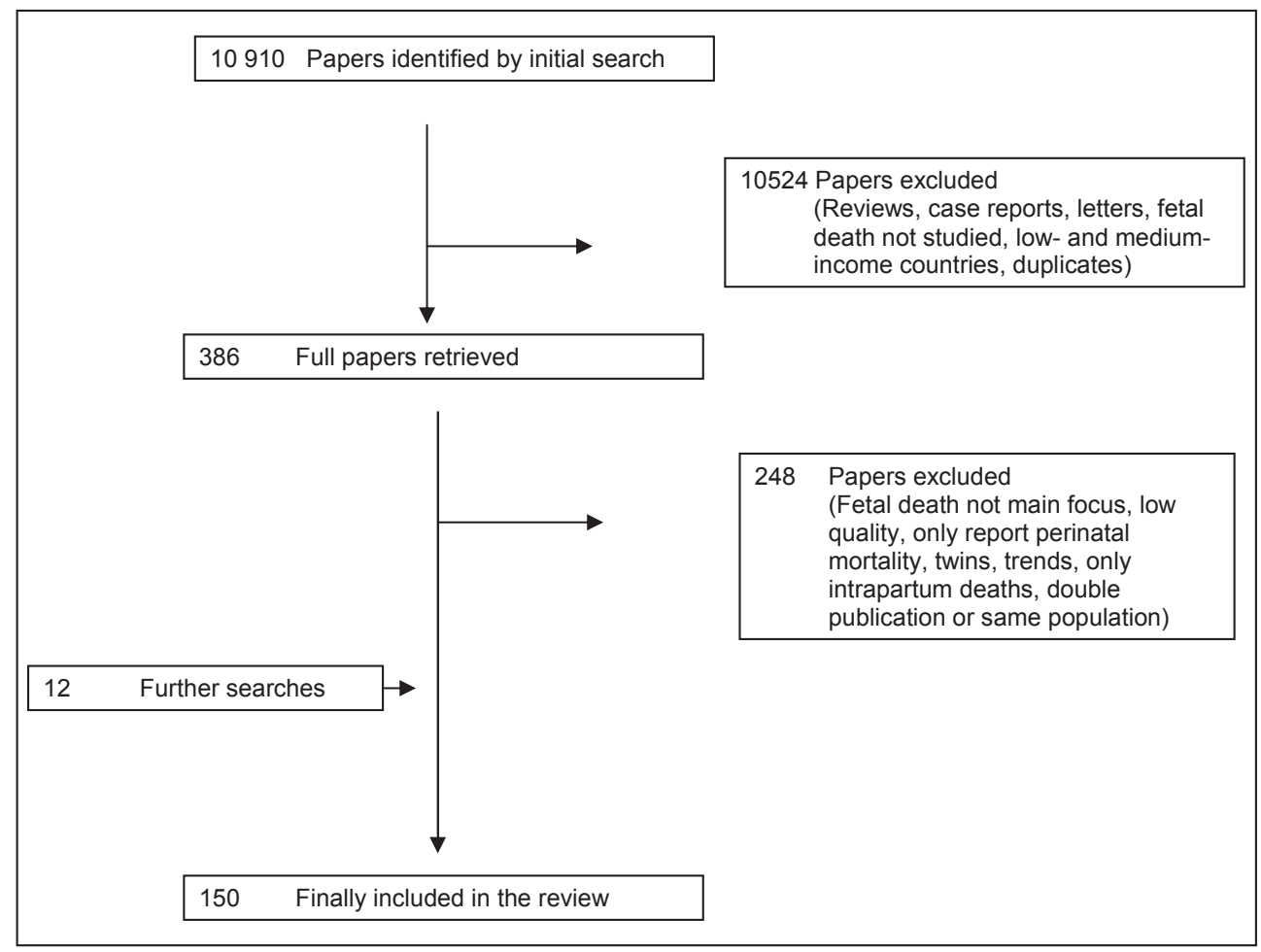

Figure 3. Inclusion and exclusion of studies for review. 


\subsection{Maternal age}

The demographic distribution of pregnant women has increasingly shifted to the right in most high-income countries. ${ }^{48}$ In Norway the proportion of childbearing women aged 35 years or older has increased from $5.6 \%$ in 1978 to $19.5 \%$ in 2012 , accordingly in the United States the proportion changed from $4.5 \%$ to $14.9 \%$ during the same period. ${ }^{1 ; 23 ; 49}$

High maternal age at childbearing is consistently associated with an increased risk of fetal death and the risk increases more with advancing age above 35 years (35-39 years (odds ratio (OR) 1.3-2.0) and $\geq 40$ years (OR 1.7-3.4)) as reported in the reviewed hospital-based ${ }^{50-53}$ and large population-based cohort studies (Table 3). ${ }^{23 ; 54-69}$ However, the OR varies between studies, and some of the most recent studies do not report an increased risk among women aged 35-39 years. ${ }^{53 ; 69 ; 70}$

The cause of this increased risk remains unclear. Older women have a higher prevalence of medical conditions (hypertension, diabetes) $52 ; 54 ; 56 ; 57 ; 61$ and of complications during pregnancy (preterm births, small for gestational age $(\mathrm{SGA})^{52 ; 56 ; 57 ; 61}$ births). However, even after adjustment for these confounding factors the increased risk remains statistically significant, ${ }^{54 ; 56 ; 60}$ indicating that increased maternal age is independently associated with increased risk of fetal death.

The incidence of fetal anomalies increases with maternal age ${ }^{71}$ however, detection and termination of anomalous fetuses have resulted in decreased impact of this cause in recent times. ${ }^{51}$

Contemporary older mothers have higher SES are more educated and have lower parity compared to older mothers a few decades ago, still the association with fetal death remains significant. ${ }^{62}$

Gestational age is an effect modifier of the relative risk (RR) of fetal death in older women, ${ }^{23 ; 60 ; 64-66}$ as the risk of fetal death compared to younger women increases throughout pregnancy with the highest risk at term and post term.

Studies of young maternal age ( $<19$ years) and fetal death are inconsistent, reporting both an increased risk, ${ }^{54 ; 58 ; 67 ; 72-74}$ and no increased risk. ${ }^{55 ; 75 ; 76}$ Large populationbased studies, most from the United States, display higher fetal mortality rates in 
women aged $<19$ years compared to older women, with an OR varying between 1.05 and 1.76. ${ }^{54 ; 55 ; 58 ; 59 ; 72}$ However, when analyses are adjusted for sociodemographic factors, ${ }^{55 ; 59}$ and preterm birth, ${ }^{72}$ the OR is no longer significantly increased in most studies. In the largest study of teenage pregnancies to-date (5.8 million births to girls aged 15-19 years), Salihu and colleagues reported that the OR of fetal death in girls aged 15-19 years became insignificant relative to women aged 20-24 years, only when preterm birth was included in the multivariable model. ${ }^{72}$ Hence, the mechanism involved in fetal death in teenage pregnancies may be different than that among older women, involving higher occurrence of unfavorable socioeconomic characteristics, ${ }^{59}$ and biological immaturity. ${ }^{77}$

\subsection{Parity}

Increased risk of fetal death in nulliparas (women with no previous births) is reported in several studies; case-control, ${ }^{78-80}$ hospital-based ${ }^{50}$ and population-based retrospective cohort studies ${ }^{23 ; 59 ; 60 ; 66 ; 68 ; 81-85}$ (OR 1.2-1.9). Some of the risk may be explained by increased prevalence of hypertensive disorders (namely pre-eclampsia) and IUGR. ${ }^{60}$ Multiparity ( $\geq 3$ pervious births) has also been reported to increase the risk of fetal death (OR 1.7-2.9). ${ }^{23 ; 50 ; 59 ; 70 ; 80}$ and may partly be explained by selective fertility (replacement of a infant loss by new pregnancy). ${ }^{86}$

\subsection{Maternal weight}

The proportion of overweight $\left(25 \mathrm{~kg} / \mathrm{m}^{2} \geq\right.$ body mass index $\left.(\mathrm{BMI})<30 \mathrm{~kg} / \mathrm{m}^{2}\right)$ and obese $\left(\mathrm{BMI} \geq 30 \mathrm{~kg} / \mathrm{m}^{2}\right)$ pregnant women is increasing in high-income countries. In the United States, reports from the National Health and Nutritional Survey estimated that $35 \%$ of women aged $\geq 20$ years were obese in $2009-2010$ (compared to $15 \%$ in 1960). ${ }^{87 ; 88}$ A large population-based cohort study in Norway during 2000-2007 reported that approximately $30 \%$ of pregnant women (total cohort of 58383 ) had a pre-pregnancy $\mathrm{BMI} \geq 25 \mathrm{~kg} / \mathrm{m}^{89}$

The first study to report an increased risk of fetal death in women with high prepregnancy BMI was a case-control study by Little and colleagues, using data from the 1980 United States National Natality and Fetal Mortality Survey. ${ }^{79}$ Even though the study only included married women, and had to rely on information collected by mail-in questionnaire, their results are in accordance with the results of several large 
population-based prospective $\mathrm{e}^{90-92}$ and retrospective cohort studies ${ }^{68 ; 70 ; 82 ; 83 ; 93-97}$ and two case-control study ${ }^{69 ; 98}$ included in this review. All studies but one reported an increased risk of fetal death in overweight and obese women, however, varying BMl reference groups were applied and hence the results were not directly comparable. A dose-dependent relationship was proposed, as the risk of fetal death progressively increased with increasing BMI (overweight: OR 1.1-2.5 and obese: OR 1.4-3.2). The retrospective cohort study by Kashan and colleagues did not find any significant association between maternal BMI and stillbirth; however, the study missed information on BMI for a large proportion of the women (37\%). ${ }^{99}$

Weight gain during pregnancy was not associated with fetal death, ${ }^{92 ; 98}$ whereas weight gain between pregnancies was reported to increase the risk. ${ }^{96 ; 100}$ The Swedish study by Villamor and colleagues reported on changes in BMI between first and second pregnancies, and demonstrated that the risk of fetal death increased linearly with weight gain, and a weight gain of $3 \mathrm{BMI}$ units increased the risk by $60 \%$ (OR 1.63, 95\% Cl 1.20-2.21). ${ }^{100}$ Overweight and obese women have a higher prevalence of hypertensive disorders, diabetes and, lower SES, but adjusting for these potential confounders did not change the risk estimates significantly. ${ }^{91 ; 92 ; 94 ; 98}$

The association between low BMI/underweight has been less extensively studied, as most early studies applied women in the lowest BMI category as reference group..$^{83 ; 90 ; 98}$ Studies assessing risk of fetal death in women with low BMI did not find any significant result. ${ }^{82 ; 91 ; 92 ; 95 ; 97}$

Two Danish studies reported causes of fetal death in overweight and obese women, and showed higher proportions of unexplained death (OR 3.6, 95\% $\mathrm{Cl} 1.8-7.6)$ and placental dysfunction (IUGR, placental infarctions and placental abruption) (OR 5.2, $95 \% \mathrm{Cl} 2.5-10.9$ ) in obese women compared to normal weight women..$^{91 ; 92}$

Furthermore one study reported that the risk of fetal death in overweight and obese women was modified by gestational age. ${ }^{92}$ Nohr and colleagues noted that the increased risk of fetal death in overweight women at 37-40 weeks (hazard ratio (HR) $1.7,95 \% \mathrm{Cl}$ 0.9-3.0) compared to normal weight women, increased more as pregnancy advanced past 40 weeks (HR 2.9, 95\% Cl 1.1-7.7). ${ }^{92}$ However, a more recent study could not confirm the interaction between $\mathrm{BMI}$ and gestational age. ${ }^{97}$ 
An association between maternal overweight and obesity and fetal death has clearly been made, however, the biological pathway remains unclear. The proposed mechanisms are: a) increased availability of nutrients causing expanded growth in the fetus, but inability of the placenta to supply oxygen to the fetus leading to hypoxia and death, ${ }^{91}$ b) hyperlipidemia resulting in lower levels of prostacycline and higher levels of thromboxane production increasing the risk of placental thrombosis, ${ }^{94} \mathrm{c}$ ) higher risk of congenital anomalies in the offspring and medical disorders as diabetes and hypertensive disorders in the mother, ${ }^{97} \mathrm{~d}$ ) impaired ability to detect decreased fetal movements. ${ }^{97}$

\subsection{Medical conditions}

Maternal medical conditions associated with fetal death are presented in Table 2. In the following section, the most prevalent disorders in pregnant women are further discussed: a) hypertensive disorders and b) diabetes.

The prevalence of hypertensive disorders in the pregnant women varies across studies (depending on data source and population characteristics), ${ }^{55 ; 101-106}$ Studies on hypertensive disorders and fetal death were very heterogeneous and therefore not easily comparable as different fetal death definitions( 20-28 weeks) and reference groups (normotensive women, low-risk pregnancies) were applied.

Hypertensive disorders in pregnancy are associated with increased risk of fetal death, most consistently demonstrated for chronic hypertension with a two to threefold increase in risk. ${ }^{53 ; 55 ; 66 ; 68 ; 101 ; 105 ; 107-112 ~}$ The Australian study by Heard and colleagues did not report significant increased risk of stillbirth among women with chronic hypertension relative to normotensive women during 1998-2001, however, the risk was significantly elevated in an earlier time period 1991-1997 (RR 3.4). ${ }^{103}$ Increased risk of fetal death is also reported among women with preeclampsia and pregnancy induced hypertension, 55;66;101;102;105;113-116 however, in the most recent studies low risk and even lack of risk is reported possibly due to closer monitoring and timely delivery of the compromised fetuses. ${ }^{22 ; 102 ; 103 ; 110 ; 114 ; 117 ~ G e s t a t i o n a l ~}$ hypertension is categorized with preeclampsia in most studies from the United States (as pregnancy induced hypertension), however, when separately studied it was not associated with any increased risk of fetal death. ${ }^{103 ; 104 ; 117}$ 
The risk of fetal death in women with hypertension is modified by gestational age. The risk of fetal death among women with chronic hypertension is increased but stable between week 36-38 and increases steadily thereafter. ${ }^{108}$ Among women with preeclampsia higher risk of fetal death was reported in early preeclampsia compared to late preeclampsia. ${ }^{115}$ The exact mechanism linking fetal death and hypertension is not clear, however, women with hypertension are more likely to give birth to low birth weight infants, ${ }^{101 ; 103 ; 104}$ most likely due to reduced uteroplacental blood flow. ${ }^{118}$

Pregnancy in women with diabetes is associated with an increased risk of fetal death, and the incidence of this disorder is increasing. ${ }^{55 ; 68 ; 119 ; 120}$

Studies included in the review reported a 3 to 4 -fold increased risk of fetal death in women with diabetes type 1, ${ }^{119 ; 121-127}$ and a 2 to 3-fold increased risk among women with diabetes type 2 or pregestational diabetes, ${ }^{53 ; 55 ; 68-70 ; 111 ; 120 ; 128-131}$ but higher risk in women requiring adjunctive insulin treatment. ${ }^{132 ; 133}$

One of the largest studies on diabetes type 1 was a multi-center study conducted in Denmark in 1993-1999 $(n=1218),{ }^{127}$ identifying suboptimal glycemic control as the main contributing factor in this study. The increased risk among women with diabetes type 2 may pertain to higher prevalence of other risk factors as high maternal age, high BMI, ethnical diversity and social deprivation. ${ }^{124}$

Factors contributing to the increased risk of fetal death in diabetic pregnancies are congenital anomalies (especially cardiac anomalies), ${ }^{121-124 ; 127 ; 129-131}$ pre-term births ${ }^{123 ; 127 ; 130}$ and fetal macrosomia. ${ }^{121 ; 127 ; 133}$ Diabetic women also have a three- to six-fold increased risk of hypertensive disorders. ${ }^{123 ; 127 ; 130}$

Gestational diabetes is more prevalent than other types of diabetes; however, the association between this disorder and fetal death is uncertain. Two studies reported increased risk of fetal death, ${ }^{98 ; 134}$ whereas three studies did not report any increased risk of fetal death, ${ }^{66 ; 126 ; 135}$ but reported higher risk of preeclampsia, caesarean section, macrosomia, preterm deliveres. ${ }^{135}$ Lack of an association between gestational diabetes and stillbirth may be due inability to diagnose all affected women, leading to high number of affected women in the control group resulting in attenuated estimates. Wood and colleagues conducted a nested case-control study 
and reported higher stilllbirth rates in pre-diabetic women (who were later diagnosed with diabetes) compared to non-diabetic controls (OR 4.7). ${ }^{128}$ The authors suggested that the unexpected increased risk could be related to undiagnosed gestational diabetes or insulin resistance

Several mechanisms have been proposed that may lead to fetal death in diabetic women: a) uncontrolled hyperglycemia and ketoacidoses, ${ }^{122}$ b) utero-placental impairment caused by microangiopathy, in particular among women with long duration type 1 or type 2 diabetes, ${ }^{133} \mathrm{c}$ ) fetal hyperglycemia leading to hyperinsulinemia, which further increases anaerobic metabolism and eventually hypoxia and acidosis. ${ }^{136}$

Table 2. Prevalence of maternal medical conditions associated with fetal death. $^{10 ; 32 ; 101 ; 103-105 ; 112 ; 113 ; 121-124 ; 127-133 ; 137-141}$

\begin{tabular}{|lcc|}
\hline & Prevalence & $\begin{array}{c}\text { Fetal mortality rate (per } \\
1000 \text { births) }\end{array}$ \\
\hline Hypertensive disorders & $3.7-10 \%$ & \\
$\quad$ Preeclampsia & $1.1-4.2 \%$ & $7-26$ \\
Gestational hypertension & $2.1-4.3 \%$ & $4-6$ \\
Chronic hypertension & $0.5-2.1 \%$ & $8-16$ \\
Diabetes & $2.5-12 \%$ & \\
$\quad$ Type 1 or type 2 diabetes & $0.5-2 \%$ & $10-34$ \\
Gestational diabetes & $2-10 \%$ & $5-10$ \\
Thrombophilia & $1-5 \%$ & $18-40$ \\
Renal disease & $<1 \%$ & $15-200$ \\
Systemic lupus erythematosus & $<1 \%$ & $40-150$ \\
Thyroid disease & $0.2-2 \%$ & $12-20$ \\
Cholestasis of pregnancy & $<0.1 \%$ & $12-30$ \\
\hline
\end{tabular}

\subsection{Smoking}

Maternal smoking is associated with an increased risk of fetal death (OR 1.2-2.0), and it has been argued that a causal relationship has been revealed. ${ }^{16 ; 53 ; 60 ; 66 ; 68-}$ 70;79;83;142-148 There is a linear relationship between increasing risk of fetal death and increasing quantity of tobacco used. ${ }^{79 ; 83 ; 142 ; 143 ; 145}$ Pregnant women that quit smoking prior to 16 weeks of gestation have the same risk of fetal death as non-smokers. ${ }^{143}$ Women, who smoked during their first pregnancy, but not their second pregnancy, have the same risk in the second pregnancy as non-smokers. ${ }^{142}$ Maternal tobacco 
exposure in utero is not associated with increased risk of stillbirth in the daughters of mothers that smoked during pregnancy. ${ }^{149}$

The retrospective cohort study by Gray and colleagues reported that $38 \%$ of the inequality in stillbirth occurrence in Scotland could be attributed to smoking. ${ }^{147} \mathrm{~A}$ population-based retrospective cohort study $(n=638,242)$ from Sweden reported an increased risk of stillbirth among smokers compared to non-smokers (OR 1.4, 95\% $\mathrm{Cl}$ 1.3-1.6), and demonstrated that after controlling for IUGR and placental complications (placental abruption, placenta previa and antepartum hemorrhage) the risk was no longer increased (RR 1.0, 95\% $\mathrm{Cl} 0.9-1.1) .{ }^{60}$ This finding supports the proposed mechanism involved in fetal death associated with smoking: a) smoking causes diffusion of nicotine and carbon monoxide across the placenta which inhibits fetal oxygen transport and increases vascular resistance, b) the placenta of smokers exhibits characteristic pathological features (decidual necrosis and infarcts), which are likely caused by smoking.

Even though the rate of daily smokers among the pregnant population in Norway has declined (from $34 \%$ in 1987 to $11 \%$ in 2004 and $9.5 \%$ in 2012) the numbers are still quite high. ${ }^{1 ; 150 ; 151}$

\subsection{Alcohol and coffee consumption}

There are few studies of the association between alcohol consumption and the risk of fetal death. ${ }^{68 ; 79 ; 152-157}$ Two case-control studies have been conducted in the United States, one did not report any increased risk of fetal death among women reporting alcohol consumption during pregnancy, ${ }^{79}$ whereas the other study reported that each additional drink per week increased the risk by $1 \% .{ }^{152}$ The increased risk of fetal death among abstainers reported by Little and colleagues may be due to "healthy drinker effect", as women with previous adverse outcome may abstain from alcohol in later pregnancies. ${ }^{79}$ Two studies reported that the risk was only significantly increased at early gestation ( $<16$ weeks and $<28$ weeks, respectively), with no significant risk in late pregnancy. ${ }^{156 ; 157}$ Kesmodel and colleagues conducted a prospective cohort study ( $\mathrm{n}=24,768$ women), and reported an increased risk of stillbirth in women who consumed $\geq 5$ drinks per week, compared to women consuming $\leq 1$ drink per week (RR $3.0,95 \% \mathrm{Cl} 1.4-6.4) .{ }^{153}$ 
The proposed mechanisms that may lead to fetal death in women with high alcohol consumption are: a) fetoplacental dysfunction, b) increased production of prostaglandins, c) hypoglycemia. ${ }^{153}$

Coffee consumption during pregnancy has been associated with increased risk of fetal death, however, only when moderate to high amounts are consumed; $\geq 3$ cups of coffee per day (RR 1.7, 95\% Cl 1.0-2.8), ${ }^{153} \geq 5$ cups of coffee per day (OR 1.4, 95\% $\mathrm{Cl} 1.0-1.8),{ }^{79} \geq 8$ cups of coffee per day (OR $\left.3.0,95 \% \mathrm{Cl} 1.5-1.9\right) .{ }^{158}$ Bech and colleagues conducted a prospective cohort study in Denmark and reported an increased risk of fetal death at 20-27 weeks of gestation in women consuming $\geq 4$ cups of coffee per day, whereas the risk was not significantly increased at gestational age $\geq 28$ weeks. ${ }^{159}$

The proposed mechanisms that may lead to fetal death in women with high coffee consumption are: a) increased levels of catecholamines in the maternal circulation that may cause vasoconstriction, b) placental dysfunction. ${ }^{159}$

\subsection{Social disparity and race/ethnicity}

Pregnant women reporting low SES or belonging to a racial/ethnic minority face a nearly two-fold increased risk of fetal death. ${ }^{24 ; 25 ; 68-70 ; 147 ; 148 ; 160-185}$ In modern urban settings, many risk factors often coexist (low SES, racial/ethnic minority, smoking, teenage pregnancies) making the contribution of each risk factor difficult to disentangle. Women with low SES are more often smokers, have a higher BMI, and are more often unmarried, but even after adjusting for these risk factors the risk of fetal death is increased compared to women with high SES, ${ }^{164 ; 166 ; 168}$ especially for antepartum fetal deaths. ${ }^{163 ; 168}$ Stephansson and colleagues found that even after controlling for an extensive number of maternal and pregnancy-related risk factors (maternal age, height, BMI, smoking, country of birth, number of antenatal care visits, involuntary childlessness) and excluding pregnant women with medical conditions (diabetes, pre-eclampsia and eclampsia) the increased risk related to low SES remained. ${ }^{168}$

Social inequality in stillbirth may be explained by an increased frequency of negative life events, low level of education and more emotional problems (stress, anxiety and 
depression), whereas the contribution of health risk behaviors (smoking, obesity) is small. ${ }^{148 ; 168}$ Educational inequality in stillbirth is reported by several studies, and appears to persist over time. ${ }^{170 ; 171}$ In addition, social disparity is more strongly associated with specific causes of stillbirth (unexplained, ${ }^{25 ; 172}$ SGA, ${ }^{25 ; 172}$ diabetes ${ }^{25}$ ), and stillbirth at preterm gestation. ${ }^{25}$

Substantial racial and ethnical disparity in stillbirth risk has recently been reported by several studies in high-income countries. ${ }^{24 ; 160 ; 162 ; 165 ; 167 ; 169 ; 173 ; 174 ; 176-186 ~}$ Most studies regarding race are from the United States, and report an increased risk of fetal death among Black women compared to White women (OR 1.6-3.1), ${ }^{24 ; 160 ; 162 ; 165 ; 176 ; 177 ; 181}$ and a higher incidence of IUGR and pre-term births. ${ }^{162 ; 165 ; 181}$ The risk of stillbirth among Black women is reported to be greatest at 20-23 weeks of gestation and at 41 weeks compared to White women. ${ }^{24} \mathrm{~A}$ Canadian study reported highest risk at late gestation (>37 weeks) among Aboriginal Canadian compared to non-Aboriginal Canadian. ${ }^{186}$

Ethnical inequality in stillbirth has been reported by studies comparing outcome among native-born and immigrant populations throughout Europe. ${ }^{173 ; 174 ; 179 ; 180 ; 183-185}$ Populations studied are heterogeneous and reason for the observed disparity remains uncertain.

Proposed mechanisms to explain inequality in stillbirth risk among minorities are low SES, ${ }^{177 ; 183}$ higher prevalence of maternal diseases, ${ }^{185 ; 186}$ teenage pregnancies, and late start of prenatal care,${ }^{179}$ consanguinity and congenital anomalies. ${ }^{186}$ Other studies did not confirm these associations. ${ }^{174 ; 179 ; 180}$

Two Norwegian studies reported a higher risk for antepartum fetal death among ethnic Somali women (OR 2.5, 95\% Cl 1.7-3.7) and non-Western women (OR 2.2, $95 \% \mathrm{Cl}$ 1.3-3.8), compared to women of Norwegian and Western origin, respectively. ${ }^{167 ; 169}$ The author hypothesized that sub-optimal care (defined as failure to act on non-reassuring fetal status or incorrect assessment of labor progression) may be an important contributing factor. ${ }^{167}$ The racial/ethnic disparity in pregnancy outcome may also be due to cultural differences concerning nutrition, self-care and compliance with medical recommendations, miscommunication and reduced effectiveness or access to health care. 


\subsection{Intrauterine growth restriction}

IUGR, in most studies defined as SGA with weight below the $10^{\text {th }}$ percentile for a specific gestational age, is associated with increased risk of fetal death. $8: 70 ; 80 ; 84 ; 187-195$ SGA is often used in studies to indicate IUGR although not all SGA fetuses are pathological small. The magnitude of the risk also depends on whether populationbased birth weight (based on birth weights of infants born at particular gestational ages including both normal and abnormal outcome), population-based intrauterine fetal weights (assessed by ultrasound) or customized birth weight percentiles have been employed (based on ultrasound assessed intrauterine weights adjusted for maternal height, weight, parity and ethnic group, with the purpose to differentiate between constitutional and pathological smallness). ${ }^{80 ; 188 ; 190 ; 192}$

Of thirteen reviewed studies, nine retrospective cohort studies ${ }^{70 ; 84 ; 187-189 ; 191-193 ; 195}$ and four case-control studies, ${ }^{8 ; 80 ; 190 ; 194}$ all reported increased risk of fetal death among fetuses that were SGA, and with accelerated risk as pregnancy advances. In the case-control study by Frøen and colleagues, among 76 validated unexplained fetal deaths (antepartum deaths that had undergone thorough post-mortem investigations) $52 \%$ were SGA (birth weight $<10^{\text {th }}$ percentile of standard adjusted for gestational age, maternal weight, height, ethnicity and parity, and sex of the baby). ${ }^{190}$ The authors concluded that IUGR is one of the strongest risk factors for fetal death particularly among smokers and overweight and obese women.

Interestingly an interaction between IUGR and certain risk factors such smoking and hypertensive disorders have recently been demonstrated. Gardosi and colleagues demonstrated that women in West Midlands who smoked during pregnancy but did not have a growth restricted fetus had the same risk of fetal death as non-smokers, whereas the risk increased when the fetus was growth restricted, but the highest risk was observed in non-smokers with IUGR. ${ }^{70}$ Likewise Helgadottir and colleagues in Norway observed that women with hypertensive disorders in pregnancy did not have an increased risk of fetal death without IUGR, whereas the risk increased when the fetus was growth restricted, and was highest among normotensive women with IUGR. ${ }^{53}$ Gardosi and colleagues concluded that women without recognized risk factors such as smoking may be considered low risk and therefore are less likely to have IUGR detected antenatally.

IUGR may be caused by maternal, placental, uterine or fetal causes; however, the majority of cases are associated with placental insufficiency. ${ }^{196}$ 


\subsection{Gestational age}

Several studies have reported increased risk of fetal death as pregnancy continues past term. ${ }^{85 ; 189 ; 197-202}$ The fetal mortality rate increases two- to three-fold at 42 weeks (1.6-3.7 per 1000 ongoing pregnancies) compared to 40 weeks (0.3-1.1 per 1000 ongoing pregnancies) ${ }^{85 ; 189 ; 197 ; 199}$ Some of the reported variation in fetal mortality is likely caused by the different methods of estimating gestational age (last menstrual period (LMP), or ultrasound), the local policy regarding expectant management or routine induction of labor at 41 weeks, and the period studied. The presumed mechanism is placental insufficiency, and this is supported by histological examinations of post-term placentas that revealed calcifications, infarcts, perivillous fibrin deposits and arterial thrombosis. ${ }^{189}$

The most recent studies report comparative estimates of gestational-age-specific fetal and neonatal mortality in high- and low risk pregnancies in an effort to deliver data regarding the optimal time for delivery. ${ }^{201 ; 202}$

The association between stillbirth and certain risk factors such as maternal age $\geq 35$ years, $\mathrm{BMI} \geq 25$, SGA, educational attainment and race is modified by gestational age. ${ }^{23-25 ; 60 ; 85 ; 92 ; 105 ; 189}$ Reddy and colleagues reported that the RR of fetal death at 41 weeks was $300 \%$ higher in women $\geq 40$ years of age (RR 3.13, 95\% Cl 2.02-4.85) compared to women $<35$ years, whereas it was $85 \%$ higher at gestational age $39-40$ weeks (RR 1.85, 95\% Cl 1.43-2.39). ${ }^{23}$

\subsection{Previous stillbirth}

Increased risk of recurrent fetal death among women with a previous fetal death has been reported in two case-control studies (OR 10.2 and HR 5.8), ${ }^{203 ; 204}$ and two population-based cohort studies. ${ }^{205 ; 206}$ Samueloff and colleagues reported higher incidence of diabetes, hypertensive disorders and low birth weight infants among women with recurrent fetal death. ${ }^{203}$ Other previous adverse outcomes of the first pregnancy, such as preterm birth, giving birth to a SGA infant and developing preeclampsia has also been associated with increased risk of fetal death in the subsequent pregnancy. ${ }^{207-210}$ 


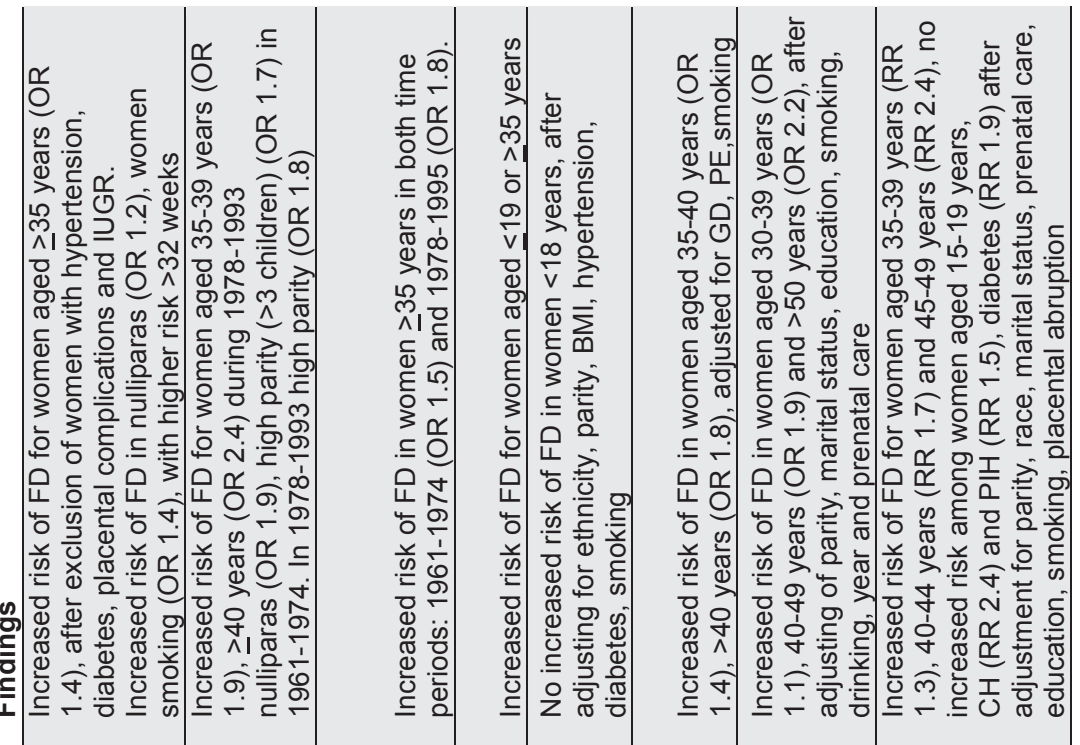

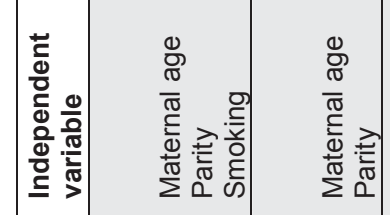

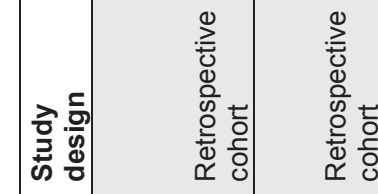

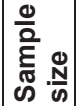

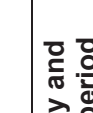

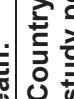

\%

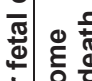

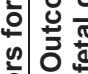

ษ

뜬

$\frac{5}{4}$

के

耪高

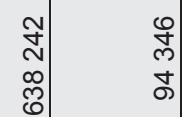

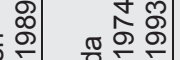

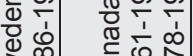

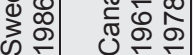

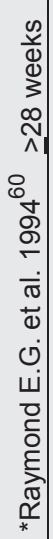

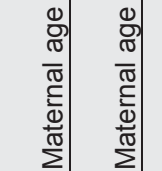

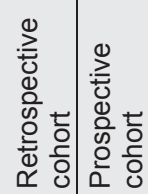

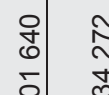

응

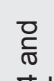

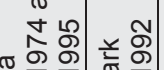

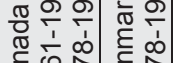

뜽요

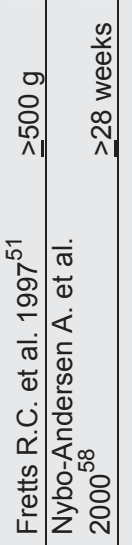

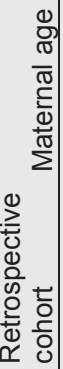

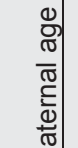

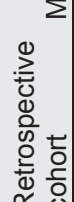

$\propto 0$

욤ำ

m ल

흠 ह 흠

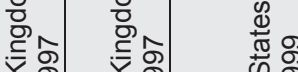

वे के के के के

言哭
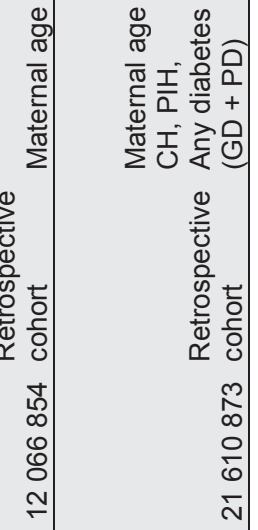

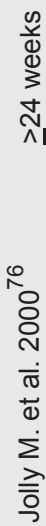

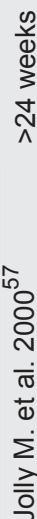




\begin{tabular}{|c|c|c|c|c|c|c|c|c|}
\hline 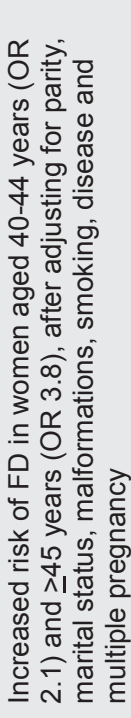 & 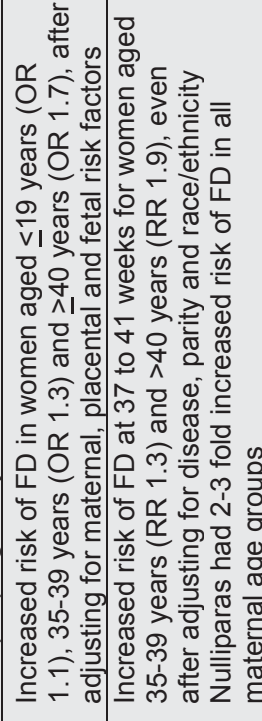 & 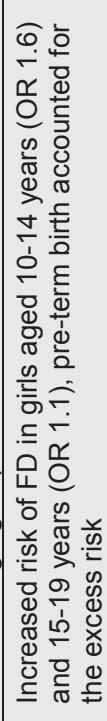 & 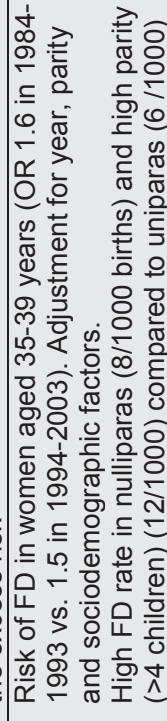 & 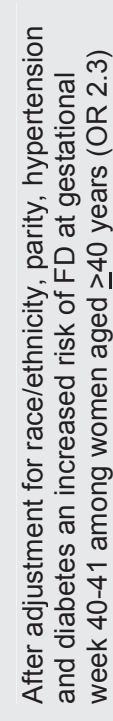 & 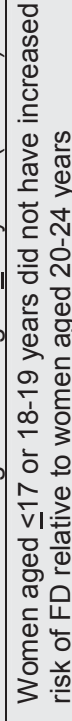 & 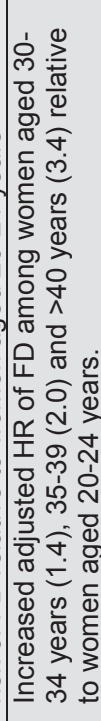 & 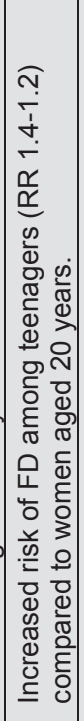 & 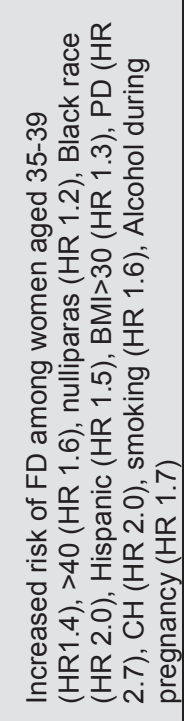 \\
\hline
\end{tabular}

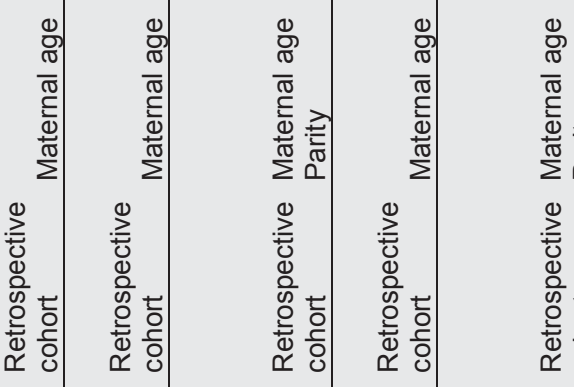

$\begin{array}{ccc}m & 0 \\ m & N \\ 0 & N \\ 0 & 0 \\ 0 & 0 \\ - & 0\end{array}$

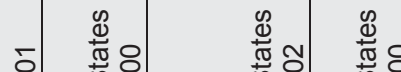

๘

ब然

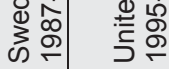

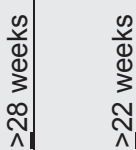

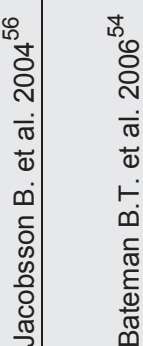

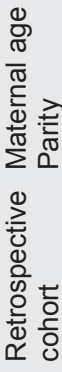

బூ

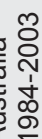

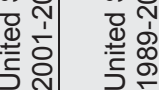

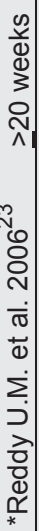

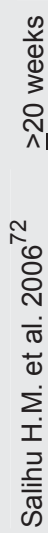

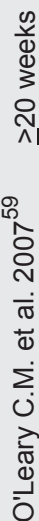

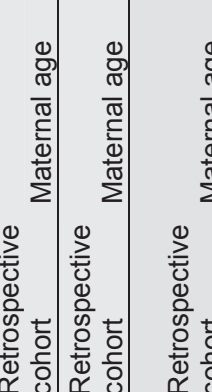

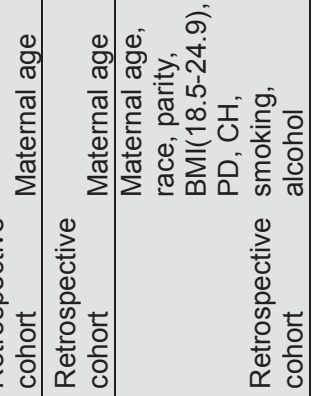
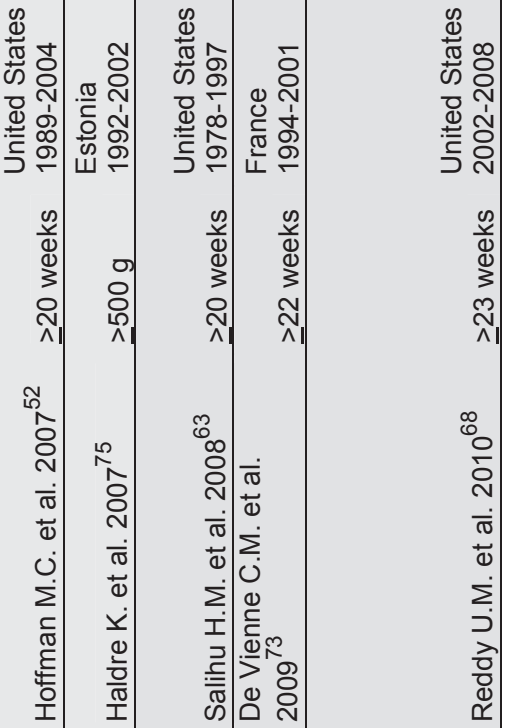

:

$\stackrel{5}{\text { N }}$

กี

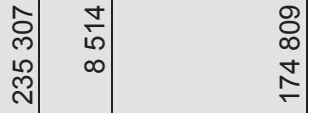

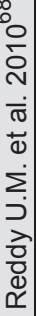




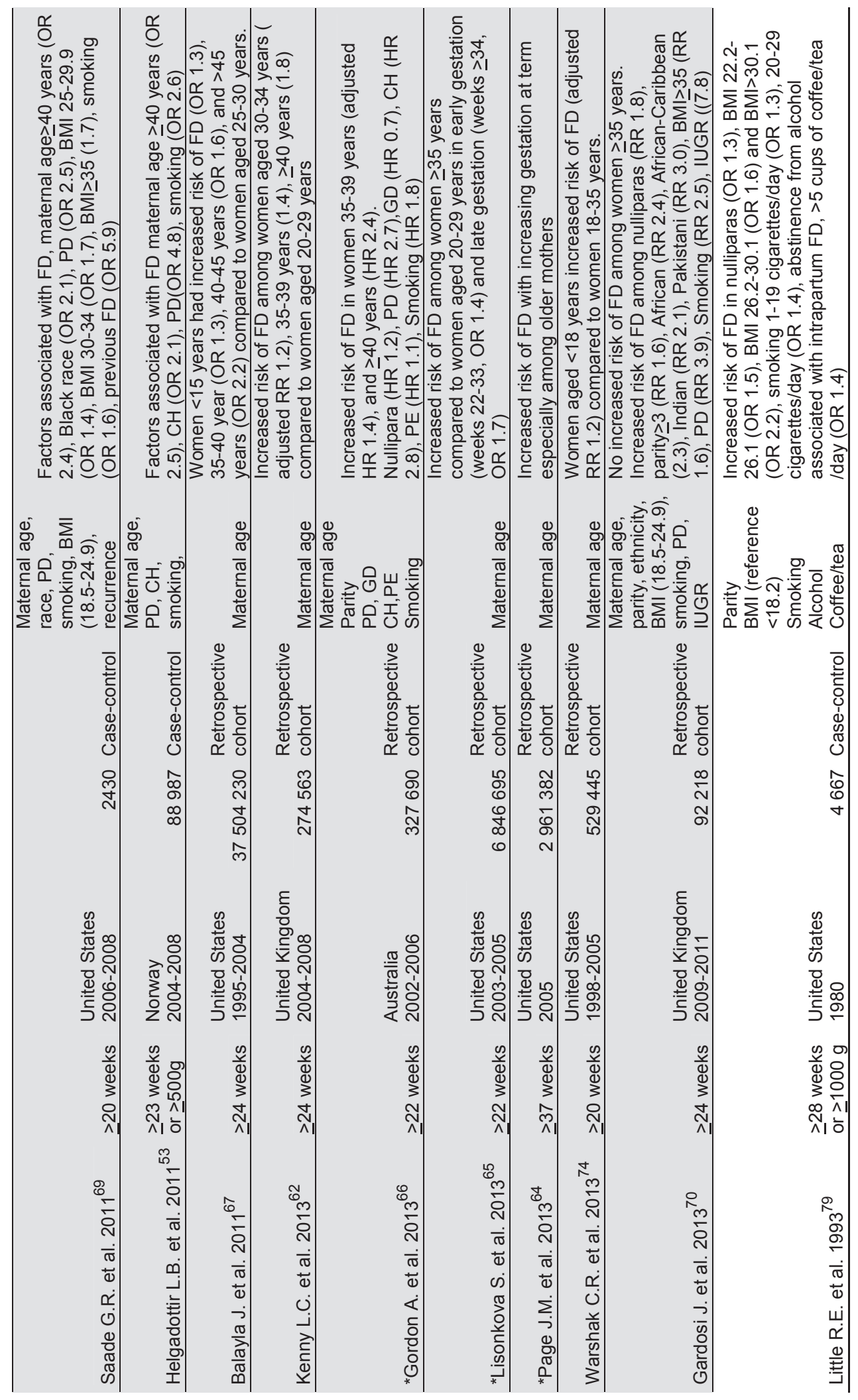




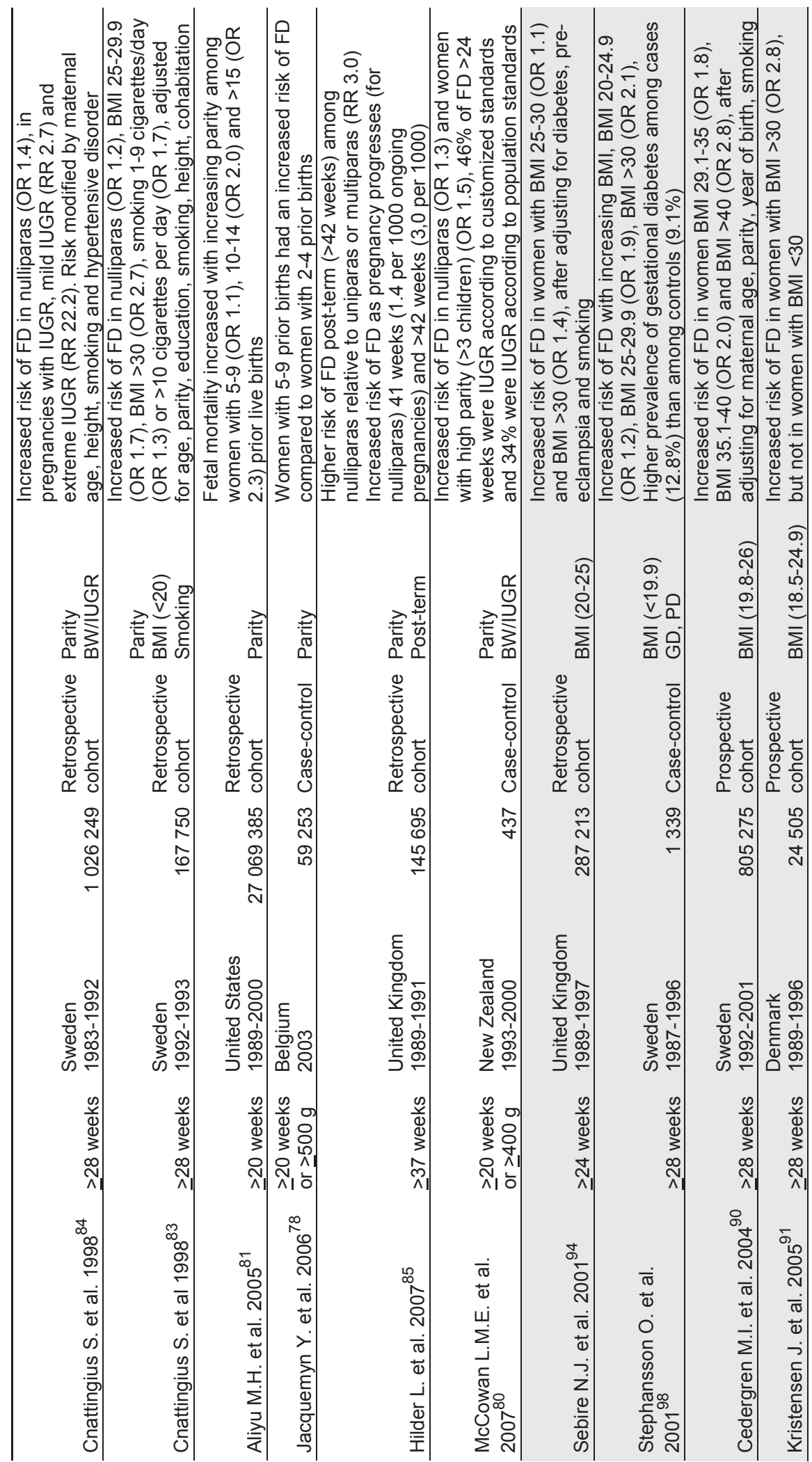




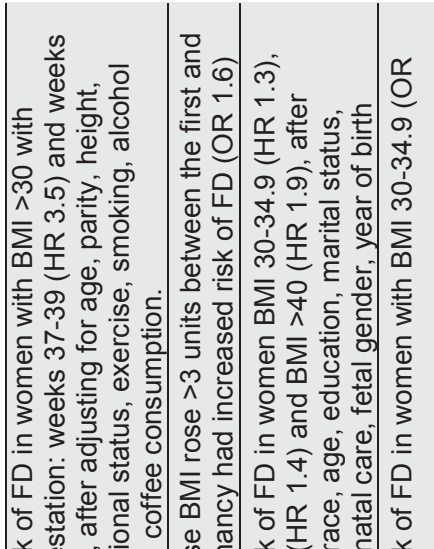

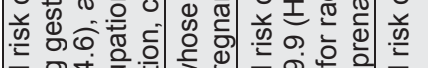

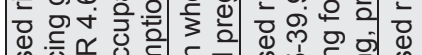
ब.

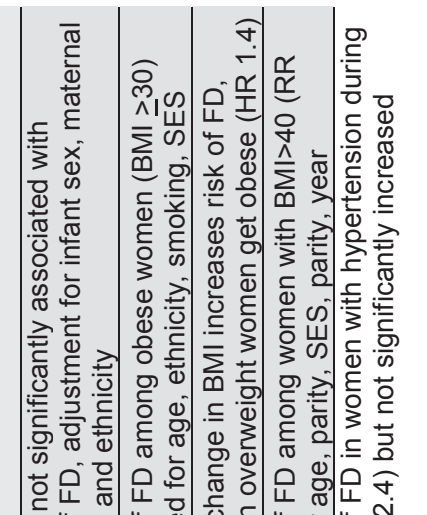

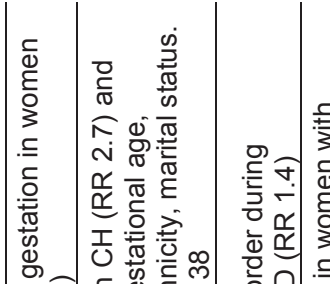

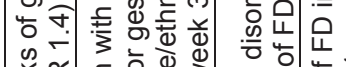
范莒 ब 0 ( )

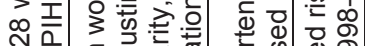
ᄉ

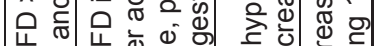

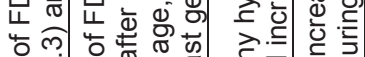

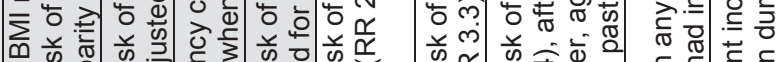
m

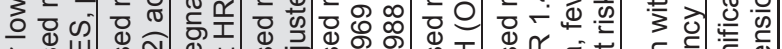

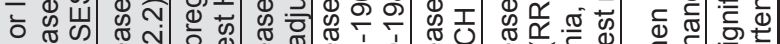
๘

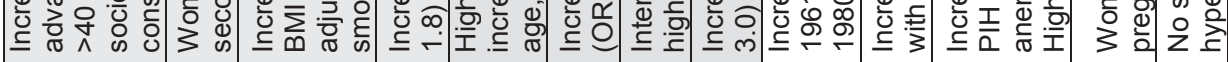

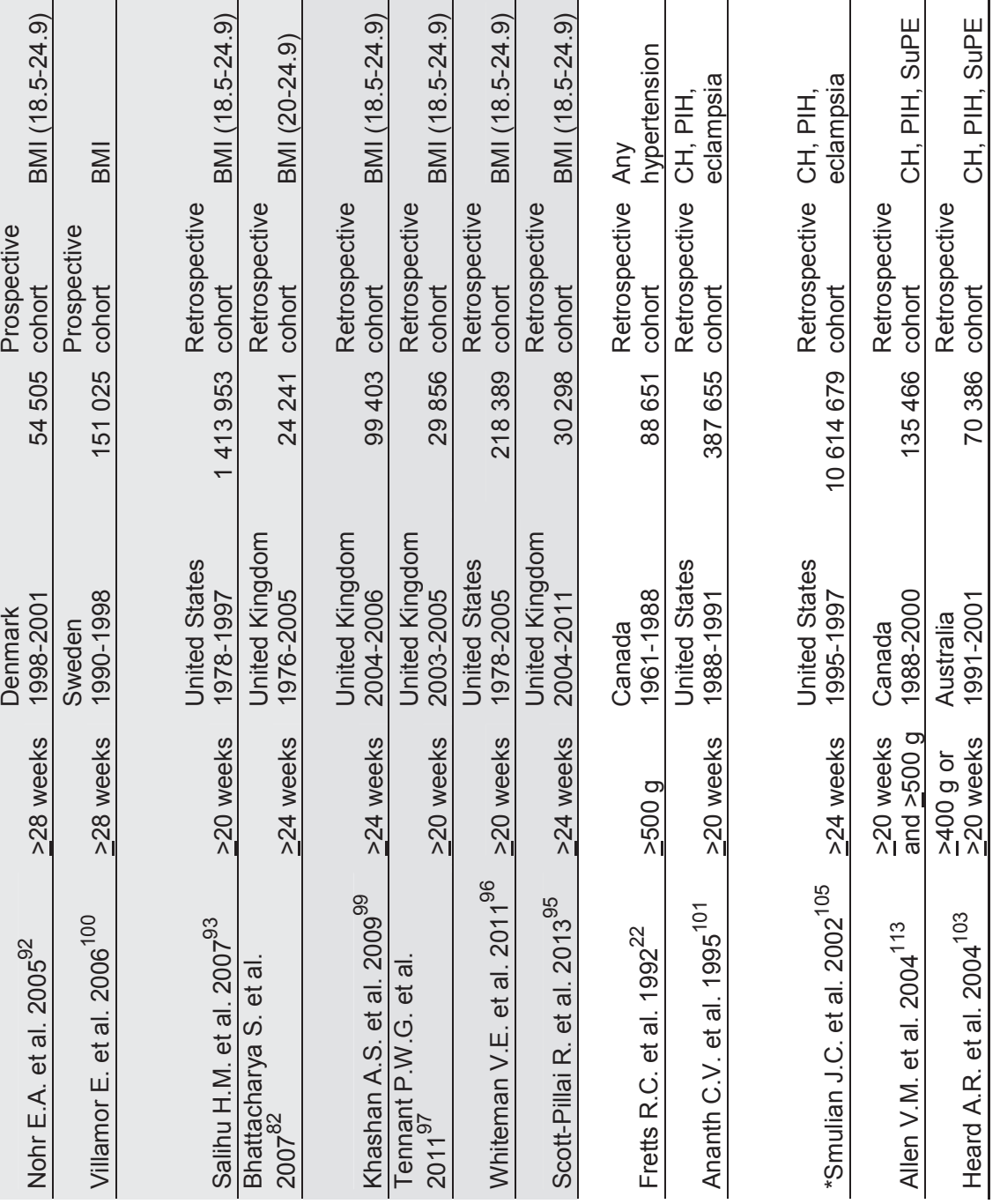




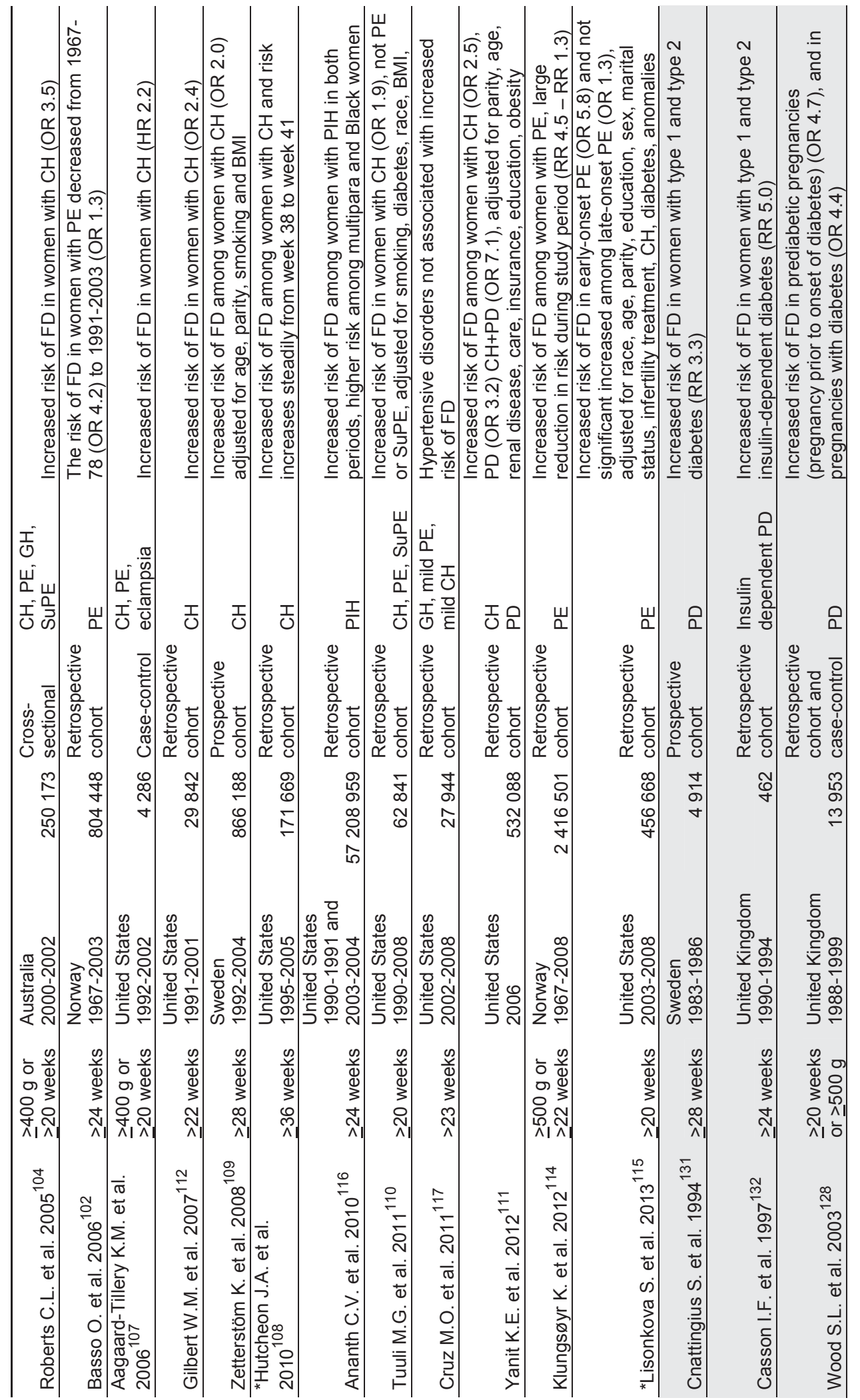




\begin{tabular}{|c|c|c|c|c|c|c|c|c|c|c|c|c|c|c|}
\hline 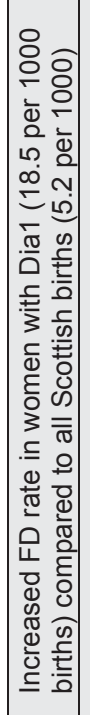 & 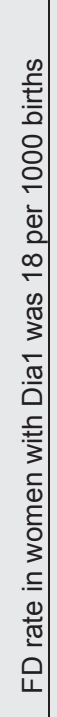 & 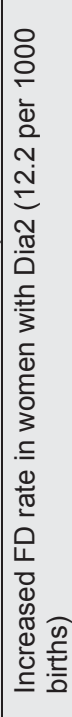 & 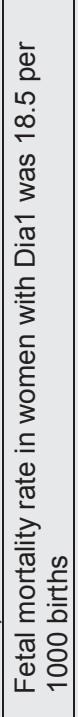 & 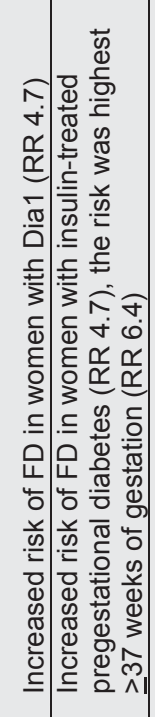 & 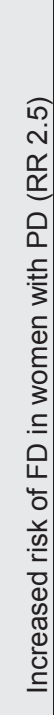 & 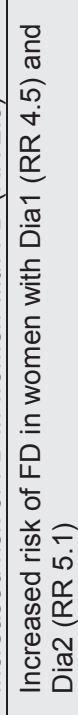 & 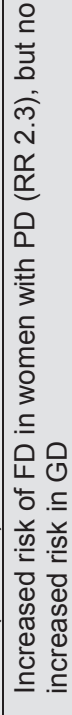 & 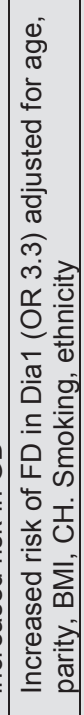 & 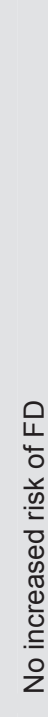 & 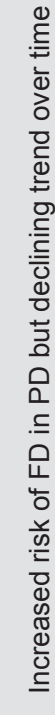 & 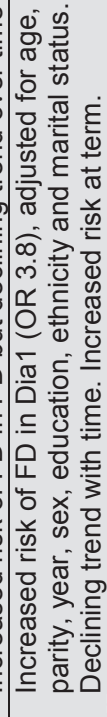 & 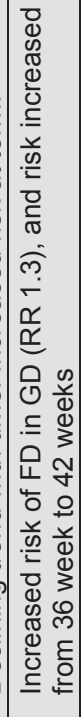 & 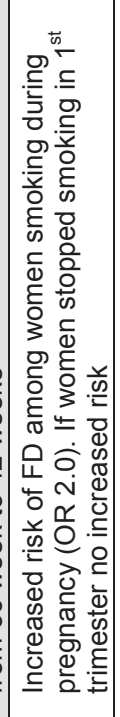 & 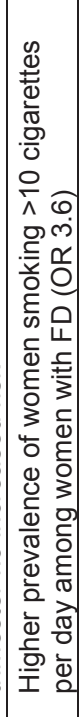 \\
\hline
\end{tabular}

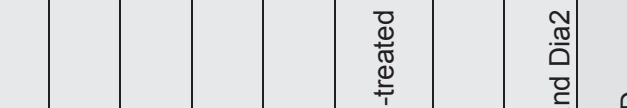

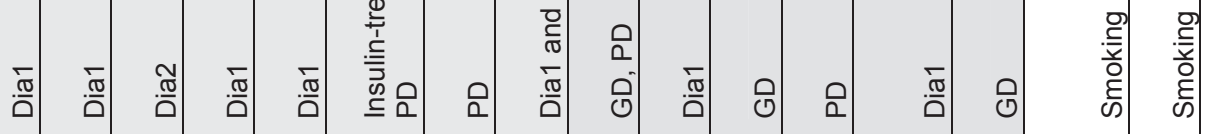

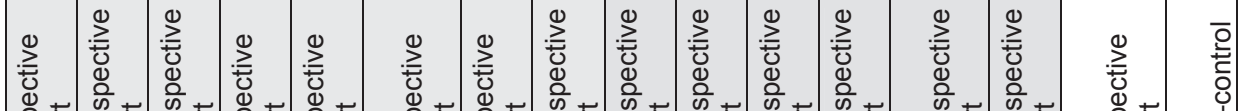

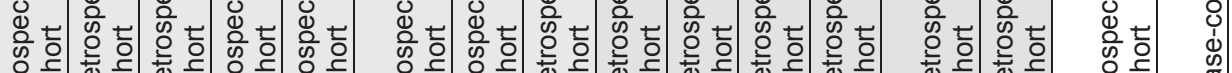

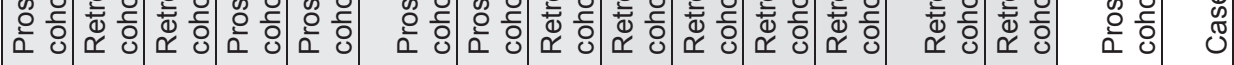

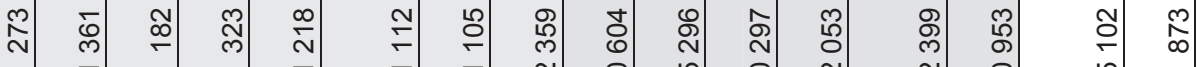
ז

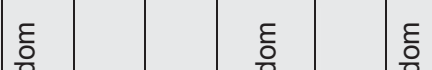

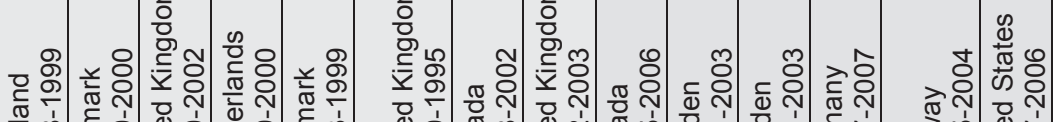

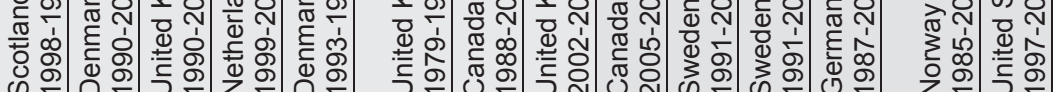

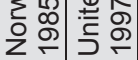

늏욤 욤 胥宁 迥号

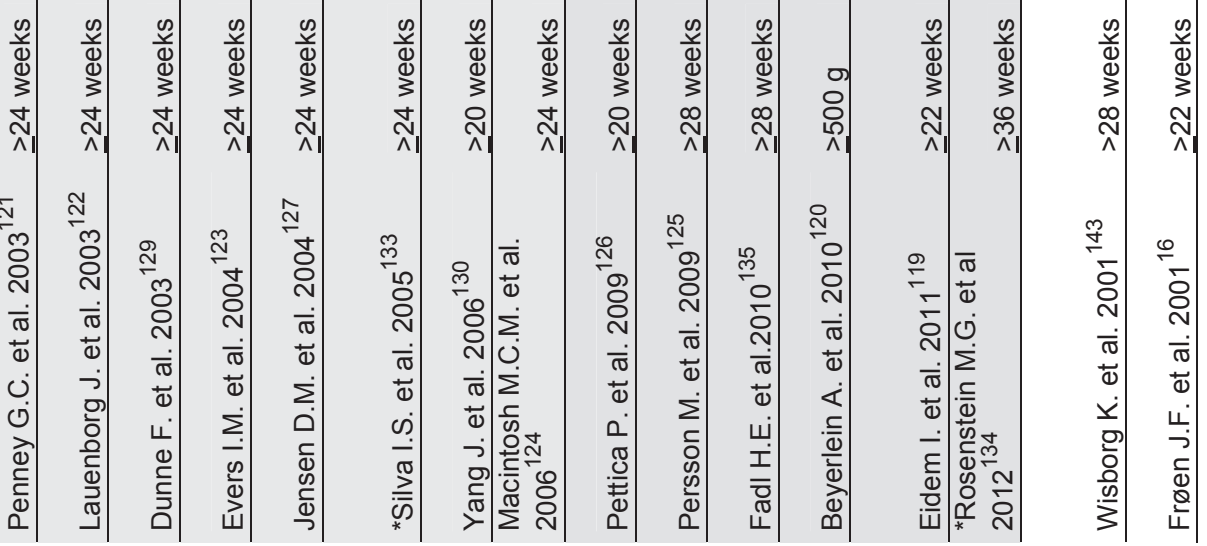




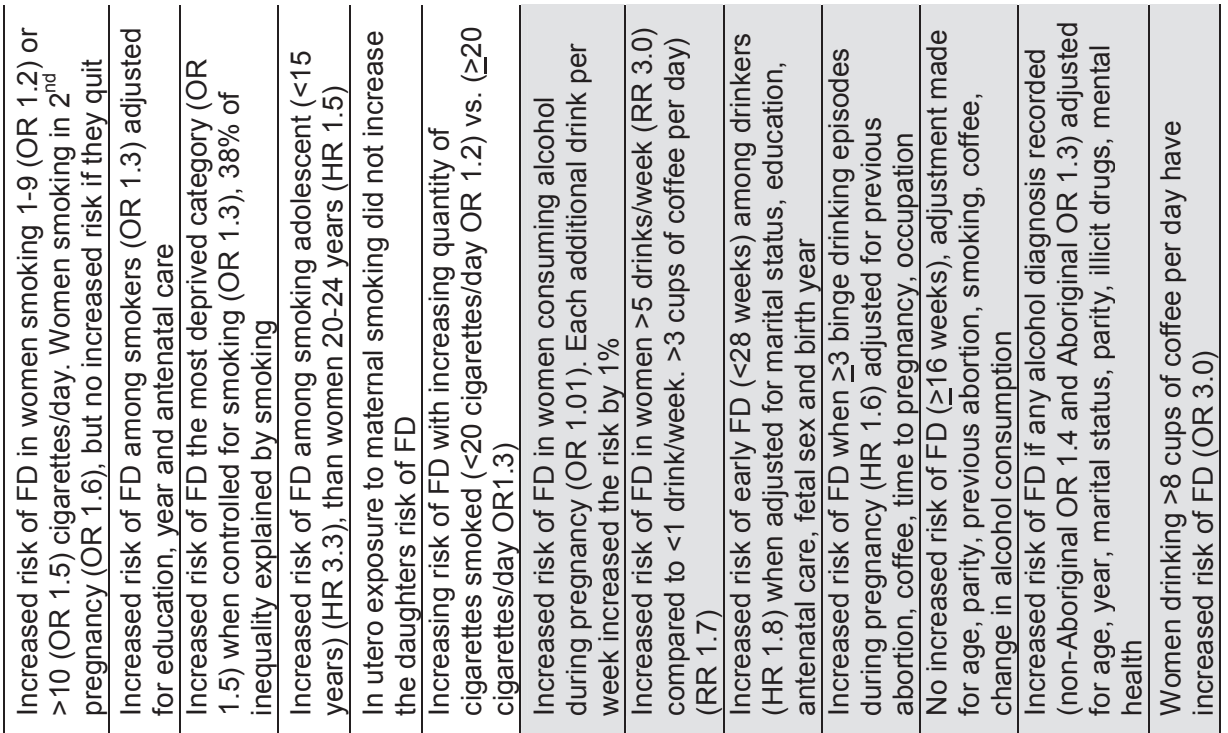

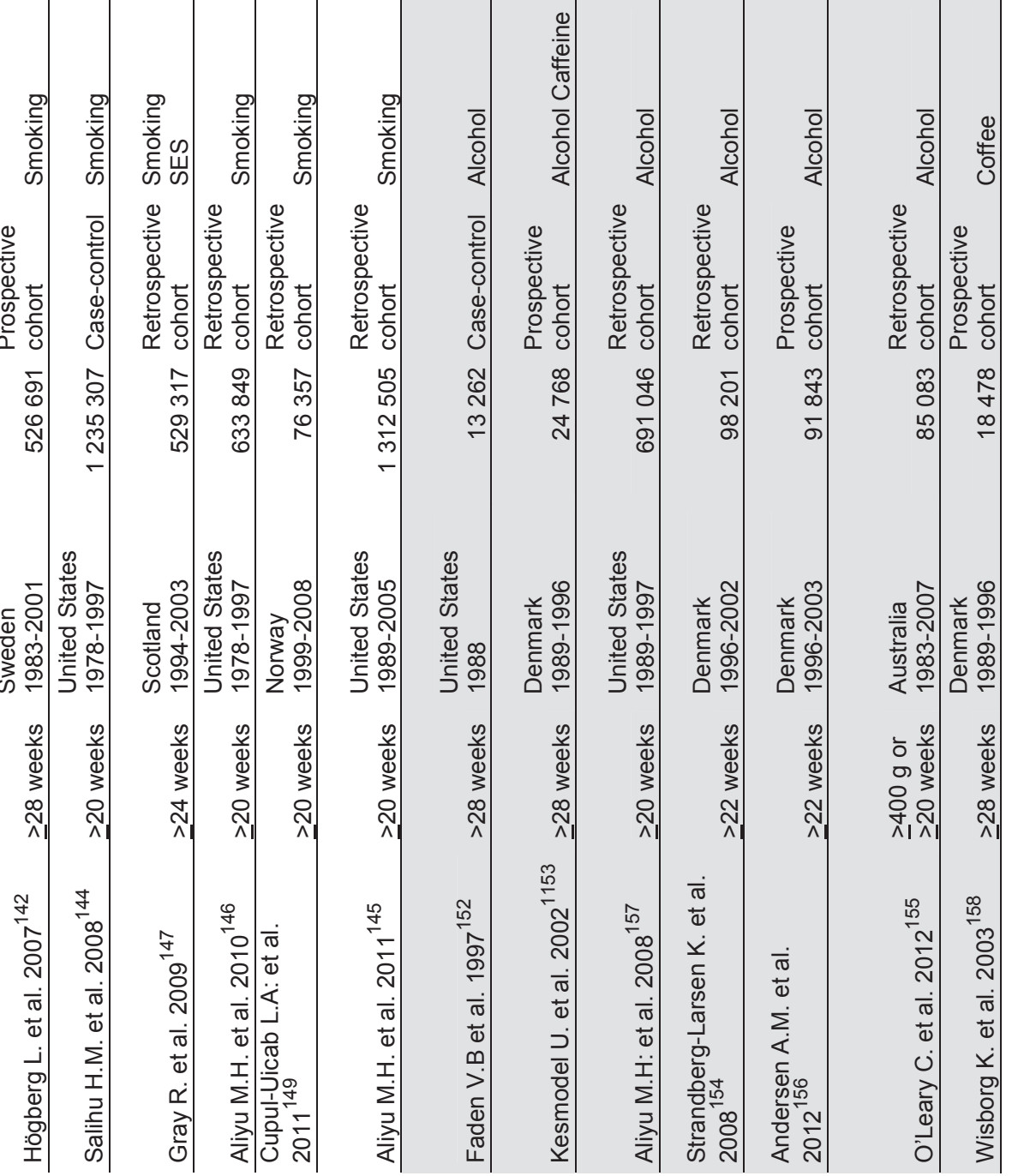




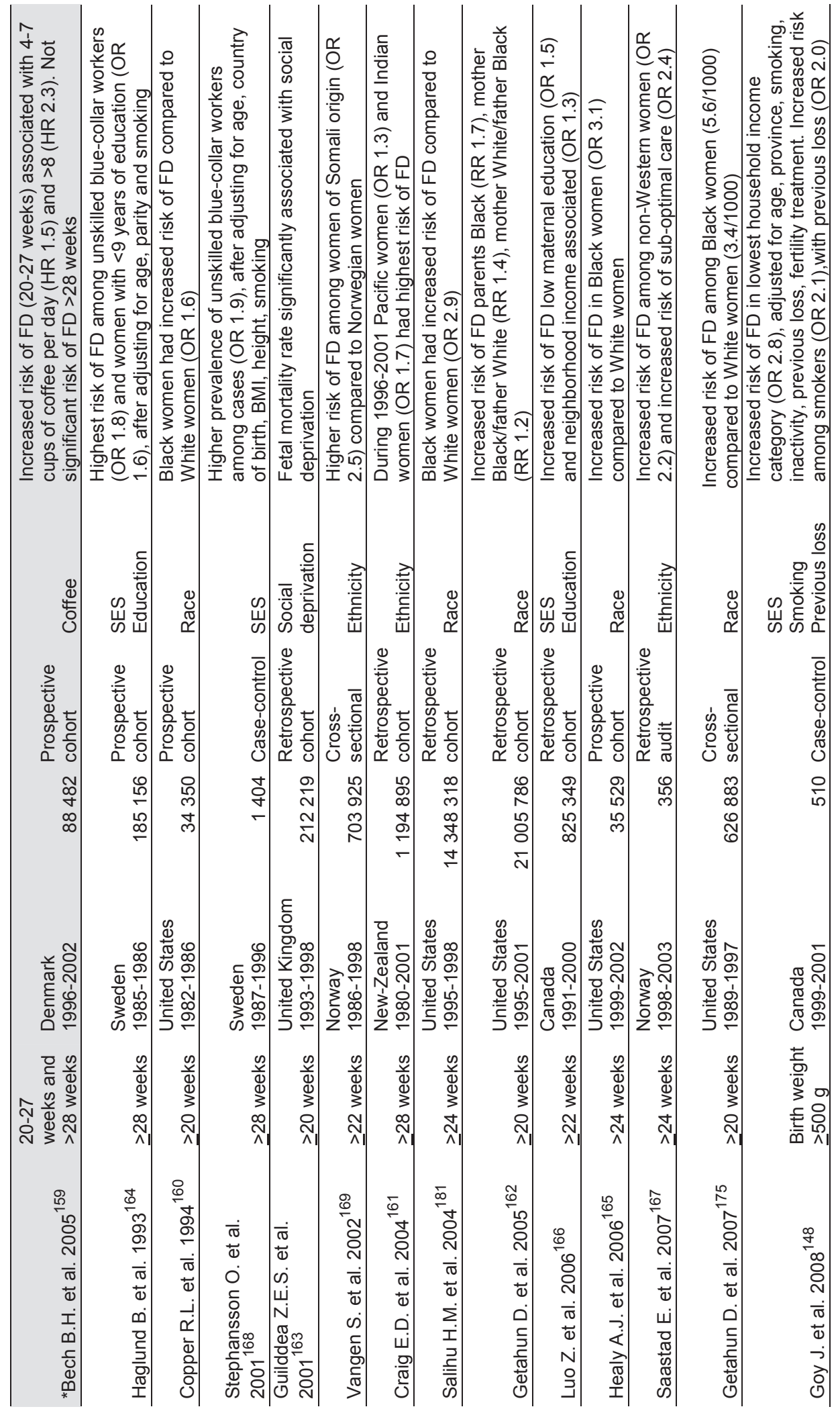




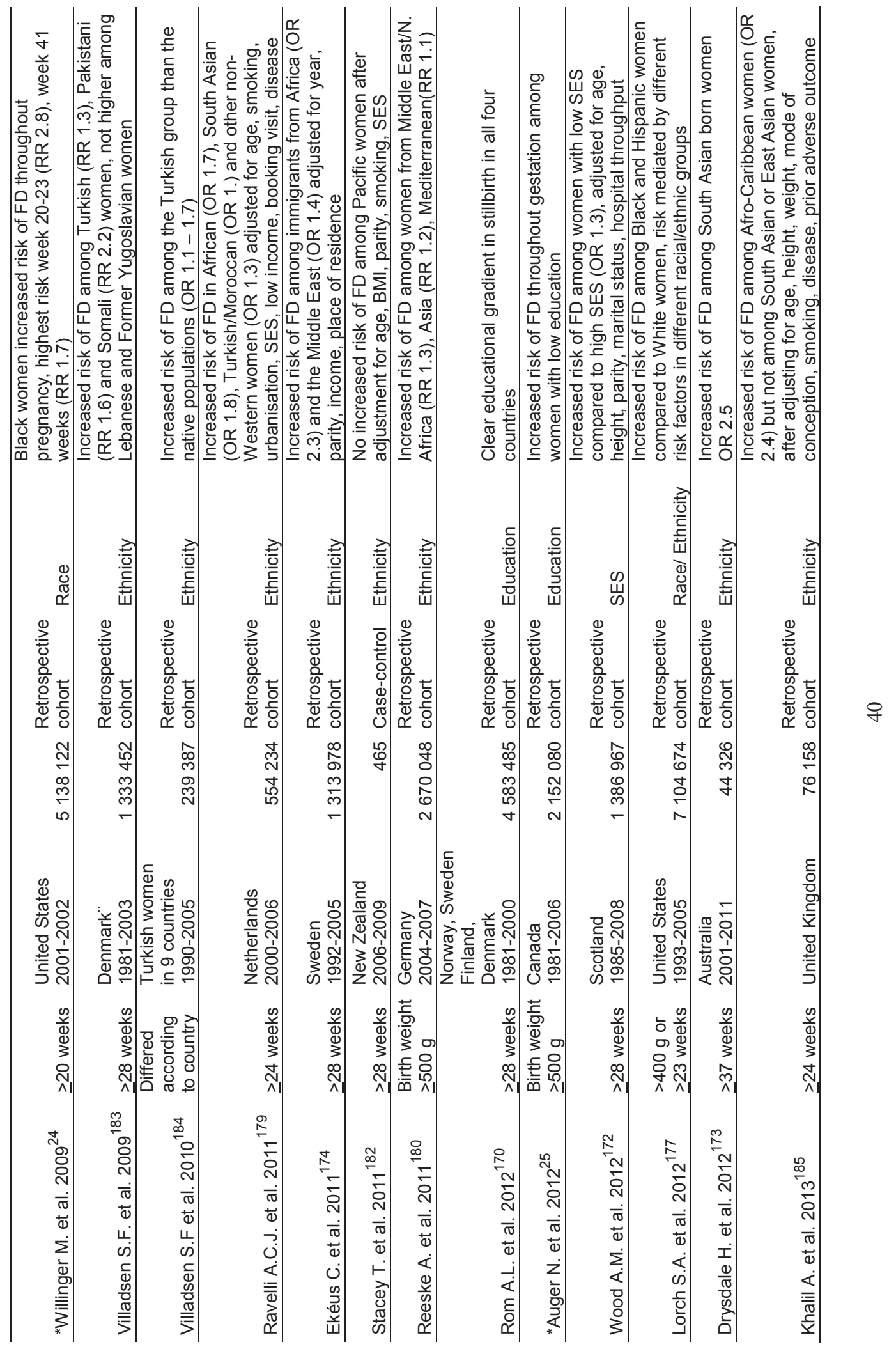




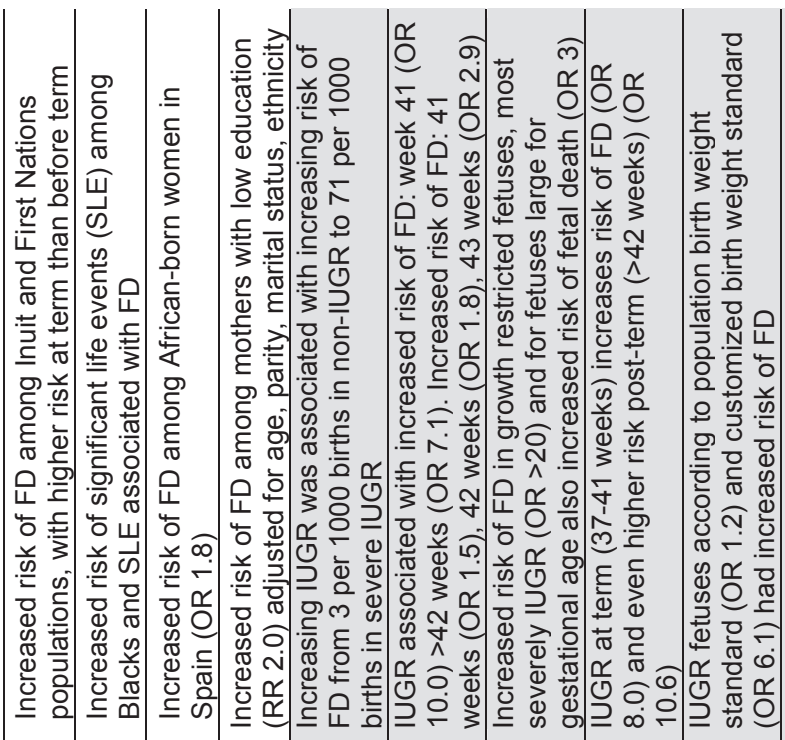

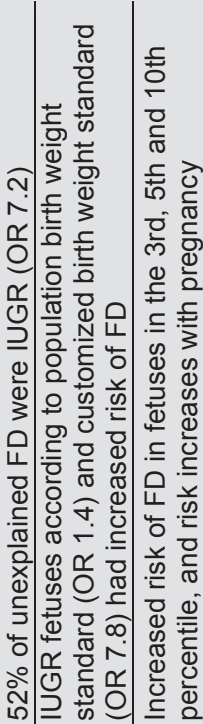

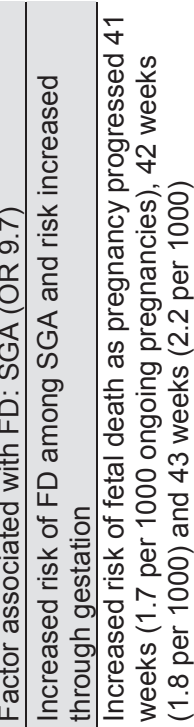

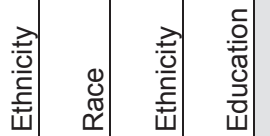

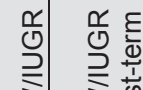

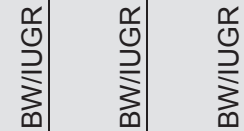

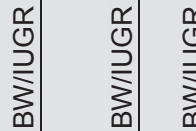

商

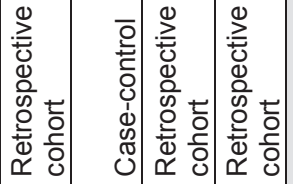

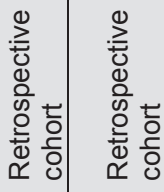

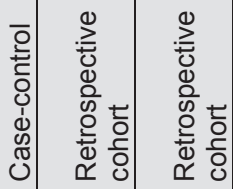

일

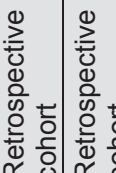

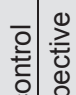

$\sum_{1}^{0}$

d

రิن

के

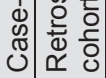

के 는

u $\llbracket$ ऽ $\llbracket$

동

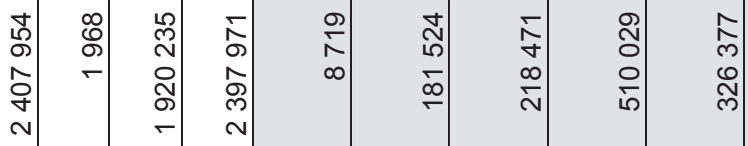

๑

ป \&

న

กิ

\&

ช

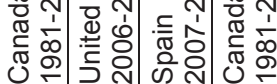

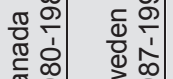

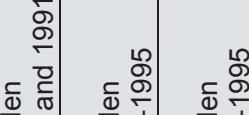

少

हัำ 일

ब

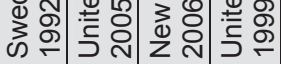

$\stackrel{\circ}{5} \stackrel{0}{\square}$

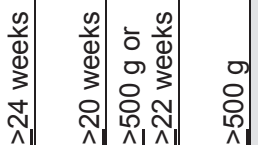

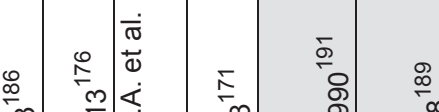

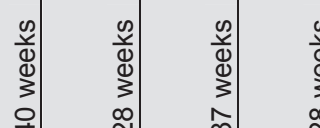

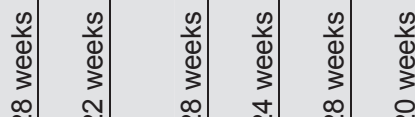

音

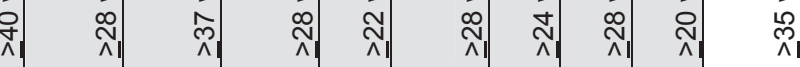

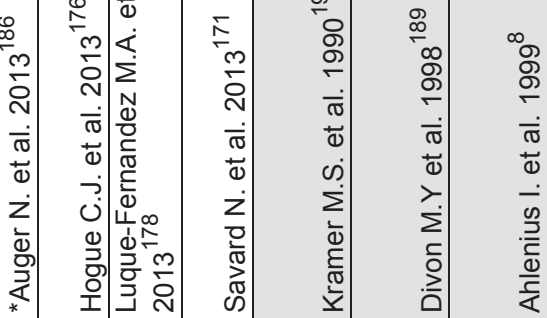

$\stackrel{\infty}{\infty} \quad \stackrel{\infty}{\leftarrow}$

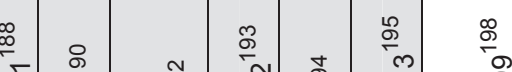

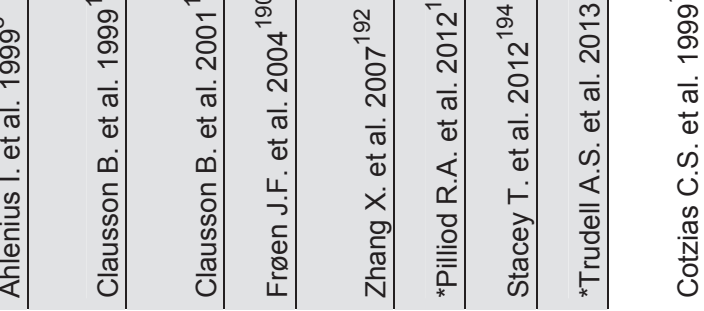




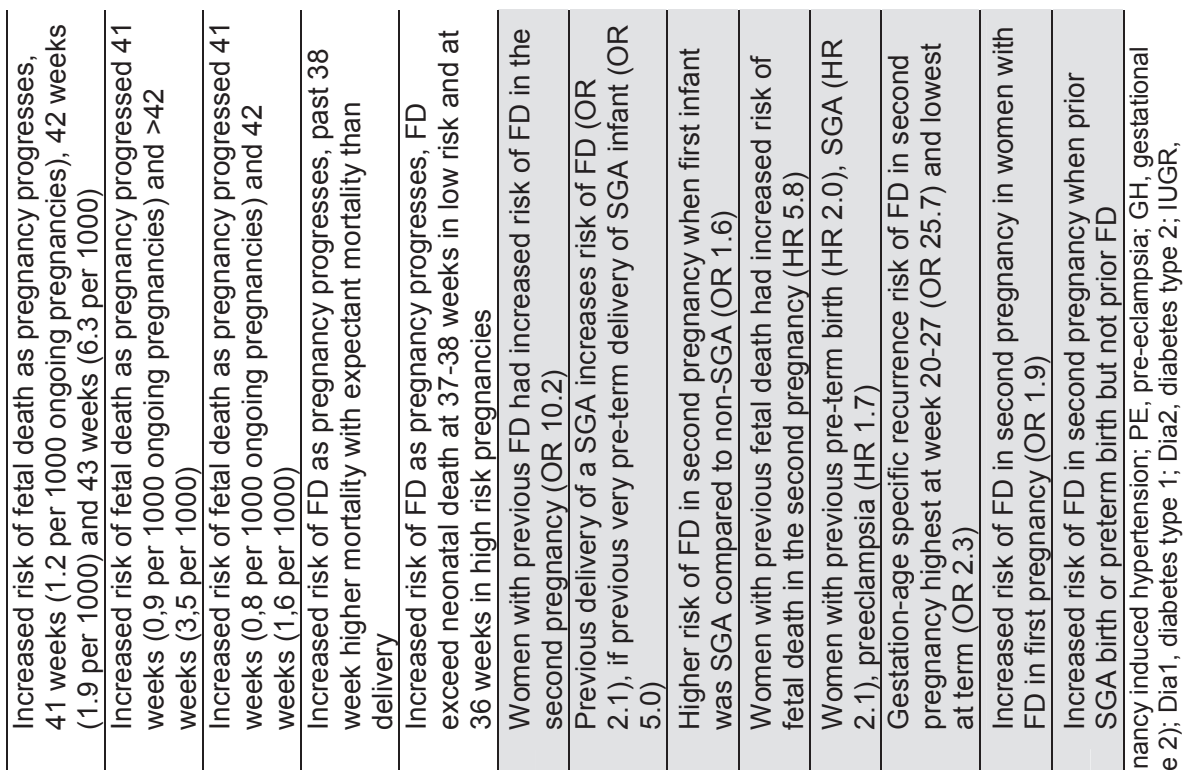

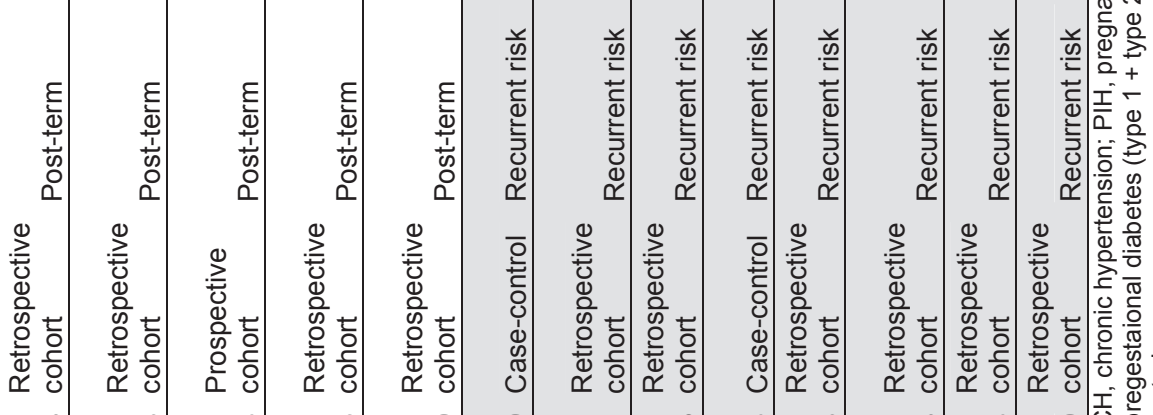

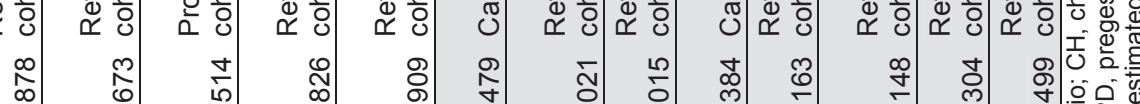

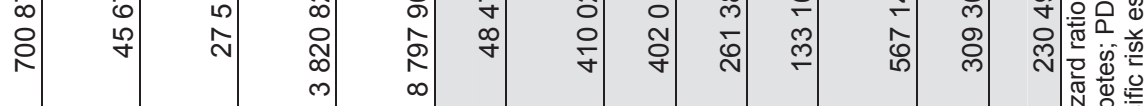

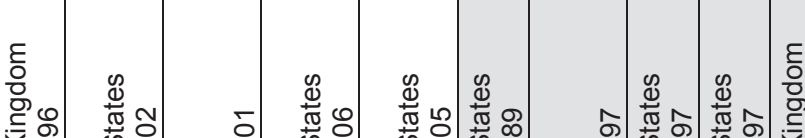

준.

또뭉

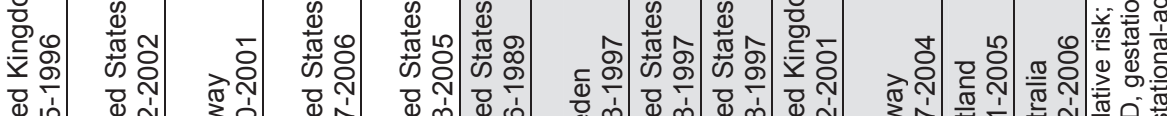

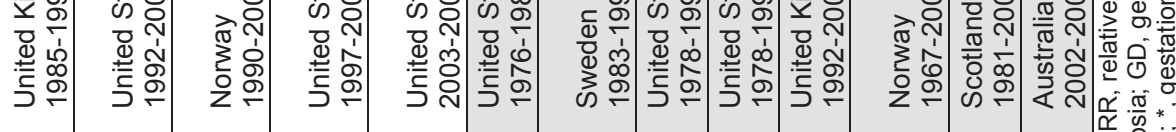

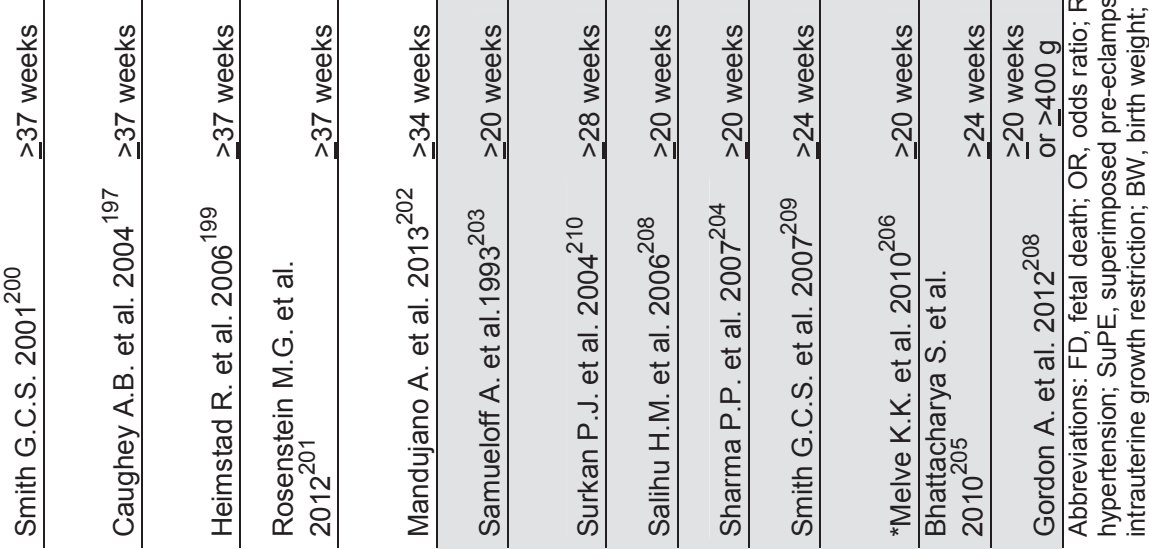




\section{CAUSES AND CONSEQUENCES OF STILLBIRTH}

\section{Causes}

Several classification systems of perinatal death have been developed since the Aberdeen classification was developed by Baird and colleagues in $1954{ }^{211}$ They developed the system after thorough examinations of 1008 perinatal deaths occurring during 1938-1952. The Aberdeen classification system identifies maternal and obstetrical clinical conditions that initiated the event leading to fetal demise. In 1986 the extended Wigglesworth system was published, which implemented the pathophysiological processes leading to fetal death. ${ }^{212}$ These two systems are the most widely used, but they have a high number of unexplained deaths. ${ }^{213}$ Moreover, placental causes of death are not included. More than 30 classification systems have been developed; however, the ReCoDe system and the Tulip system are reported to perform better than other systems. ${ }^{36}$

Several studies have been conducted aiming to establish the cause of fetal death, but the proportion of unexplained deaths in these studies varied greatly, both due to the classification system applied and the intensity of investigations performed after stillbirth. $^{12-14 ; 16 ; 17}$

\section{Fetal conditions}

In high-income countries approximately $5-10 \%$ of fetal deaths are caused by fetal conditions, namely congenital anomalies (chromosomal anomalies and congenital malformations). ${ }^{17 ; 19 ; 214}$ Data from the Wisconsin Stillbirth Service Program reported that the most common disorders associated with fetal death are malformation syndromes and single malformations. ${ }^{215}$ In Canada, Liu and colleagues reported a declining fetal mortality rate due to congenital anomalies at term, presumably a result of the implementation of ultrasound screening (and other prenatal diagnostic tools) in antenatal care and selective termination of affected pregnancies. ${ }^{216}$

\section{$\underline{\text { Infections }}$}

Maternal bacterial or viral infections during pregnancy have been reported to account for approximately $12 \%$ of fetal deaths in high-income countries. ${ }^{14}$ The microorganisms most frequently isolated in fetal death are group B streptococcus, Escherichia coli and Enterococcus fecalis. ${ }^{217}$ However the mere presence of 
microorganisms does not prove causality, as chorioamnionitis or isolation of bacteria from the placenta is a common finding not only in cases of fetal death, but also in healthy controls.

Some perinatal viral and protozoan infections have been associated with fetal death including human parvovirus B19 (PVB), cytomegalovirus, enterovirus, rubella, varicella zoster and Toxoplasmosa gondii (T. gondii). ${ }^{217}$ The majority of studies on viral infection and fetal death concern PVB, but show inconsistent results. ${ }^{218-224}$ Three Swedish hospital-based studies carried out in 1992-1999 reported that between $7 \%$ and $15 \%$ of fetal deaths were PVB DNA-positive in fetal or placental tissue, compared to non PVB DNA-positive placentas among live born controls. ${ }^{220 ; 223 ; 224}$ However in these studies only a few cases had concomitant positive fetal and placenta specimens, and the use of placentas from live births as controls have been questioned. Hence the association of maternal PVB infection with fetal death needs to be further explored.

The proposed mechanisms that may lead to fetal death in women with any type of infection are: a) high maternal fever, b) infection of the placenta causing impaired placental function, c) chronic fetal infection, which may lead to congenital anomalies, organ damage and pneumonia, d) infections promoting pre-term labor, increasing the risk of fetal death (in the very premature fetus). ${ }^{217}$

\section{Umbilical cord abnormalities and cord accidents}

Umbilical cord abnormalities and cord accidents such as cord prolapse, nuchal cord and true knots may cause fetal death. ${ }^{13 ; 14}$

\section{Placental pathology}

Placental pathology is involved in more than $25 \%$ of fetal deaths. ${ }^{14}$ A comprehensive Dutch prospective cohort study of 750 intrauterine fetal deaths ( $>20$ weeks of gestation) during 2000-2006, reported placental pathology as the main cause of fetal death. ${ }^{225}$ They reported that the pathology involved differed according to gestational age: fetal death <32 weeks involved placental bed pathology (i.e. spiral artery pathology or inadequate spiral artery remodelling causing placental abruption and infarction), whereas for fetal deaths $>32$ weeks of gestation, placental developmental 
pathology (i.e. morphologic abnormalities due to abnormal development, causing placental hypoplasia and villus immaturity) dominated.

Fetal maternal haemorrhage may cause fetal death if there is sufficient blood loss, leading to cardiovascular collapse.

\section{Prematurity/immaturity}

Preterm premature rupture of membranes, preterm labor and cervical incompetence may cause intrapartum death in the immature fetus. ${ }^{13}$

\section{Consequences}

Women who have given birth to a stillborn infant in the past more often report symptoms of anxiety than do women with live-born infants. ${ }^{226}$ A case-control study from the United Kingdom reported an increased risk of depression, post-traumatic stress disorder and anxiety in the subsequent pregnancy of women with previous fetal death (>18 weeks gestation) compared to women with one previous live birth. ${ }^{227}$ The authors conducted a 7-year follow-up study to assess the long-term psychosocial sequelae among these women. They reported no difference between cases and controls with respect to depression and post-traumatic stress disorder. However, the subgroup of women who reported symptoms of post-traumatic stress disorder 7 years earlier reported significantly higher levels of symptoms in the followup study. ${ }^{228}$

A population-based cohort study conducted by Calderon-Margalitt and colleagues reported higher premature mortality in women with one prior fetal death (>28 weeks) compared to women with only live births (HR 1.40, 95\% Cl 1.11-1.77), even after adjusting for age, SES, parity, medical conditions at cohort enrolment and placental syndrome. ${ }^{229}$ Women with prior fetal death were at increased risk of death from coronary heart disease, circulatory or renal disorders. However, this association may have been confounded by pre-pregnancy BMI. A recent Danish study by Ranthe and colleagues with $>15,000,000$ person-years of follow up reported increased incidence of myocardial infarction, cerebral infarction and renovascular hypertension in women with prior stillbirth. ${ }^{230}$ It has been proposed that previous fetal death can be utilized as a sex-specific predictor of future cardiovascular disease. ${ }^{231}$ 


\section{CONCERNS AND GAPS RELATED TO STUDIES OF STILLBIRTH}

The literature review revealed several risk factors associated with fetal death. The association between maternal age and fetal death has been most frequently explored, and all studies reported an increased risk of fetal death among women aged $\geq 40$ years, ${ }^{23 ; 50-70}$ and all but three reported an increased risk among women $\geq 35$ years, ${ }^{53 ; 69 ; 70}$ whereas six ${ }^{54 ; 58 ; 67 ; 72-74}$ studies reported increased risk associated with young maternal age and three $e^{55 ; 75 ; 76}$ reported no risk. The studies applied different definitions of stillbirth and different reference groups. The effect of maternal age on the risk of stillbirth remains an object of concern, and further research is needed to elucidate the causal mechanisms involved.

Primiparity was associated with fetal death, ${ }^{23 ; 50 ; 59 ; 60 ; 66 ; 68 ; 70 ; 79-81 ; 83-85}$ whereas six studies reported increased risk of fetal death in multiparous women. . $^{\text {50;59;70;78;80;81 }}$ Obesity was associated with increased risk of fetal death in all the reviewed papers but one, whereas five studies also reported an increased risk among overweight women. ${ }^{68-70 ; 79 ; 82 ; 83 ; 90-100}$ Four of these five studies utilized $>15$ years old data, ${ }^{79 ; 83 ; 94 ; 98}$ hence, lack of an association between fetal death and maternal overweight in the majority of studies in this review, may be due to increased surveillance and interventions among these women.

Increased risk of stillbirth in women with pregestaional diabetes was reported by 22 studies, ${ }^{53 ; 55 ; 66 ; 68-70 ; 98 ; 111 ; 119-133}$ seven studies reported on diabetes type 1 , $^{119 ; 121-125 ; 127}$ and two studies reported on diabetes type 2. ${ }^{124 ; 129}$ Gestational diabetes was associated with increased risk of fetal death in two studies, ${ }^{98 ; 134}$ whereas three did not report an increased risk. ${ }^{66 ; 126 ; 135}$ Chronic hypertension was reported to increase the risk of fetal death in 15 studies. ${ }^{53 ; 55 ; 66 ; 68 ; 101 ; 104 ; 105 ; 107-113 ; 117}$ One Australian study did not report increased risk of fetal death among women with chronic hypertension, 103 however, the authors reported a significantly higher elective Caesarean rate in these women compared to normotensive women and women with pregnancy hypertension. Preeclampsia was associated with increased risk in four studies, ${ }^{66 ; 102 ; 114 ; 115}$ and no risk in three studies. ${ }^{104 ; 110 ; 117}$

Sixteen studies reported an increased risk of fetal death among smokers and the result was very consistent. ${ }^{16 ; 53 ; 60 ; 66 ; 68-70 ; 79 ; 84 ; 142-148}$ Studies on alcohol consumption during pregnancy and risk of fetal death were few and very heterogeneous; one study reported increased risk among abstainers, whereas the majority of studies 
reported increased risk associated with alcohol consumption. ${ }^{68 ; 79 ; 152-157}$ However, two studies reported that the risk was only significantly increased at early gestation $(<16$ weeks and $<28$ weeks, respectively). ${ }^{156 ; 157}$ Moderate to high amounts of coffee consumption was associated with increased risk of fetal death in 4 studies. ${ }^{79 ; 153 ; 158 ; 232}$ Low SES measured by educational attainment, household income or employment, was associated with an increased risk of stillbirth. ${ }^{25 ; 147 ; 148 ; 163 ; 164 ; 166 ; 168 ; 170-172}$ Likewise, a consistent strong association between fetal death and ethnic minority status or being Black was reported by large number of studies (24 papers). 24;68-70;160162;165;167;169;173-186 Understanding why disadvantaged women have a poorer pregnancy outcome and how to create prenatal care that is better targeted to this group is required.

IUGR assessed by the proxy SGA was associated with increased risk of fetal death

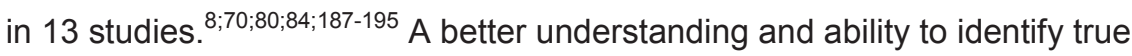
pathological growth is warranted. In addition an optimal timing for the delivery of cases with pathological growth needs to be estimated.

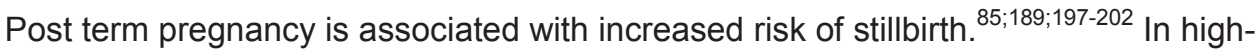
risk pregnancies, in which diabetes, pre-eclampsia or severe SGA are a factor, labor is routinely induced near term. However, there is continuing controversy about the appropriate management of low-risk singleton pregnancies past term.

Women with a previous stillbirth have an increased risk of recurrence, ${ }^{203-210}$ and previous stillbirth was claimed to be the strongest pre-pregnancy risk factor in one study. ${ }^{69}$

Stillbirth is the endpoint of numerous pathways, and different risk factors are associated with different causes. In Figure 4, a conceptual model of risk factors associated with fetal death from the literature review is depicted. Risk factors may be both directly and indirectly associated with stillbirth, for example high maternal age, which is directly associated with stillbirth but also indirectly associated through the increased risk of medical conditions or high BMI. The figure further depicts the link between sociodemographic, behavioral and pregnancy-related risk factors and more proximate factors in the causal pathway to fetal death (congenital anomalies, placental disorders, infections and preterm labor). However, the Figure is not exhaustive. 


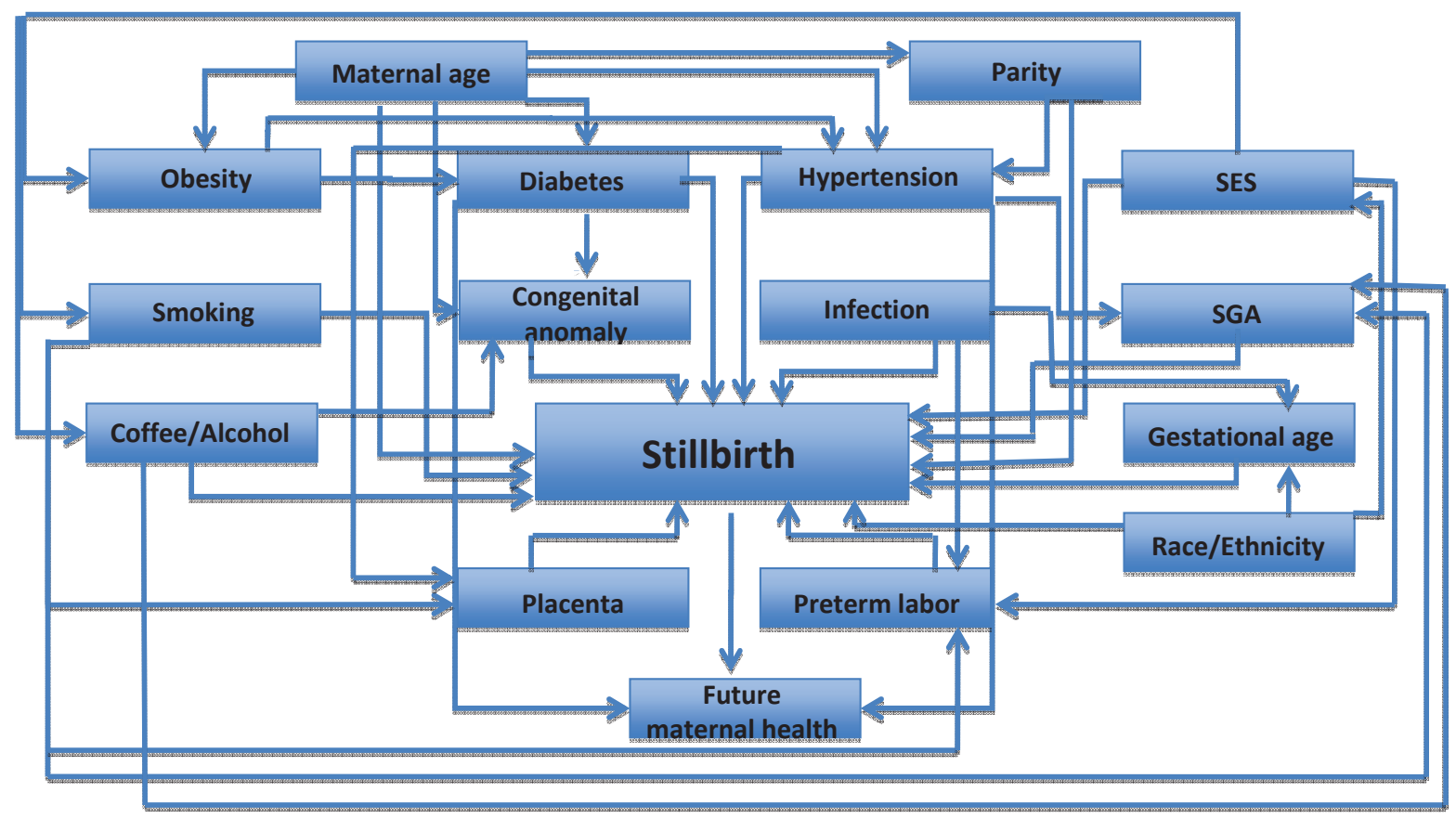

Figure 4. A conceptual model illustrating causes and risk factors associated with fetal death.

During the last century fetal mortality rates in most high-income countries have declined. ${ }^{233}$ However, there is still significant inter- and intra-country inequality in stillbirth. ${ }^{44 ; 45 ; 234}$ To address these differences and achieve further reductions it is imperative that the specific causes of, and risk factors for fetal death are identified, and predictive models established. Even though several risk factors have been identified, understanding and prevention is hampered by limitations and gaps in the knowledge on fetal death. ${ }^{70}$ The only antenatal screening method in recent time, that has been shown to reduce risk of stillbirth is the use of fetal umbilical Doppler blood flow measurements in high-risk pregnancies. ${ }^{235 ; 236}$

Epidemiological research on fetal death is conducted using observational studies, which harbor the inherent risk of finding an association due to chance or bias. However, the probability of finding a "true" association increases when observations 
are repeated in different populations with consistent results, and at the same time are plausible and exhibit a biological gradient. Furthermore, it has been indicated that real-life observational studies of mortality trends may provide strong reality-based evidence, in particular when studying fetal mortality in obstetrics as noninterventional studies are not feasible due to ethical considerations. ${ }^{237}$ Cohort studies of outcomes that are as rare as fetal death require large datasets. Hence most research to-date has taken the form of retrospective studies utilizing vital statistics from registries data that often lack detailed information on confounders. Several large population-based cohort studies conducted in the United States obtained data on fetal death from the Centers for Disease Control and Prevention's National Center for Health Statistics, which receives standard reports of fetal death from the independent reporting areas (states and territories). However, reporting requirements and criteria vary between the reporting areas, and fetal death reports are flawed by underreporting, missing data and low accuracy. ${ }^{238 ; 239}$ We were able to study fetal death in Norway by utilizing data from the MBRN. This registry, like the other Nordic medical birth registries, is a valuable resource for population-based data that has been prospectively collected in a standardized manner with nearly $100 \%$ coverage of all births in Norway. ${ }^{6}$ The use of MBRN data eliminates selection bias due to non-response. Longitudinal monitoring over time enables the study of trends to elucidate changes in disease/mortality patterns in the population, and at the same time facilitates the evaluation of healthcare services delivered. However, as will be elaborated upon later, the use of secondary data (data generated for a different purpose) has certain drawbacks, such as inaccuracy in the measurement of exposure and outcome, and limited data on confounders. ${ }^{240}$ 


\section{AIMS OF THE THESIS}

The main aim of this thesis was to study trends of fetal death and associated factors in Norway.

It has been reported that infection is an important cause of stillbirth, specifically in early fetal deaths (<28 weeks of gestation). ${ }^{22 ; 217}$ Hence, studies of late fetal death (>28 weeks) may underestimate the impact of infection. Moreover, knowledge on viral causes of fetal death is limited due to complex detection techniques, so studies in high-income countries differ in the reported rate of infection as a cause of fetal death, due to different study designs and the degree to which investigations were performed, with higher numbers reported in prospective studies with extensive investigation protocols (culture, serology, histology, molecular biology techniques). ${ }^{17 ; 241}$

PVB has been reported to be an important cause of fetal death throughout gestation, however, studies on PVB and fetal death are not consistent. Hence we aimed to study the association between PVB and fetal death in a large population-based study in Norway in Paper I.

In Norway, there have been large changes in the management of pregnant women, especially since the 1980s, with the introduction of ultrasound, cardiotocography, increasing numbers of caesarean sections and inductions of labor performed. We wanted to study trends in fetal death at different gestational ages in Paper II. Moreover, in this thesis we wanted to estimate the impact of certain risk factors reported to be associated with fetal death, such as high maternal age in Paper III, and hypertensive disorders in Paper IV. There is a lack of knowledge on gestationalage-specific risk of fetal death in high-risk pregnancies, and therefore this was further explored in this thesis.

More specifically we aimed to:

1. Study the association between past and present maternal human PVB infection and fetal death, birth weight and length of gestation.

2. To study trends in fetal mortality at different gestational ages in Norway in 1967-2006. 
3. To study changes in the association of fetal death with maternal age at different gestational ages.

4. To study changes in the association of fetal death with maternal hypertensive disorders (pre-eclampsia, gestational hypertension and chronic hypertension). 


\section{MATERIALS AND METHODS}

\subsection{Toxoplasmosis Study (Paper I)}

In the first study we used data from the Toxoplasmosis Study. This nationwide prospective study was conducted by the Norwegian Institute of Public Health from June 1992 to May 1994, and included approximately $60 \%$ of all pregnant women in Norway during this period ( $\mathrm{n}=35940$ pregnant women). ${ }^{242}$ It was primarily designed to study risk factors, prevalence, incidence and vertical transmission rate of $T$. gondii among pregnant women.

Women were invited to participate in the study at their first antenatal visit to the primary healthcare center (mean gestational age 10.2 weeks) where the first of three serum samples was requested. Retesting was requested for the women without antibodies against $T$. gondii at 22 and 38 weeks of gestation (76.3\% women provided all three serum samples). If any sample indicated possible primary infection an additional sample was requested for confirmation. An additional serum sample was also requested in the case of fetal death or miscarriage.

\subsubsection{Study design and population}

A linkage between the Toxoplasmosis Study Registry and the MBRN was performed by personal identification numbers so as to identify women with live-born $(n=957$ controls) and stillborn ( $\geq 16$ weeks of gestation) ( $n=281$ cases) infants (Figure 5). Based on this a case-control study was conducted.

\subsubsection{Blood sampling and analysis}

The blood samples were collected during June 1992 to May 1994 and stored at $-20^{\circ} \mathrm{C}$ at the Norwegian Institute of Public Health. The sera were analyzed for PVB antibodies during 1996. The first serum sample from each woman was tested separately for immunoglobulin $\mathrm{G}(\mathrm{lg} \mathrm{G})$ and immunoglobulin $\mathrm{M}(\mathrm{IgM})$ antibodies against PVB (IDEIA, DAKO A/S, Copenhagen, Denmark). If the first serum sample was negative the last available serum sample from the woman was analyzed to detect seroconversion. Serum that tested positive within the grey zone was retested. 


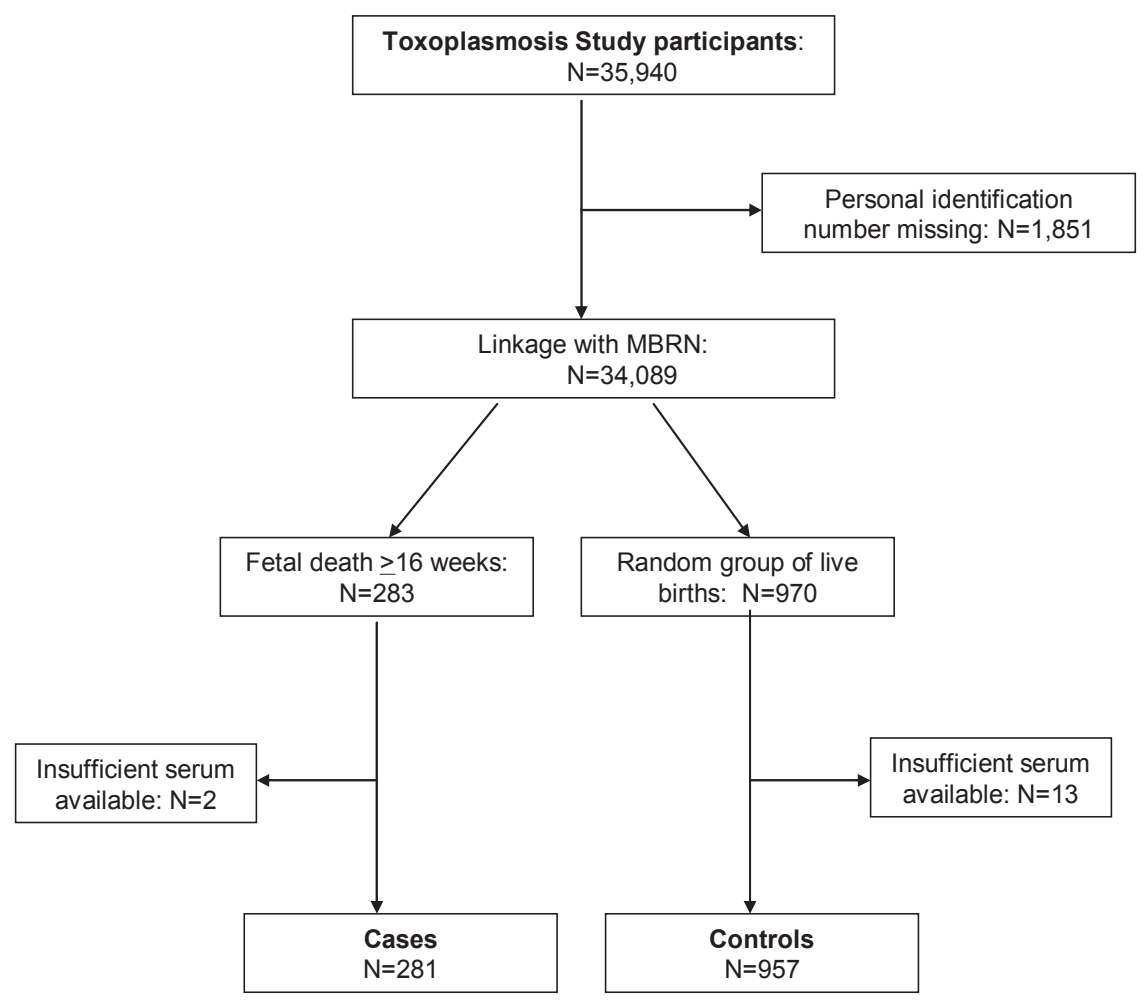

Figure 5. Study population for Paper I.

\subsubsection{Variables}

\section{Main outcome variable}

Fetal death was defined as death $\geq 16$ weeks of gestation as notified to the MBRN.

No distinction was made between antepartum and intrapartum deaths.

\section{Secondary outcome variables}

Birth weight information on birth weight $(\mathrm{g})$ was obtained from the MBRN. Previous studies have reported higher than expected proportion of small for gestational age infants among serologically confirmed maternal PVB infection. ${ }^{218}$ 
Gestational age (weeks) was obtained from the MBRN. Perinatal infections generally have been associated with preterm delivery. ${ }^{217}$

\section{Explanatory variables}

Maternal PVB antibody status was categorized in the following manner:

1. Antibodies against PVB not detected: no past or present infection.

2. Presence of IgG antibodies against PVB in the first serum sample (but no IgM antibodies): previous infection.

3. Presence of IgM antibodies against PVB in the first serum sample: acute infection.

4. Seroconversion (occurrence of $\lg G$ or $\lg M$ antibodies in seronegative women): acute infection.

Maternal age at delivery was categorized as ( $<30$ or $\geq 30$ years). Previous studies have reported increased risk of fetal death at both extremes of maternal age ${ }^{58}$ and seroprevalence of IgG increases with age. ${ }^{243}$

Parity was defined as the number of previous births (after $\geq 16$ weeks of gestation) and was categorized as 0,1 and $\geq 2$. High parity is associated with increased risk of fetal death, and increased risk of acquiring PVB infection. ${ }^{244}$

\subsubsection{Statistical analysis}

The association (ORs with $95 \% \mathrm{Cls}$ ) between maternal PVB antibody status (exposure) and fetal death (outcome) was estimated by contingency tables. Hypothesis testing was performed by chi-squared test $\left(\mathrm{X}^{2}\right)$, and by Fishers exact test when the expected frequencies were less than 5 . Multivariate logistic regression models were applied to assess the relationship between exposure and outcome allowing for adjustment for the confounding effect of maternal age and parity. Among women followed with regard to seroconversion additional adjustment for follow-up time was made.

Differences in mean birthweight and length of gestation among cases and among controls according to maternal PVB antibody status were tested by the Student t-test. Among cases with presence or absence of IgM antibodies or occurrence of IgG or IgM antibodies, the Mann-Whitney test (non-parametric) was applied due to small numbers and non-normally distributed outcomes as this test is more robust to 
outliers. All statistical analyses were performed using the Statistical Package for the Social Sciences (SPSS, version 15.0; SPSS Inc., Chicago, Illinois, USA).

\subsubsection{Ethical aspects}

The study was approved by the Norwegian Data Inspectorate, the National Board of Health, the Regional Ethical Committee for Medical Research and the Advisory Committee for the MBRN.

\subsection{The Medical Birth Registry of Norway (Papers II-IV)}

In the Papers II-IV we used data from the MBRN, which was established in 1967 with the following purpose:

"to perform epidemiological surveillance of birth defects and other perinatal health problems in order to detect increases in rates." 6

It is mandatory to report all births (live births and fetal deaths) $\geq 16$ weeks of gestation (since 1999, 12 weeks of gestation) to the registry. A standardized notification form is filled in after the delivery by the attending midwife or physician within 7 days of delivery. The form contains information on maternal health (before and during pregnancy) and outcome of the pregnancy (maternal and neonatal). The form went unchanged from 1967-1998, but as from 1999 a new form was implemented. The main changes in the new form were the inclusion of information regarding maternal smoking habits, use of nutritional supplements, and the former text regarding maternal health was replaced by pre-coded fields for maternal disorders. Before 1988 terminated pregnancies were only infrequently notified to MBRN, and from 1988 to 1998 terminations due to serious congenital anomalies were notified as stillbirths. In 1999 a separate register for pregnancy terminations after 12 weeks of gestation was established within the MBRN. Complete case ascertainment (births and deaths) is maintained in the registry due to routinely executed record linkage with the Cause of Death Registry and the National Population Registry. 


\subsubsection{Study design and population}

In the Papers II-IV we conducted population-based retrospective cohort studies. For details about the population and exclusion criteria see Figure 6 . The inclusion and exclusion criteria were the same in Papers II-III whereas in Paper IV we included only pregnancies $\geq 20$ weeks and excluded multiple pregnancies.

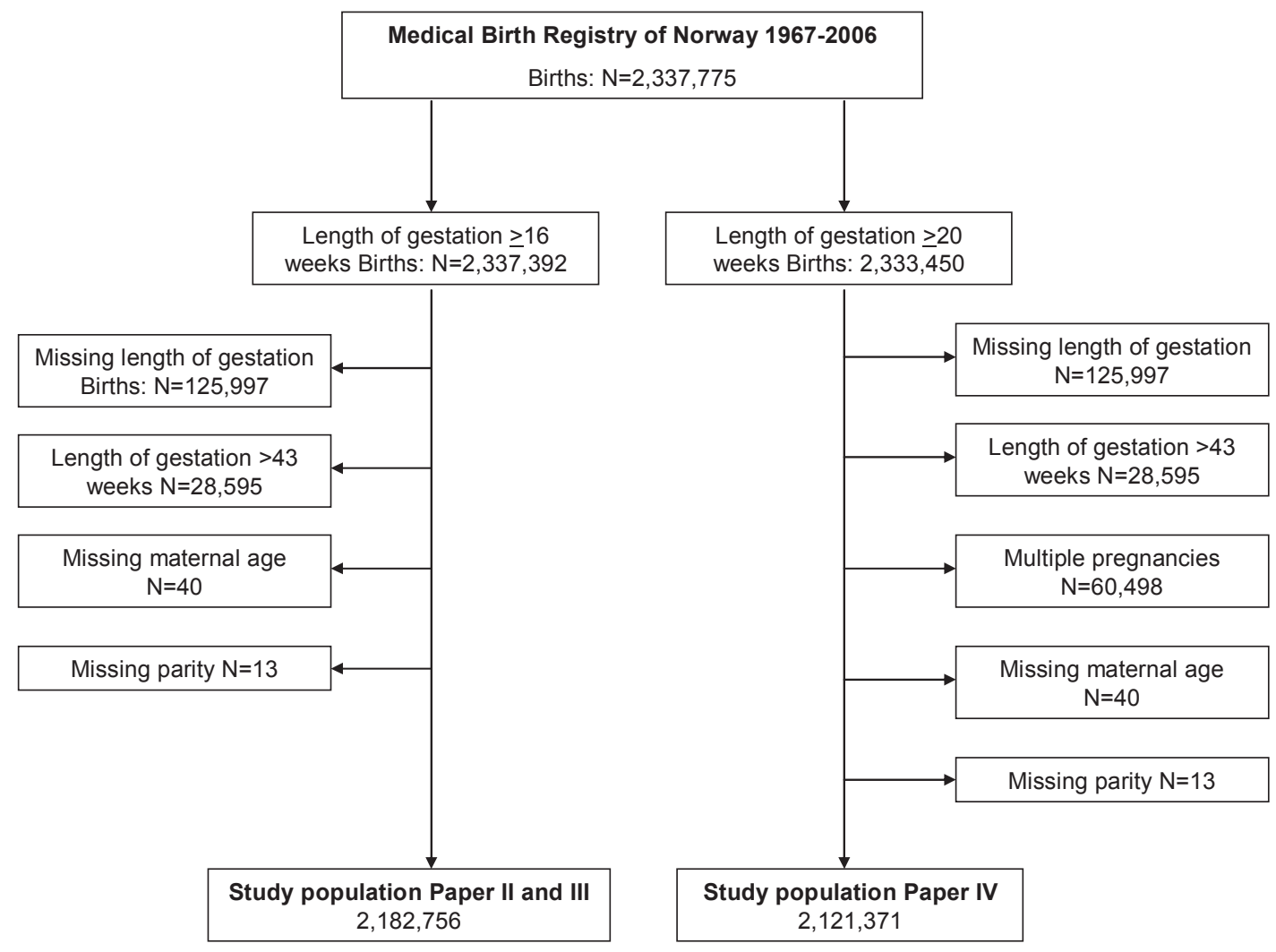

Figure 6. Study population for Papers II-IV. 


\subsubsection{Variables}

\section{Main outcome variables}

\section{Paper II}

Fetal death was defined as death at $\geq 16$ weeks of gestation as notified to the birth registry. We studied fetal death at different equal lengths of gestation: $16^{+0}-22^{+6}$, $23^{+0}-29^{+6}, 30^{+0}-36^{+6}$ and $37^{+0}-43^{+6}$ weeks (the superscripts denote days in addition to completed weeks).

Perinatal mortality was defined as the sum of fetal death at $\geq 22$ weeks of gestation and infant death within 7 days of birth.

Early neonatal mortality was defined as the number of infant deaths within 7 days of birth.

Stillbirth (Paper II) was defined as fetal death $\geq 22$ weeks of gestation.

\section{Paper III}

Fetal death was defined as death at $\geq 16$ weeks of gestation as notified to the birth registry. We studied fetal death at different equal lengths of gestation: $16^{+0}-22^{+6}$, $23^{+0}-29^{+6}, 30^{+0}-36^{+6}$ and $37^{+0}-43^{+6}$ weeks. We also studied fetal death at: $38^{+0}-39^{+6}$, $40^{+0}-41^{+6}$, and $42^{+0}-43^{+6}$ weeks of gestation.

\section{Paper IV}

Fetal death was defined as death at $\geq 20$ weeks of gestation. We studied risk of fetal death at the following equal lengths of gestation: $20^{+0}-23^{+6}, 24^{+0}-27^{+6}, 28^{+0}-31^{+6}, 32^{+0}$ $35^{+6}, 36^{+0}-39^{+6}$ and $40^{+0}-43^{+6}$ weeks.

Perinatal mortality was defined as the sum of fetal death at $\geq 22$ weeks of gestation and infant death within 7 days of birth.

\section{Explanatory variables}

\section{Paper II}

Period of delivery (year) or year of birth as reported to the MBRN was the main explanatory variable, and was categorized as: 1967-1971, 1972-1976, 1977-1981, 
1982-1986, 1987-1991, 1992-1996, 1997-2001 and 2002-2006. In the analysis the years 1967-1971 was used as reference to study trends in fetal death.

Maternal age at delivery was categorized as <20, 20-24, 25-29, 30-34, 35-39, 40-44, and $\geq 45$ years. Previous studies have reported increased risk of fetal death at both extremes of maternal age ${ }^{23 ; 58}$ and maternal age at delivery has increased in recent years. $^{1}$

Parity was defined as the number of previous births (after $\geq 16$ weeks of gestation) and was categorized as $0,1,2,3$ and $\geq 4$. Primiparity and also grand multiparity may increase the risk of fetal death. ${ }^{60 ; 78}$

Plurality was coded as either a single infant or two infants or more. Multiple pregnancies confer an increased risk of fetal death, ${ }^{36}$ and the number of multiple pregnancies has also increased in the last 40 years. ${ }^{1}$

Paternal age was categorized as $<30,30-39, \geq 40$ years and missing (1\%). High paternal age is associated with increased risk of fetal death. ${ }^{245}$ Paternal age is correlated with maternal age, and as maternal age has increased, paternal age may also have changed.

Pre-eclampsia was defined as an increase in blood pressure to at least 140/90 $\mathrm{mmHg}$ combined with proteinuria after completed 20 weeks of gestation (1967-1998: ICD-8 codes 637.4 / 637.5 / 637.6 / 637.9 and 1999-2006: ICD-10 codes 013 and 014). Preeclampsia is associated with fetal death ${ }^{102}$ and increased prevalence in Norway since 1967 has been reported. ${ }^{246}$

\section{Paper III}

Maternal age at delivery was the main explanatory variable and was categorized as $<20,20-24$ (reference), 25-29, 30-34, 35-39, 40-44, and $\geq 45$ years. The last two categories (40-44 and $\geq 45$ years) were merged due to insufficient numbers in certain analyses.

Period of delivery (year) was categorized as: 1967-1971, 1972-1976, 1977-1981, 1982-1986, 1987-1991, 1992-1996, 1997-2001 and 2002-2006.

Parity was defined as the number of previous births (after $\geq 16$ weeks of gestation) and was categorized as $0,1,2,3$ and $\geq 4$. Primiparity and also grand multiparity may increase the risk of fetal death and is associated with maternal age. ${ }^{60 ; 78}$ 
Plurality was coded as either a single infant or two infants or more. Multiple pregnancies confer an increased risk of fetal death ${ }^{36}$ and are associated with high maternal age. ${ }^{247}$

Paternal age was categorized as $<30,30-39, \geq 40$ years and missing (1\%). High paternal age is associated with increased risk of fetal death. ${ }^{245}$, and is correlated with maternal age.

Pre-eclampsia was defined as an increase in blood pressure to at least 140/90 $\mathrm{mmHg}$ combined with proteinuria after completed 20 weeks of gestation (1967-1998: ICD-8 codes 637.4 / 637.5 / 637.6 / 637.9 and 1999-2006: ICD-10 codes 013 and 014). Preeclampsia is associated with fetal death, ${ }^{102}$ and also associated with maternal age. ${ }^{56}$

\section{Paper IV}

Pre-eclampsia, gestational hypertension and chronic hypertension were the main explanatory variables:

Pre-eclampsia was defined as an increase in blood pressure to at least 140/90 $\mathrm{mmHg}$ combined with proteinuria after completed 20 weeks of gestation (1967-1998: ICD-8 codes 637.4 / 637.5 / 637.6 / 637.9 and 1999-2006: ICD-10 codes 013 and O14). Eclampsia was defined as preeclampsia with seizures. Eclampsia and HELLP (Hemolysis, Elevated Liver Enzymes, and Low Platelets) were grouped together with pre-eclampsia. Women with chronic hypertension who developed preeclampsia during pregnancy were assigned to the preeclampsia group.

Gestational hypertension was defined as an increase in blood pressure to $\geq 140 / 90$ mmHg after 20 weeks of gestation without concomitant proteinuria (1967-98: ICD-8 codes 637.0/637.2 and 1999-2006 ICD-10 code 016).

Chronic hypertension was defined as pre-pregnancy systolic blood pressure at $\geq 140$ $\mathrm{mmHg}$ or diastolic blood pressure at $\geq 90 \mathrm{mmHg}$, or an increase in blood pressure to these values before 20 weeks of gestation (1967-1998: ICD-8 codes 400-404 and 1999-2006: ICD-10 codes I10//11//12//13//15/O10/011).

Maternal age at delivery was the main explanatory variable and was categorized as $\leq 19,20-24,25-29,30-34,35-39$ and $\geq 40$ years. Maternal age is associated with fetal death and older women have higher prevalence of hypertensive disorders. ${ }^{56}$ 
Parity was defined as the number of previous births (after $\geq 16$ weeks of gestation) and was categorized as $0,1,2,3$ and $\geq 4$. Primiparity and also grand multiparity may increase the risk of fetal death ${ }^{78}$ and primiparity is associated with pre-eclampsia. ${ }^{248}$

\subsubsection{Data preparation}

The source of data for the studies was raw data file from the MBRN. The file was examined and data converted trough several syntaxes. Fetal death was collapsed into one category, and then grouped according to gestational age at death. For the regression analyses continuous variables were categorized to be able to adjust for explanatory variables.

\subsubsection{Theoretical basis of the statistical analysis in Papers II-IV}

The concept of stillbirth risk has to be further elaborated. The overall stillbirth risk is straightforward calculated as the proportion of stillbirths among all births. However, gestational-age-specific risk of stillbirth is more complicated, but nevertheless important in the understanding and prevention of this outcome. There is an ongoing dispute on which epidemiologic method to apply when estimating gestational-agespecific risk of stillbirth. ${ }^{249-253}$ The conventional definition is the number of stillbirths at a given gestational week divided by all births (live birth + stillbirths) at that gestational week:

Stillbirth rate in week $i=\frac{\text { number of stillbirths }(i)}{\text { total births }(i)}$

By applying the conventional definition, the fetal death risk is highest early in gestation, declines with advancing pregnancy duration, and then rises slightly at post term gestational age. ${ }^{249}$ This is claimed to be inconsistent with the observed changes in obstetric practice, where increasing rates of medically indicated iatrogenic preterm deliveries has coincided with declining stillbirth rates. ${ }^{251}$

The second problem with the conventional definition regards the paradox of intersecting gestational-age-specific perinatal mortality curves. ${ }^{251}$ This phenomenon pertains to the observed difference in the gestational-age-specific perinatal mortality 
rates for different risk factors such as smoking or race. For such factors the stillbirth rate curves are expected to intersect as gestation advances; with high risk women (smokers) having relatively lower risk of stillbirth in early gestation and relatively higher risk at late gestation compared to low risk women (non-smokers). The alternative definition proposed to circumvent these issues is by applying the "fetus-atrisk" model.

The "fetus-at-risk" model first proposed by Yudkin and colleagues ${ }^{21}$ has the following definition (numbers of stillbirths at a given week divided by number of total births at a given week of gestation or greater):

$$
\text { Stillbirth rate in week } i=\frac{\text { number of stillbirths }(i)}{\sum \text { total births }(j \geq i)}
$$

As not only fetuses delivered at a specific gestational week are at risk of fetal death but all ongoing pregnancies are included in the denominator. By applying the "fetus at risk" definition the fetal mortality rate is very small in early gestational age and increases exponential with gestation, ${ }^{249}$ hence, justifying early selective delivery for medical indications. ${ }^{251}$ Platt and colleagues further proposed that gestational age should be considered as the timescale in time to event analysis with "fetus's-at-risk" as denominator. ${ }^{254}$ The risk of stillbirth is then compared between different groups by Cox-regression analysis.

Both models of estimating gestational-age-specific rate of fetal death are widely applied in the literature, and may answer different clinical questions. ${ }^{250}$ In Paper II and III we applied the "fetus-at-risk" model, whereas in Paper IV the conventional model was applied.

\subsubsection{Statistical analysis}

\section{Papers II-III}

In Papers II-III Cox regression (or proportional hazards) models were applied to compare the rate of fetal death among the exposed and unexposed, and adjustment for confounding was made by including these variables as explanatory variables. These models were applied to estimate the hazard rate ratio (referred to as RR in the 
Papers II and III) of fetal death according to period of delivery (Paper II) and maternal age (Paper III), as we had censored data with varying follow-up times. Event times (or "survival times as fetuses") were gestational age until the study outcome (fetal death). Live births were treated as censored observations. Separate analyses were performed for the different gestational age intervals since the purpose of the studies was to investigate gestational specific differences. A fetus not born at the end of an interval was treated as a censored observation in that interval (irrespectively of the eventual outcome of pregnancy).

Due to the fairly short gestational age intervals the results are not very sensitive to the proportional hazards assumption. To illustrate this I used a standard technique for validating the proportional hazards assumption, namely the log-minus-log plots. Assuming that the hazard ratio between the exposed and unexposed groups is constant, the log-minus-log plot of survival against gestational age should give parallel lines. The proportional hazards assumption was fairly good when stratified by short gestational length groups as illustrated by parallel lines in Figure 7, compared to complete pregnancy in Figure 8 where the curves crossed.

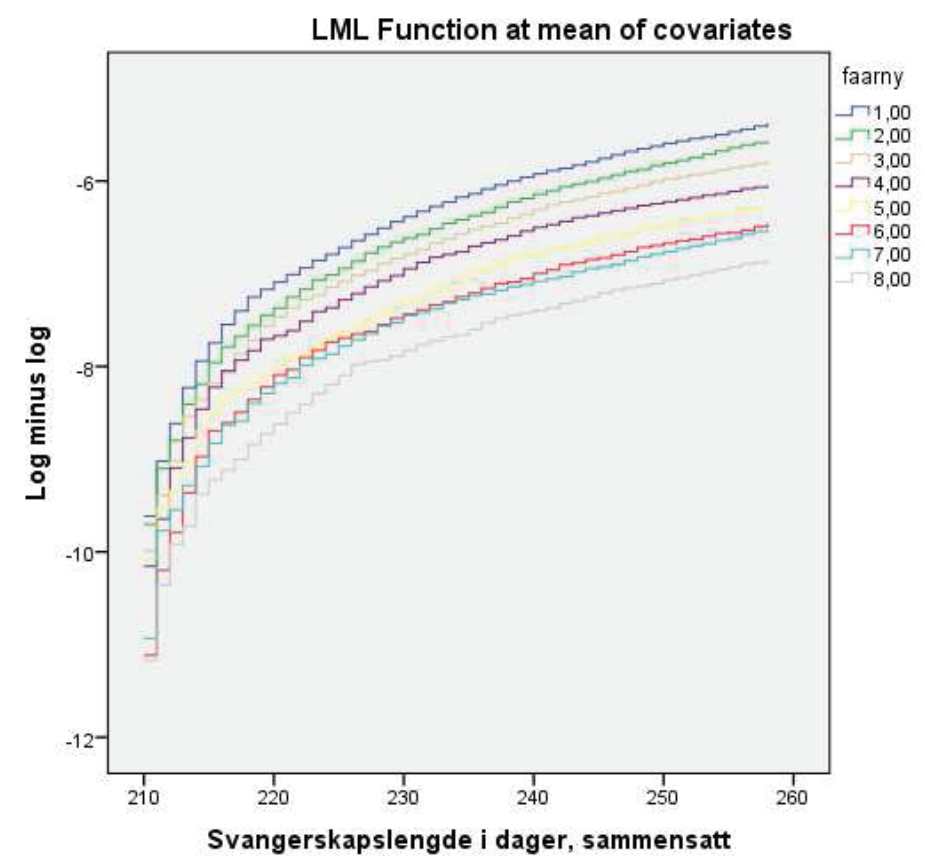

Figure 7. Logminuslog plot for gestational weeks 30-36. *

*(faarny: birth year group; svangerskapslengde i dager: gestational length in days) 


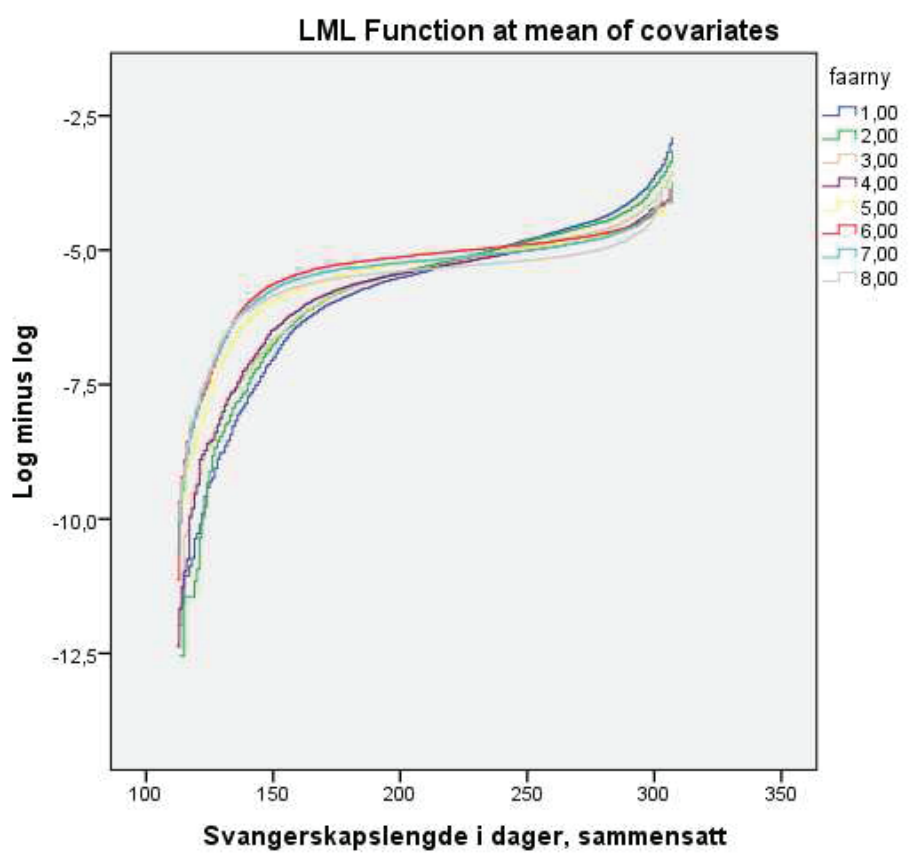

Figure 8. Logminuslog plot for gestational weeks 16-43. *

*(faarny: birth year group; svangerskapslengde i dager: gestational length in days)

Perinatal mortality, early neonatal mortality and stillbirth rates were estimated per 1000 births. The occurrence of fetal death at different gestational ages was estimated per 1000 ongoing pregnancies, and for the last gestational age group (37-43 weeks of gestation) a correction was made to more accurately estimate the incidence rate, by multiplying the denominator with a correction factor (0.5), as only fetus's in utero are under risk of fetal death.

\section{Paper IV}

In Paper IV the models applied were different than those in Papers II-III, as presence of the time-dependent covariates pre-eclampsia and gestational hypertension were only registered at delivery. Therefore it was not possible to address the hazard rates of fetal death at different periods of pregnancy. It was, however, possible to estimate the probability of a fetal death given a birth at a specific time by applying the conventional model to estimate the gestational-age-specific stillbirth risk. Thus the 
proportion of fetal death per 1000 births for the different hypertensive disorders in different time intervals of pregnancy were estimated. Furthermore, at each time interval regression models were applied to calculate (adjusted) RRs of fetal death given a birth.

Instead of using a logistic regression model we estimated the associations between the different hypertensive disorders and fetal death by RRs by applying generalized linear models with a log-link to the binary outcome fetal death (yes/no). This model was applied in order to have an easy parameter interpretation. With this model one estimates risk ratios or the ratio of probabilities of fetal death among different groups adjusted for the confounder. When the outcome is rare the RR-estimates are approximately equal to the ORs, but for non-rare events such as the risk of fetal death early in the pregnancy, the interpretation of OR is not straightforward. Uncertainty of estimates was reported by $95 \% \mathrm{Cls}$.

All statistical analyses were performed by using the SPSS, version 16.0 (SPSS Inc., Chicago, Illinois, USA).

\subsubsection{Ethical aspects}

The MBRN was approved by the Norwegian Data Inspectorate. The Publishing Committee of the MBRN approved our study. 


\section{MAIN RESULTS (summary of Papers I-IV)}

\subsection{Paper I}

\section{Maternal human parvovirus B19 infection and the risk of fetal death and low birth weight: a case-control study within 35940 pregnant women.}

Aim: The aim of this study was to assess the association between maternal PVB infection and fetal death, birth weight and length of gestation.

Method: We conducted a population-based case-control study in Norway. Cases $(n=281)$ were all women who experienced fetal death within a cohort of 35940 pregnant women that participated in the Toxoplasmosis Study during 1992-1994, and the control group consisted of a random sample of 957 women with a live-born child. Information on pregnancy outcome was obtained from the MBRN. First trimester serum samples were tested for antibodies against PVB (IgM and IgG). In seronegative women, additional sera were analyzed to detect seroconversion during pregnancy. The association between parvovirus B19 infection and fetal death was estimated by contingency tables and logistic regression. The mean birth weight and length of gestation among cases and controls according to maternal antibody status was calculated and differences tested with the Student t-test and the Mann-Whitney test.

Results: Two of the $281(0.7 \%)$ women who experienced fetal death, and nine of the $957(0.9 \%)$ controls had IgM antibodies (crude OR 0.8, 95\% Cl 0.2-3.5). In women who were seronegative in the first trimester, 3.1\% (2/65) with fetal death and $2.6 \%$ (8/307) with a live birth seroconverted (crude OR 1.2, 95\% Cl 0.2-5.7). Neither presence of maternal PVB-specific IgG or IgM antibodies in the first trimester, nor was seroconversion during pregnancy associated with lower birth weight or reduced length of gestation in live-born children, but it was associated with low birth weight in stillborn infants, however, this difference was not statistically significant $(P=0.1)$.

Conclusion: In this case-control study PBV infection was not significantly associated with risk of fetal death, and only four of the 281 women with fetal death were infected. However, the lack of association may also be due to sample size limitations. 


\subsection{Paper II}

\section{Changes in fetal death risk during $\mathbf{4 0}$ years - different trends for different gestational ages: a population-based study in Norway.}

Aim: The aim of this study was to study trends in perinatal mortality, early neonatal mortality and gestational-age-specific risk of fetal death during 1967-2006.

Method: We conducted a register-based observational study of all pregnancies $(\geq 16$ weeks of gestation) during 40 years in Norway ( $n=2182756)$. Data was obtained from the MBRN. Changes in the absolute risks and hazard ratios (HR) of fetal death in ongoing pregnancies were estimated. Cox regression models were applied to estimate the HRs of fetal death according to period of delivery (1967-1971, as reference) in the following gestational weeks: 16-22, 23-29, 30-36 and 37-43. Adjustment for confounding was made by including these variables as explanatory variables in multivariable Cox regression models.

Results: In all pregnancies lasting longer than 22 weeks, the fetal mortality rate decreased during 1967-2006. The greatest absolute decline was in term pregnancies (37-43 weeks) in which fetal mortality rates declined from 10.8 per 1000 ongoing in 1967-1971to 3.3 in 2002-2006 (crude HR $0.35,95 \%$ Cl 0.31-0.38). In pregnancies at 30-36 weeks the fetal mortality rate declined from 4.5 to 1.1 per 1000 (crude HR $0.23,95 \% \mathrm{Cl} 0.21-0.26$ ). At 23-29 weeks, the rate declined from 2.8 to 1.3 per 1000 (crude HR $0.46,95 \% \mathrm{Cl} 0.40-0.52$ ). An opposite trend was observed at early gestation (16-22 weeks) with an increase from 1.7 to 3.4 fetal deaths per 1000 ongoing pregnancies (crude HR 2.05, 95\% Cl 1.84-2.27). Adjustments for maternal age, parity, multiple pregnancies, paternal age and pre-eclampsia did not significantly alter the estimated associations.

Conclusion: Since 1967 the risk of fetal death has been reduced by almost $70 \%$ in pregnancies lasting longer than 22 weeks. However, at 16-22 weeks of gestation an increase in risk was observed. This increase may be artificial, perhaps caused by improved reporting routines of early fetal deaths. However, we speculate that some of this increase may be caused by an increased proportion of childbearing women being treated with cervical cone excision prior to pregnancy. 


\subsection{Paper III}

\section{The impact of maternal age on fetal death: does length of gestation matter?}

Aim: Several studies have reported an increased risk of fetal death among older women. The aim of this paper was to study the association between fetal death and maternal age by length of gestation in Norway.

Method: We conducted a population-based observational study including all ongoing pregnancies $\geq 16$ weeks of gestation in Norway in 1967-2006 ( $n=2182756)$. Data was obtained from the MBRN. Changes in the absolute risks and HRs of fetal death in ongoing pregnancies were estimated. Cox regression models were applied to estimate the $\mathrm{HR}$ of fetal death according to maternal age at delivery categorized as less than 20, 20-24 (reference), 25-29, 30-34, 35-39, 40-44, and 45 years and older in the following gestational weeks: 16-22, 23-29, 30-36 and 37-43. Adjustment for confounding was made by including these variables as explanatory variables in multivariable Cox regression models.

Results: The risk of fetal death was 1.4 times higher in women $40-44$ years old than in women aged 20-24 in mid-pregnancy (crude HR 1.43, 95\% Cl 1.18-1.74), but 2.8 times higher at term (crude $\mathrm{HR} 2.8,95 \% \mathrm{Cl} 2.43-3.23$ ). In term pregnancies the relative importance of maternal age increased with each additional week of pregnancy. In gestational weeks $42-43$, the crude risk was 5.1 times higher in mothers $\geq 40$ years (crude HR $5.09,95 \% \mathrm{Cl} 3.55-7.31$ ). In the more recent period (1987-2006), the elevated risk of fetal death in elderly mothers at term was attenuated.

Conclusions: Women $\geq 40$ years had the highest risk of fetal death throughout pregnancy, particularly in term and post-term pregnancies. Improved obstetric care may explain the attenuation of risk of fetal death ( $>40$ weeks of gestation) associated with age in recent time. 


\title{
7.4 Paper IV
}

\section{Hypertensive disorders in pregnancy and fetal death at different gestational} lengths: a population-based study of 2,121,371 pregnancies.

\author{
Aim: The aim of this paper was to compare the proportion of stillborn infants in \\ pregnancies with pre-eclampsia, gestational hypertension or chronic hypertension \\ with normotensive pregnancies.
}

Method: We conducted a register based observational study including all singleton births $\geq 20$ completed weeks of gestation in Norway in 1967-2006 ( $n=2121371)$. Data was obtained from the MBRN. The proportion of fetal death per 1000 births was estimated in normotensive pregnancies, and in pregnancies with pre-eclampsia, gestational hypertension and chronic hypertension at different lengths of gestation. The associations between the different hypertensive disorders and fetal death were estimated as RRs, by applying log-link models for binary data. Also changes in the proportions of stillborn infants by maternal hypertensive disorder from 1967-1986 to 1987-2006 were estimated.

Results The prevalence of hypertensive disorders in pregnancy was $4.7 \%$. In total 17,933 fetal deaths occurred and $9.2 \%$ of these were in hypertensive pregnancies. In normotensive pregnancies $0.8 \%$ (16 290/2 022 400) experienced fetal death. That was true for $1.9 \%$ (1 170/62 261) of the pregnancies with pre-eclampsia, $1.2 \%$ (390/32 068) with gestational hypertension and 1.8\% (83/4 642) with chronic hypertension. There was a $44 \%$ overall reduction in the fetal mortality rate from $1967-$ 1986 to $1987-2006$. The largest decline was in women with pre-eclampsia $(80 \%$ reduction). In women with gestational hypertension and chronic hypertension the overall reduction in fetal mortality rates was $49 \%$ and $57 \%$ respectively, comparable to the $41 \%$ decline in normotensive pregnancies.

Conclusion In our nationwide study during 1967-2006 the risk of fetal death among women with hypertensive disorders in pregnancy was greatly reduced, especially among pre-eclamptic women at term. 


\section{DISCUSSION}

The main findings in this thesis are:

1. Maternal PVB infection was not found to be significantly associated with fetal death. PVB infection does not seem to have any sizeable contribution to the overall risk of fetal death, since only four of 281 cases of fetal death were infected.

2. The risk of fetal death in Norway has been reduced by nearly $70 \%$ in pregnancies lasting longer than 22 weeks during 1967-2006, however, at 1622 weeks of gestation, an increase in risk was observed.

3. Women 40 years old or older had the highest risk of fetal death throughout pregnancy, particularly in term and post-term pregnancies. However, the risk associated with high maternal age was attenuated in recent times.

4. In our nationwide study during 1967-2006, the risk of fetal death among women with hypertensive disorders in pregnancy was shown to be greatly reduced, especially among pre-eclamptic women at term. The risk of fetal death among women with gestational or chronic hypertension decreased, but in a different manner

In the following sections the methods used in the thesis are briefly discussed (the individual Papers contain more in-depth considerations). Thereafter the individual results of the Papers included in the thesis are discussed.

\subsection{Methodological considerations}

Epidemiological studies are conducted with the purpose to achieve reliable and valid estimates of the association between exposures and disease. Imprecision of estimates are caused by random error and improvement is generally achieved by increasing the sample size. Cls are computed to assess the precision of point estimates, thus the narrower the $\mathrm{Cl}$ the more precise is the estimate.

The validity of epidemiological studies has two aspects: internal and external validity. Internal validity relates to the inference of the estimates to the study population. 
Internal validity is impaired in epidemiological studies by selection bias, information bias and confounding. High internal validity is a requirement for external validity, which relates to inference beyond the study population. ${ }^{255}$

\section{Sample size considerations}

Paper I Fetal death and PVB infection in pregnancy are rare events; hence a casecontrol design was chosen in Paper I. The reported lack of association between PVB infection and fetal death in our study may be due to sample size limitations (type 2 error), as indeed numbers were limited in the sub-analysis (only 4 cases among 281 were PVB-positive by serology). In our study, 17 women among 957 controls had either IgM in the first serum sample or seroconverted. It was estimated that approximately 9000 women (cases + controls) would be needed in the study to detect a OR of 1.5 with $80 \%$ power using a two-sided $5 \%$ test. $^{256 ; 257}$

Papers II-IV In Papers II-IV we utilized population-based data from the MBRN (>2 million births and >17 000 fetal deaths). By utilizing this resource, we were able to study the rare outcome of fetal death with limited random error and narrow confidence intervals.

\section{Selection bias}

Selection bias is caused by systematic error in the selection process of the study sample, leading to a different association of exposures and outcomes in participants relative to non-participants. ${ }^{255}$

Paper I In Paper I, we conducted a case-control study within the nationwide prospective Toxoplasmosis Study. In this study the risk of selection bias was limited, as cases were all fetal deaths occurring in the cohort of 35940 pregnant women who had participated in the Toxoplasmosis Study. ${ }^{242}$ The exact participation rate is not known, but is assumed to be very high judging by the number of live births in the 11 participating counties. ${ }^{242}$ Controls were randomly selected among all women in the Toxoplasmosis Study cohort delivering a live-born child at the end of follow-up, thus assuring that the exposure distribution of controls reflected the exposure distribution in the source population for cases. 
Selection bias may also be considered due to incomplete/losses to follow-up of initially seronegative women $(n=442)$ in the Toxoplasmosis Study cohort. These women did not have IgG antibodies against PVB in the first serum sample and therefore were at risk of seroconversion, but 68 of these women did not have followup serum available, and therefore PVB seroconversion could not be determined. This could cause biased estimates if the association between PVB infection and fetal death differed among women lost to follow-up compared to women with more than one serum sample collected. However, there were 25 cases of fetal death among these women, and for nine of these women the lack of follow-up was according to Toxoplasmosis Study protocol, as they had $\lg G$ antibodies against $T$. gondii in the first trimester. We do not believe that this would bias our estimates, as we only encountered 10 seroconversions among 372 susceptible women, and it is unlikely that lack of follow-up or presence of antibodies against T.gondii is associated with an increased risk of PVB infection.

The study has limited generalizability beyond the Norwegian study population, as the seroprevalence of $\operatorname{lgG}(35 \%-81 \%)$ and seroconversion rate among pregnant women has been reported to vary across countries, and genetic susceptibility may be different as well. ${ }^{243}$

Papers II-IV In Papers II-IV we conducted population-based retrospective cohort studies using the MBRN, which comprises information on all live births and fetal deaths from 16 weeks of gestation in Norway, hence selection bias was limited. Fetal deaths are prone to underreporting in vital registries, ${ }^{258}$ however, temporal increases in early fetal deaths (birth weight $<500 \mathrm{~g}$ corresponding to approximately 20-22 weeks of gestation) due to better registration have been reported. ${ }^{259}$ Potential increased registration of early fetal deaths in the MBRN in recent time could have biased our results, causing some of the observed association between period (year) and early fetal death in Paper II. In Paper III, however, the results are not likely to be biased as registration of early fetal death is not associated with maternal age.

\section{Information bias}

Information bias occurs when the obtained information about exposure or outcome is erroneous (misclassification). Misclassification can be non-differential, that is, 
unrelated to other variables, while differential misclassification differs according to other study variables. ${ }^{255}$

Paper I In Paper I the risk of information bias for the exposure (maternal antibody status) was low, as maternal antibody status was determined by serological testing in the laboratory. The kits used for detection of antibodies have a high specificity, and retesting of borderline positive sera was performed to further increase the specificity. Moreover, as serum samples were prospectively collected (prior to birth outcome), any potential misclassification of PVB infection according to fetal vital status would be non-differential, leading to attenuation of the association. Non-differential misclassification of a dichotomous explanatory variable causes bias in the estimates toward the null value. ${ }^{255}$

Another potential source of non-differential misclassification for the exposure may be due to the timing of the serum sampling. After infection there is a serological window of approximately 7 days where $\lg M$ and $\lg G$ are not detectable. $\lg M$ then rises and is detectable from day 7-10 and then decreases during 2-3 moths, whereas IgG is detectable only after 2 weeks. ${ }^{260}$ If the women acquired PVB infection prior to pregnancy, but had persistent IgM at the time of serum sampling, they may have been erroneously categorized as having an acute infection, whereas women infected shortly prior to serum sampling may erroneously be categorized as un-infected.

Information on outcome (fetal death or live birth) was obtained from the MBRN. Notification of these outcomes to the MBRN is reported to be good, ${ }^{38}$ and the high quality of information in the MBRN is maintained by routine linkage to other population registries, and comprehensive quality assurance. ${ }^{6}$ However, as previously mentioned, before 1999 some elective pregnancy terminations (due to serious congenital anomalies) may have been misclassified as fetal death, which may underestimate the association between fetal death and PVB infection in our study. According to a national study, the estimated induced abortion rate after 16 weeks of gestation in Norway in 1996-1997 was 2-3 per 1000 births, and induced abortions were seldom performed after 21 weeks of gestation. ${ }^{261}$ The fetal mortality rate at $\geq 16$ weeks of gestation in the MBRN was 9-10 per 1000 births during the same period. ${ }^{1}$ In our study $25 \%$ of fetal deaths occurred before 21 weeks of gestation ( $25 \%$ of 283 
fetal deaths), ${ }^{262}$ hence between 14-23 fetal deaths (<21 weeks of gestation) (that is 2-3 induced abortions per 9-10 fetal deaths) could potentially have been misclassified.

Fetal death occurring at the lower limit of registration (16 weeks of gestation) may have been underestimated if the women were not hospitalized or if the length of gestation was uncertain. The impact of this bias is probably low and independent of the exposure (PVB).

Papers II-IV In all three papers fetal death was the main outcome measure. This variable has not been validated in the MBRN, but the diagnosis of unexplained antepartum fetal death ( $\geq 28$ weeks) has been validated in the registry, and has been reported to have high validity, ${ }^{263}$ as have several other validated variables in the registry. ${ }^{264-269}$

As formerly stated, some elective pregnancy terminations (due to serious congenital anomalies) during 1986-1998 could have been differentially misclassified as fetal death. This would cause a falsely increased rate of fetal death between 16-20 weeks of gestation, since induced abortions were seldom performed after 21 weeks of gestation after the implementation of ultrasound examinations in antennal care during $1986 .^{261}$ This may have biased the association between early fetal death and period (1986-1998) in Paper II. Indeed the highest risk of early fetal death (gestational weeks 16-22) was observed during 1992-1996, though the risk remained significantly increased during the most recent period (2002-2006) as well.

High maternal age is associated with a higher number of pregnancy terminations due to the increased risk of malformations or anomalies detected at prenatal ultrasound examinations. ${ }^{71}$ Hence, the observed association of early fetal death and high maternal age in Paper III may be overestimated. This was further explored by repeating analysis including births during 1999-2006 only. The analysis demonstrated an attenuated HR of fetal death among women aged 40-44 years (relative to women aged 20-24 years) at gestational weeks 16-22 (Appendix I, Table A). 
Misclassification of gestational age could have biased our results in Paper II-IV. Gestational age estimations were based on the women's reporting of the first day of her LMP during 1967-1998, whereas from 1999 ultrasound dating was available in the MBRN. ${ }^{6}$ LMP could cause inaccurate determination of length of gestation in women with irregular menstrual cycles, or uncertain first day of LMP. Studies comparing the accuracy of ultrasound and LMP to estimate gestational age have reported higher incidence of post term ( $\geq 42$ weeks) births when LMP is applied, whereas there were only minor discrepancies in the prediction of preterm $(<37$ weeks) and term births. ${ }^{270 ; 271}$

This could have caused biased estimates in Paper II, however, any overestimation of post-term pregnancies caused by applying LMP to predict term (before 1999) would underestimate, rather than overestimate, the reduction in fetal death post term in the later time period (1987-2006).

As misclassification of gestational age estimations is probably not differential according to maternal age or hypertensive disorders in pregnancy, the results in Paper III-VI are most likely not biased.

In Paper IV, maternal hypertensive disorders in pregnancy were studied, however, only pre-eclampsia has been validated previously (reporting positive predictive value of $64 \%-88 \%)$. ${ }^{272}$ Blood pressure measurements and urine examinations are an essential part of the Norwegian public antenatal care program, and clinical findings are registered in the standard antenatal form that the women bring to the hospital at the time of delivery. As compulsory notification of birth to the MBRN is made on standardized forms shortly after delivery, differential misclassification due to recall bias or according to vital status of the infant is probably low. However, nondifferential misclassification is more likely and would attenuate the association between exposure and outcome in the study.

Although the diagnostic criteria for hypertensive disorders in pregnancy have remained nearly unchanged, ${ }^{272}$ the registration of hypertensive disorders may have become more complete (less frequently misclassified) after 1998, when the MBRN introduced a new form with pre-coded check boxes regarding maternal hypertensive disorders. This would most likely not differentially affect any one type of hypertensive disorder, ${ }^{273 ; 274}$ or differ according to fetal vital status. 


\section{Confounding}

Confounding, or mixing of effects, occurs when the effect of an exposure on the outcome is distorted by a confounding variable. The confounding variable is associated both with the exposure and outcome (but is not an effect of outcome or exposure) (Figure 9). Figure 9 depicts a causal diagram of confounding, with the confounder being a common cause of both the exposure and the outcome variable. Known confounders can be dealt with at the analysis stage of the study, e.g. by including it as an explanatory variable in multivariable regression models, or by stratification, given that this variable has been measured. ${ }^{255}$
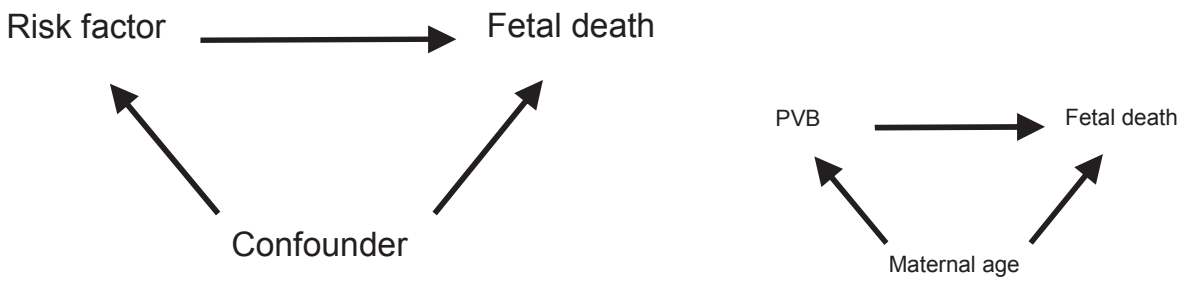

Figure 9. Causal diagram with Confounding

In Paper I the association between maternal PVB infection and fetal death could be confounded by maternal age ${ }^{58 ; 243}$ and parity, ${ }^{60 ; 244}$ hence, effect estimates were adjusted for these risk factors.

Residual confounding refers to the distortion that remains after adjustment for confounders, and is due to additional confounding factors that were either not considered or not available. ${ }^{275}$ Data on potential confounders such as maternal stress $^{276 ; 277}$ and SES ${ }^{170 ; 244}$ were not available, and thus their contribution could not be assessed. However, previous studies have indicated that parity/number of children in the household has a stronger association with seroconversion (exposure) in susceptible women compared to other risk factors. ${ }^{244}$ 
In Paper II we adjusted for maternal age, parity, multiple pregnancies, paternal age and pre-eclampsia, as these risk factors are associated both with the explanatory variable (period) and outcome (fetal death). Other risk factors were not adjusted for either because we lacked information on the variable or because no confounding effect was suspected.

In Papers II-III we adjusted the risk estimates for the confounding effect of multiple pregnancies (plurality) whereas in Paper IV multiple pregnancies were excluded from the sample. In retrospect, the latter approach is preferable as multiple pregnancies differ in many aspects from singletons pregnancies; multiple pregnancies are more susceptible to low birth weight, short gestational age, higher perinatal mortality, and have an increased risk of complications during delivery. ${ }^{278}$ In the study sample of Papers II-III, only $2.7 \%$ were multiple pregnancies, and subsequently exclusion of multiple pregnancies from did not significantly alter the risk estimates (Appendix I, Table B and C).

We lacked information on maternal BMI, smoking, SES and ethnicity, and thus where not able to control for the effect of these factors.

Maternal BMI is associated with risk of fetal death ${ }^{36 ; 83}$ and varies by calendar period (year), ${ }^{279}$ thus BMI may have biased our results. However, as high BMI is associated with fetal death and the prevalence of high BMI in our population has increased, our estimates of temporal declines in the rate of fetal death may be underestimates. In Paper III, BMI is a potential mediator associated with both the outcome (fetal death) and the explanatory variable (maternal age). ${ }^{280}$ Since BMI is differentially associated with advanced gestation, ${ }^{92}$ the observed increased risk of fetal death as gestation advances among older women may partly be explained by BMI. In Paper IV, as hypertensive disorders in pregnancy are associated with $\mathrm{BMI},{ }^{281}$ the observed risk of fetal death may represent overestimates.

In Papers II and III we did not adjust for maternal diabetes or hypertensive disorders in pregnancy (apart from pre-eclampsia). Diabetes ${ }^{55 ; 69}$ and hypertensive disorders $^{13 ; 248}$ are associated with an increased risk of fetal death, and as the prevalence of these disorders has increased, ${ }^{1}$ our estimates may be deflated. In Paper III we did not adjust for these risk factors, as they were perceived as mediators 
of the association between maternal age and fetal death, and as such should not be adjusted for (Figure 10).
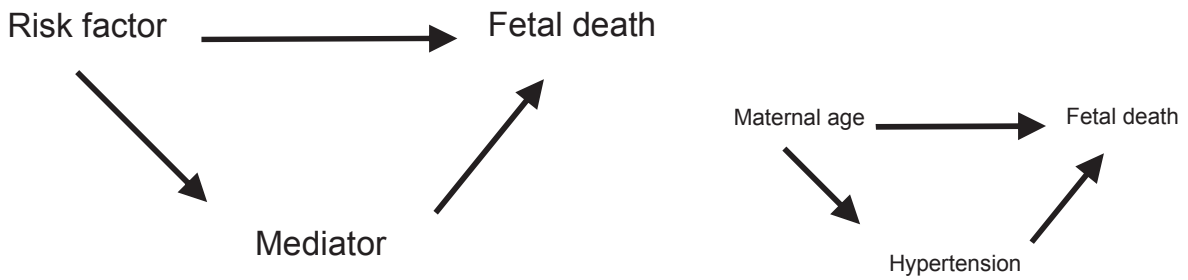

Figure 10. Causal diagram with Mediator

In Papers II-III we did not test for interaction between exposures and confounders as we had no reason to believe that it would influence fetal death at different gestational lengths. This assumption was subsequently explored by conducting analysis of gestational-age-specific risk of fetal death according to maternal age stratified by parity (Appendix I, Table D). This exercise revealed that the detrimental effect of high maternal age on risk of fetal death is more pronounced among nulliparous than multiparous women. However, within each strata high maternal age was associated with an increased risk of fetal death.

\subsection{Interpretation of the results}

\subsubsection{Maternal human parvovirus B19 infection and risk of fetal death}

The main aim of Paper I was to asses the association between maternal PVB infection (serological confirmed) and risk of fetal death ( $\geq 16$ weeks of gestation) in the Norwegian population. In our study maternal PVB infection was not associated with fetal death, as the proportion of pregnant women exposed to PVB infection did not differ among cases and controls (presence of IgM: crude OR 0.76, 95\% Cl 0.163.52; seroconversion: crude OR $1.18,95 \% \mathrm{Cl} 0.25-5.70)$. In addition, maternal PVB 
antibody status was not significantly associated with gestational age or birth weight. There are several possible explanations for the lack of association in our study:

1) In our population PVB was not significantly associated with fetal death.

2) Our study is underpowered to find an association.

3) Lack of complete follow-up/under ascertainment.

4) Low diagnostically accuracy.

Since the first case reports in the early 1980 s, ${ }^{282}$ several large prospective cohort studies of pregnant women with serologically-confirmed PVB infection have shown an increased risk of fetal death of $5-11 \%,{ }^{218 ; 219 ; 283 ; 284}$ whereas others did not report an increased risk. ${ }^{285 ; 286}$ The increased fetal mortality rate reported by some of these studies could be due to inclusion of pregnant women with symptoms of PVB infection, as being symptomatic may be associated with more severe infection. This is supported by the recent prospective cohort study by Bonvicini and colleagues, who reported higher PVB IgM and DNA values in symptomatic women compared to women with PVB infection discovered during routine screening (asymptomatic). ${ }^{287}$ Hence, some of the association reported in these studies may be due to the selection of symptomatic women (non-representative sample). In one of the first large prospective studies of PVB serology positive women $(n=190), 11 \%$ of the women who experienced a fetal loss had $\geq 1$ prior stillbirth compared to only $1 \%$ among women with live birth. ${ }^{218}$ Thus some of the increased risk of fetal death in PVB seropostive women could be due to factors other than PVB infection. We included all cases of fetal death from a large population-based cohort, hence, the risk of selection bias was limited and we also had a representative control group for comparison.

PVB IgG antibodies were present in the first serum sample of $64 \%$ of the women, rendering $36 \%$ susceptible to infection. This is comparable to previous reports. ${ }^{276 ; 285 ; 288-290}$ Among 442 susceptible women 21 had serological signs of infection (4.8\%). Previous studies have reported seroconversion rates among susceptible pregnant women during endemic periods between $0.6 \%-1.5 \%$ and during epidemic period up to $13.5 \%{ }^{244 ; 276 ; 289}$

Higher risk of fetal demise has been reported when maternal PVB infection occurs at $\leq 20$ gestational weeks, ${ }^{218 ; 219 ; 287}$ with most fetal deaths occurring between 13-20 
weeks of gestation. ${ }^{218 ; 219 ; 291}$ The increased vulnerability at early gestational ages is explained by the increased expression of P-antigen receptor in the trophoblast during the first and second trimesters, whereas it is missing in the third trimester. This receptor is utilized by PVB for transplacental transfer, followed by destruction of erythroid precursors that may cause severe fetal anemia. The anemic fetus may develop hydrops fetalis, which is associated with increased risk of fetal death, although most cases resolve spontaneously. ${ }^{243}$ Recently, Weiffenbach and colleagues proposed that increased vulnerability prior to 20 weeks of gestation, may be due to limited transfer of maternal IgG across the placenta to the fetus, coupled with a poor fetal antibody response, by which the fetuses ability to control the infection is impaired. ${ }^{292}$

As we only included cases of fetal death $\geq 16$ weeks of gestation, early fetal deaths associated with PVB were excluded, but also some cases $>16$ weeks may have been missed if the women were not hospitalized. Thus low ascertainment may have caused attenuation of the association.

Three Swedish studies reported PVB infection to be a common cause of nonhydropic fetal death in the third trimester. ${ }^{220 ; 223 ; 224}$ Tolfvenstam and colleagues examined 47 cases of fetal death ( $\geq 22$ weeks of gestation). ${ }^{224}$ Seven of the cases (15\%) and none of the healthy controls were PVB DNA-positive. However, PVB DNA was detected in different specimens among cases (placental or fetal tissue) and controls (placental tissue). The suitability of placentas from live births as control material has been questioned. ${ }^{219}$ The majority of fetuses $(n=5)$ were non-hydropic and no specific organ manifestation was detected, and maternal serology was negative. It remains unclear if these findings are spurious, or if the differing clinical picture presents manifestations of PVB-related late fetal death. The authors speculated that the pathophysiological mechanism involved in the third trimester may be different than in the second trimester, and may involve persistent low-grade infection and placental dysfunction. ${ }^{293}$ If PVB is a common cause of late fetal deaths occurring in PVB seronegative women, we may have underestimated the number of fetal deaths associated with PVB. However, others have questioned the Swedish studies. ${ }^{294 ; 295}$ Recently Riipinen and colleagues retrospectively studied 169 cases of late fetal death (>22 weeks), and only detected PVB DNA in four cases $(2.4 \%) .{ }^{295}$ 
Detection methods for maternal PVB infection may be direct (PCR) or by serology. In our study serological testing was utilized to confirm maternal infection, as this diagnostic method has high specificity and sensitivity. Molecular techniques for the detection of the viral genome by PCR have an even higher sensitivity, but contamination can also increase the number of false-positives. Thus it is possible that we missed some cases of fetal death caused by PVB, as we did not use the most reliable diagnostic methods: serology in combination with PCR. ${ }^{287 ; 296}$

PVB is not a common cause of fetal death in the Norwegian population, but for the time being, PVB investigation should remain a part of the work-up after fetal death, as some fetal death may be caused by PVB, and for a grieving couple, knowing the cause of fetal death can have immense value.

\subsubsection{Trends in fetal death in Norway}

The main aim of this paper was to study temporal trends and gestational-age-specific changes in fetal death. We reported a significant reduction in the fetal mortality rate ( $\geq 22$ weeks) during 1967-2006. The largest absolute decline was in pregnancies at term ( $\geq 37$ weeks), however, for pregnancies at 16-22 weeks an opposite trend was observed.

The majority of high-income countries (Sweden, Denmark, Norway, Iceland, France, Spain, Italy, the United Kingdom, the Netherlands, Wales, the United States) have reported declining trends in fetal death, from $25-45$ fetal deaths ( $\geq 28$ weeks) per 1000 births in 1940 , to $3-5$ per 1000 births in the year $2000,{ }^{233}$ and between 1.5-4.3 per 1000 births in $2009 .{ }^{44}$ In the United States the fetal mortality rate ( $\geq 20$ weeks) was reported to have declined from 18.4 per 1000 births in 1950 to 6.2 per 1000 in $2005 .{ }^{297}$ This trend is likely explained by improvements in general public health and in maternity care. In Norway, all pregnant women are offered routine antenatal examinations free of charge and the attendance rate is high (>99\%). ${ }^{298}$ A Norwegian cross-sectional study by Backe reported that the mean number of antenatal visits increased slightly from the 1980s to 1996, and a follow-up study reported a similar number of antenatal visits in 2000 (mean=12). ${ }^{298}$ In addition, advances in obstetric services, such as routine ultrasound, extensive use of cardiotocography, induction of 
labor and the increased caesarean section rate, has contributed to the success of modern obstetrics.

The European project for monitoring and evaluating perinatal outcomes on the European level (EURO-PERISTAT Project) estimated fetal mortality rates from European countries/regions in 2004 and 2009, and reported large inter-country differences in fetal mortality rates ( $\geq 22$ weeks), from 2.6 to 9.1 per 1000 in 2004 and from 4 to 8 per 1000 in 2009. ${ }^{43 ; 44}$ Differences were most likely due to differing registration policies, inclusion of pregnancy terminations in some countries and differing prevalence of risk factors and perinatal care. Hence the underlying causes of the observed trends are best studied at the national level. ${ }^{299}$

In our study the fetal mortality rate varied according to length of gestation, and the largest absolute decline occurred in term pregnancies ( $\geq 37$ weeks). This trend has been confirmed by others, ${ }^{300 ; 301}$ and may be attributed increased fetal surveillance and intervention at term. Indeed, some of the racial inequality in stillbirth at term in the United States was linked to Black women being less likely to undergo induction compared to non-Hispanic Whites. ${ }^{24 ; 239}$ Willinger and colleagues demonstrated that women with medical conditions, such as diabetes or hypertensive disorders in pregnancy, have an increased risk of fetal death at term (week 37-41), and exclusion of women with these conditions from their analysis reduced the hazard of fetal death by $5-10 \% .{ }^{24}$ Thus some of the decline in late stillbirths in our population may be due to close monitoring and timely delivery of women with medical conditions.

Postponement of childbearing may also contribute to increased risk at term and post term, as reported in Paper III and other studies. ${ }^{23 ; 65 ; 66}$ The hazard of fetal death at term declined further when we adjusted for maternal age and preeclampsia, as both risk factors have increased in our population. We lacked information on BMI, smoking, ethnicity and SES, which may have a differential impact on term births. A recent study from Norway demonstrated that the effect of social inequality on offspring mortality was lowest at term and post term (week 37-43), and increased during preterm gestation and 1 week after birth. ${ }^{302}$ The authors attributed the observed risk reduction to equal access to public health care.

During our extensive observation time (1967-2006) the method for the estimation of term date has changed: during 1967-1998 it was based on LMP, but from 1999 it was 
based on ultrasound examinations. The proportion of post term pregnancies may have been overestimated before the introduction of ultrasound; ${ }^{271}$ however, any overestimation of post term pregnancies due to the use of LMP to predict term may have underestimated the temporal reduction in term fetal mortality.

Contrary to the reduction in fetal death at term, we report an almost doubled fetal mortality rate at 16-22 weeks of gestation in 2002-2006 compared to 1967-1971. This observation could be due to increased registration or the observed trend is real and merits further investigation.

Increased case ascertainment over time may be a possible explanation for our findings; however, increased risk of fetal death at early gestation has been confirmed by other studies. ${ }^{11 ; 23 ; 24}$ Joseph and colleagues conducted a retrospective cohort study of births in British Columbia during 2000-2010, and reported an increasing number of stillbirths with a birth weight $<500 \mathrm{~g}$, which was largely attributed to pregnancy terminations due to congenital anomalies. ${ }^{11}$ However, even after exclusion of pregnancy terminations, the rate of fetal death at early gestation exceeded the rate in mid-gestation (week 28-36). Compared to spontaneous fetal death with birth weight $>1000$ g, which declined significantly during 2000-2010, fetal deaths with birth weight $<500 \mathrm{~g}$ declined non-significantly. Similarly, Martin and colleagues reported a declining trend in late fetal mortality at $\geq 28$ weeks of gestation in the United States, but a steady fetal mortality rate at $20-27$ weeks of gestation. ${ }^{301}$ However, after 1999 our data did not include pregnancy terminations.

Our findings could reflect a true increase, and some of this increase may be due to the advancing age of childbearing women. This is supported by the observed attenuation of the risk of fetal death in gestational week 16-22 when adjustment for maternal age was performed (in 2002-2006, crude RR 2.05 vs. adjusted RR 1.87). Reddy and colleagues also reported an increased risk of fetal death at early gestation among older women. ${ }^{23}$

This reported trend could also be caused by a higher number of women undergoing treatment with excisional cervical surgery due to cervical intraepithelial neoplasia, as this treatment increases the risk of perinatal mortality and extreme preterm delivery with intrapartum death as a consequence. ${ }^{303}$ In Norway, the proportion of childbearing women treated with excisional cervical surgery increased more than 20- 
fold between the periods 1967-1979 and 2000-2003, and cumulative incidence of treatment is higher among older women. ${ }^{304}$ Another possible cause of the increased fetal mortality rate could be infections, as infections are assumed to be related to fetal death at early gestation.

Willinger and colleagues reported that women with certain pregnancy risk factors (incompetent cervix, premature rupture of membranes, uterine bleeding, hypertensive disorders in pregnancy) have an increased risk of fetal death at early gestation (week 20-27), and demonstrated that exclusion of women with these conditions from their analysis reduced the hazard of fetal death by $15-22 \%{ }^{24}$

The perinatal mortality rate is a quality parameter of obstetric and neonatal care, hence it is important to study temporal trends to evaluate interventions and healthcare services delivered. Variations in gestational-age-specific fetal death may reveal further differences in registration practice and quality of care.

\subsubsection{The impact of maternal age and fetal death}

The aim of Paper III was to assess the association of maternal age with fetal death by gestational age and by time period by applying the fetuses-at-risk model. We reported an increased risk of fetal death with advancing maternal age throughout pregnancy; the risk was particularly increased in early gestation, and as pregnancy progressed to term and past term the increased risk in older women intensified.

An association between high maternal age and increased risk of fetal death has been reported in several studies. ${ }^{36 ; 305}$ The mechanisms involved remain uncertain, as the increased risk may be attenuated, but not completely explained, by medical conditions, ${ }^{50 ; 60}$ uteroplacental insufficiency, ${ }^{306}$ high BMI or low SES. ${ }^{62}$ In two recent, large population-based studies from the United States and the United Kingdom, when only non-anomalous deliveries were included in the study the association between maternal age and stillbirth risk disappeared. ${ }^{69 ; 70}$ However, our estimates did not change when we repeated our analysis excluding deliveries with congenital anomalies. 
In a recent multi-center case-control study from Italy, of 254 fetal deaths (cases) and 497 live births (controls), maternal age $>35$ years was not associated with increased risk of fetal death. BMI $>25$ was the only risk factor significantly associated with fetal death at term $(\mathrm{OR} 7.70,95 \% \mathrm{Cl} 2.9-20.5) .{ }^{307}$ Hence, in some populations the increased risk of fetal death in older mothers may be explained by an increased prevalence of overweight and obesity. Carolan and colleagues conducted a systematic review of advanced maternal age and adverse perinatal outcome. ${ }^{305}$ The review included nine studies (>40 million women), but only one study adjusted for maternal BMI, and after adjustment the increased risk of perinatal mortality in women 35-39 years old was no longer significant (adjusted OR 1.1, 95\% Cl 0.6-1.9). However, the risk in women $\geq 40$ years was still increased (adjusted OR $2.2,95 \% \mathrm{Cl}$ 1.1-4.5). ${ }^{308}$ As we lacked information of maternal BMI in the registry, we were not able to adjust for this confounding factor.

The reported increased risk among older mothers at gestational week 16-22 could be due to: a) increased registration of early fetal losses by time (years), b) a true increase that may be caused by higher cumulative incidence of treatment with excisional cervical surgery. Both alternatives are likely to contribute, as studies from other high-income countries have reported increased registration of fetal deaths weighing $<500$ g. ${ }^{259}$ However, under-registration of these fetuses is also of concern, ${ }^{258}$ hence our high estimate in the last time period may be an underestimate rather than an overestimate.

As already mentioned, the proportion of childbearing women treated with excisional cervical surgery increased more than 20-fold in Norway during 1967-2003, and cumulative incidence of treatment is higher among older women. ${ }^{304}$ This treatment increases the risk of perinatal mortality ( $R R 2.08,95 \% \mathrm{Cl} 1.04-4.13$ ) and extreme preterm delivery ( $<28$ weeks, $\mathrm{RR} 13.00,95 \% \mathrm{Cl} 1.70-99.12$ ) with intrapartum death as a consequence. ${ }^{303 ; 309}$

Our reported association between advanced maternal age and risk of fetal death at term and post term is in accordance with several recent studies. ${ }^{23 ; 64-66}$ Uteroplacental insufficiency has been proposed as a possible link between maternal age and fetal death at late gestational age ${ }^{57}$ whereas others have rejected this. ${ }^{306}$ 
Interestingly, the impact of maternal age on the risk of fetal death at term and post term was attenuated in the most recent time period 1987-2006 compared to 19671986. This is most likely due to a "cohort effect". During the last decades, vast advances in antenatal and obstetric care have occurred, which may have benefited older women and enabled safe delivery. Our observations are supported by the declining rates of post term births in Norway (the proportion of women giving birth in week 42 declined from $9.4 \%$ in 1967 to $3.8 \%$ in 2012) and the increase in the caesarean section rate (1.8\% in 1967 to $16.3 \%$ in 2006). ${ }^{1}$ Herstad and colleagues analyzed population-based Norwegian data for 1999-2006 and reported a significantly higher incidence of elective caesarean section in low-risk women $\geq 40$ years old relative to women aged 20-24 years (RR 11.7, 95\% Cl 8.9-15.4). ${ }^{310}$ The other possible explanation is "the healthy mother effect", i.e. older childbearing women in recent times may be healthier and better-educated than mothers of the same age 40 year ago. Data from the EURO-PERISTAT project support this theory. ${ }^{311}$ Wide variations in the proportion of childbearing women $\geq 35$ years old across 12 European countries were reported, from $7.4 \%$ in Estonia to $21.9 \%$ in Ireland. The association between high maternal age and risk of fetal death decreased as the prevalence of childbearing women aged $\geq 35$ years increased in the populations studied. The authors proposed two possible explanations for this: a) higher SES among older childbearing women, b) adaptation of clinical practice in countries with a high prevalence of older pregnant women.

In the last period (1987-2006) we observed an increased risk of fetal death among women aged $<20$ years old (HR 1.77, 95\% Cl 1.20-2.60) in gestational weeks 38-39. This observation may be explained by increased immigration in Norway during the last decades. Ethnic background has been related to teenage pregnancies and an increased risk of fetal death. ${ }^{183 ; 312}$ This observation was further confirmed when additional analyses were conducted, limiting the study period 1999-2006, and demonstrated a significant increased risk of fetal death at gestational weeks 16-22 and 37-43 among women aged $<20$ years relative to women aged 20-24 years (Appendix I, Table A).

Results from prior studies diverge regarding the risk of fetal death among young women. A recent study reported an increased risk of fetal death among women 16 years of age (adjusted RR 1.37, 95\% Cl 1.09-1.7) and women 18 years of age 
(adjusted RR 1.17, 95\% Cl 1.04-1.30) relative to 20 -year-old women. ${ }^{73}$ The authors hypothesized that childbearing young women in recent times may have a more disadvantageous risk profile (low SES, high BMI, increased prevalence of smoking) than older women.

\subsubsection{Hypertensive disorders in pregnancy and risk of fetal death}

The main aim of Paper IV was to study and compare the association between different hypertensive disorders in pregnancy and fetal death.

The prevalence of hypertensive disorders in our study was: preeclampsia $2.9 \%$, gestational hypertension $1.5 \%$ and chronic hypertension $0.5 \%$. The prevalence of gestational hypertension and chronic hypertension were lower than those reported in other studies, as the prevalence of gestational hypertension is reported to be $2-3 \%$ and approximately $0.5-2 \%$ for chronic hypertension. ${ }^{109 ; 248}$ Hence, these diseases may have been under reported in the registry, and may attenuate the association. As the "normotensive" population is large misclassification of hypertensive disorders would not have affected the prevalence in this group.

Our study demonstrated an increased risk of fetal death in women with preeclampsia (RR 2.3), gestational hypertension (RR 1.5), and chronic hypertension (RR 2.1) relative to normotensive women during the study period 1967-2006. Previous studies in Norway only reported on preeclampsia. ${ }^{102 ; 114}$ During the 40 years studied, the stillbirth rate among women with any hypertensive disorder in pregnancy declined, but the largest decline was observed in women with preeclampsia. This decline is likely due to the changes in the organization and execution of antenatal care. In 1983, a committee appointed by the government of Norway developed the "Maternal healthcard" and systematic guidelines regarding antenatal care. Early detection and timely delivery of infants at increased risk of fetal death likely contributed to the reported decline. ${ }^{102}$ Klungsøyr and colleagues reported an increased proportion of preeclamptic singleton pregnancies delivered by caesarean section (RR 3.0) and induced labor (RR 1.3) during 1967-2008 in Norway. ${ }^{114}$ Similar trends have been reported by several studies from high-income countries. ${ }^{70 ; 110 ; 115 ; 117 ; 307}$ Cruz and colleagues conducted a retrospective cohort study 
including 12723 pregnant women with hypertensive disorders, and reported significantly more fetal deaths in the control group (defined by the absence of past and present medical conditions). The authors hypothesized that this may be due to higher rates of induction of labor prior to the event of fetal death. ${ }^{117}$ Facchinetti and colleagues reported pre-eclampsia to be a protective factor in modern maternity care (OR $0.4,95 \% \mathrm{Cl} 0.2-0.8$ ), attributing this to increased alertness to the clinical presentation of this disorder, and to extensive access to antenatal care. ${ }^{307}$

A decline in the risk of stillbirth among women with gestational hypertension and chronic hypertension was also observed, but to a lesser extent than for preeclampsia. This may be due to improved registration after implementation of the new notification form with pre-coded check boxes in 1999, or to less clinical alertness and intervention on the part of healthcare professionals in these women compared to preeclamptic pregnancies. This could also be due to the demographic change in Norway during the study period, with increased incidence of pregnancies among women of advanced age and non-Western women. Women with chronic hypertension are more likely to be either older, Black or to have diabetes, ${ }^{110 ; 117}$ and a high rate of stillbirth is reported among women with both chronic hypertension and diabetes mellitus due to a proposed additive effect of these conditions. ${ }^{111}$

We studied the gestational-age-specific risk of fetal death among women with hypertensive disorders, and reported an increased risk as pregnancy advanced relative to normotensive pregnancies, with the highest $R R$ at term and post-term. This may imply that the mechanism involved in the increased risk of fetal death is placental dysfunction. ${ }^{115}$ This is further supported by the increased risk of SGA infants in hypertensive pregnancies. ${ }^{248}$ Helgadottir and colleagues studied 377 cases of fetal death occurring in two hospitals in Norway during 1990-2003, and observed that the risk of fetal death in hypertensive pregnancies was mediated by SGA infants, as the risk of fetal death among pregnant women with hypertensive disorders but without a SGA infant was only moderately increased. ${ }^{53}$ In the later period 1987-2006, a paradoxical relationship between preeclampsia and gestational-age-specific fetal death was observed, with a higher risk among preeclamptic pregnancies compared to normotensive pregnancies at term, but a 
lower risk or protective effect of preeclampsia in early gestation. This observation could be true or spurious.

Infants delivered preterm due to preeclampsia may have a more favorable outcome than the control group of infants delivered preterm for other pathological causes, such as infection. ${ }^{313}$

Yet another possibility is the potentially increased survival advantage among fetuses in preeclamptic pregnancies, due to an increased level of maternal cortisol, which may lead to expedited lung maturation. ${ }^{248}$

When studying fetal death at early gestation by applying the conventional method to estimate risk, we conditioned on birth and in this case, preterm birth. However, according to knowledge obtained from direct acyclic graphs (DAG), gestational age is a collider, a common effect, and conditioning on a collider (collider stratification) may cause spurious effects to occur, or even reversal of the association (Figure 11). ${ }^{314}$ Preeclampsia is associated with fetal death, and preterm birth is a common effect, therefore conditioning on births (and not all ongoing pregnancies) introduces bias, and may cause reversal of the association from increased risk to a protective effect (personal communication with Dr. Allen J. Wilcox). This can be avoided by applying the fetus-at-risk model, but this was not possible within the present data, as gestational age at preeclampsia occurrence is not registered in the MBRN.

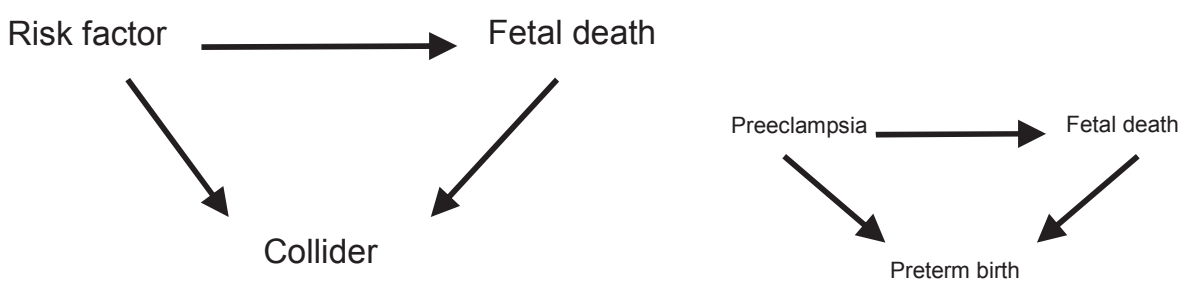

Figure 11. Causal diagram with Collider.

However, our choice to apply the conventional model for the estimation of stillbirth risk in Paper IV may be justified, as stillbirths and live births could be considered competing events. In that case the conventional measure of fetal death risk can be interpreted as the ratio between the hazards toward live births and towards stillbirths 
(personal communication with my supervisor Sven Ove Samuelsen). Thus the "protective effect" of the exposure (pre-eclampsia), especially around gestational weeks 28-35 may be due to a larger impact towards live birth than stillbirth.

The benefit of maternal anti-hypertensive therapy on the risk of fetal death is limited. ${ }^{315}$ Thus, the most efficient means to reduce fetal deaths in pregnant women with hypertensive disorders is close clinical follow-up and induction of delivery in threatened pregnancies. Our study indicates that pregnant women with hypertensive disorders would benefit from closer follow-up near term.

\section{CLINICAL IMPLICATIONS AND FUTURE CHALLENGES}

In conclusion, we showed that:

PVB infection was not significantly associated with fetal death in our populationbased study.

The risk of fetal death has significantly declined over the last 40 years in pregnancies $\geq 22$ weeks of gestation, with the absolute largest reduction observed at term ( $>37$ weeks). However, the risk increased at 16-22 weeks.

Advanced maternal age is associated with increased risk of fetal death in early gestation (weeks 16-22) and late gestation (week 37-43); however, in recent years the risk associated with age has attenuated.

Women with disorders in pregnancy have an increased risk of fetal death, however, the risk has been greatly reduced during 1967-2006, especially among preeclamtic women at term.

We speculate that this decline is most likely due to widespread access to free, highquality antenatal care and advances in obstetric care. ${ }^{310}$ The largest decline in fetal death in our studies was observed at $>37$ weeks of gestation, when the gestationalage-specific risk in most studies is reported to increase, which further supports that the decline is due to obstetric intervention.

The clinical implications of our study are: 
PVB should remain part of the investigations after fetal death. Even though PVB was not significantly associated with fetal death in our study, our study may have been underpowered. However, we do not think PVB is a common cause of fetal death in our population; hence, investigations should only be performed when indicated by the clinical picture.

Women $>35$ years have an increased risk of fetal death past term, at which point they should be monitored closely. This has already been implemented in the clinic at our institution.

Women with any hypertensive disorders in pregnancy have an increased risk of fetal death past term and should be followed with equal vigilance.

The comprehensive Lancet Stillbirth Series, published in $2011,{ }^{316}$ presented priority areas for stillbirth prevention in high-income countries, and suggested that to achieve further improvement in the future, focus should be placed on specific risk factors and specific vulnerable groups. Indeed the largest reductions in fetal death happened when intervention strategies were developed and applied for specific causes, such as rhesus isoimmunization or implementation of population-based prenatal screening for congenital anomalies. ${ }^{10}$ Hence, to achieve further reductions in fetal death, judicious estimates of risk should be made. Research should aim to estimate the gestationalage-specific risks of fetal death in women with certain risk factors and to estimate the effect of interaction between risk factors.

Maternal overweight and obesity is reported to be the highest ranking modifiable risk factor, contributing to nearly 8000 stillbirths per year. Hence there is a need for preventive strategies that target this modifiable risk factor.

Sub-optimal care (both self-care and care delivered by health professionals) has been associated with up to $60 \%$ of stillbirths, and may explain some of the variation in fetal mortality that exists in high-income countries. Racial and ethnic disparities, ${ }^{179 ; 317}$ and social inequalities in fetal mortality ${ }^{170 ; 318}$ needs to be addressed. Recent studies have concluded that pregnancy risk factors known at pregnancy start have limited predictive value; hence, future research should explore new risk factors. The importance of environmental factors, health care related factors, occupational hazards, psychological stress, diet, physical activity need to be further explored. 


\section{Reference List}

(1) The Medical Birth Registry of Norway. [http://mfr-nesstar.uib.no/mfr/]. Last accessed 19.01.2014.

Ref Type: Online Source

(2) Cousens S, Blencowe H, Stanton C, Chou D, Ahmed S, Steinhardt L et al. National, regional, and worldwide estimates of stillbirth rates in 2009 with trends since 1995: a systematic analysis. Lancet 2011; 377(9774):13191330.

(3) Lawn JE, Gravett MG, Nunes TM, Rubens CE, Stanton C. Global report on preterm birth and stillbirth (1 of 7): definitions, description of the burden and opportunities to improve data. BMC Pregnancy Childbirth 2010; 10 Suppl 1:S1.

(4) Stanton C, Lawn JE, Rahman H, Wilczynska-Ketende K, Hill K. Stillbirth rates: delivering estimates in 190 countries. Lancet 2006; 367(9521):14871494.

(5) Woods RI, Lokke A, van PF. Two hundred years of evidence-based perinatal care: late-fetal mortality in the past. Arch Dis Child Fetal Neonatal Ed 2006; 91(6):F445-F447.

(6) Irgens LM. The Medical Birth Registry of Norway. Epidemiological research and surveillance throughout 30 years. Acta Obstet Gynecol Scand 2000; 79(6):435-439.

(7) Odlind V, Haglund B, Pakkanen M, Otterblad OP. Deliveries, mothers and newborn infants in Sweden, 1973-2000. Trends in obstetrics as reported to the Swedish Medical Birth Register. Acta Obstet Gynecol Scand 2003; 82(6):516-528.

(8) Ahlenius I, Thomassen P. The changing panorama of late fetal death in Sweden between 1984 and 1991. Acta Obstet Gynecol Scand 1999; 78(5):408-414.

(9) Flemming K. Confidental enquiry into maternal and child health. Stillbirth, neonatal and post neonatal mortality, 2000-2002, England, Wales and Northern Ireland London: CEMACH, 2004.

(10) Smith GC, Fretts RC. Stillbirth. Lancet 2007; 370(9600):1715-1725.

(11) Joseph KS, Kinniburgh B, Hutcheon JA, Mehrabadi A, Basso M, Davies C et al. Determinants of increases in stillbirth rates from 2000 to 2010. CMAJ 2013; 185(8):E345-E351.

(12) Korteweg FJ, Erwich JJ, Timmer A, van der Meer J, Ravise JM, Veeger NJ et al. Evaluation of 1025 fetal deaths: proposed diagnostic workup. Am J Obstet Gynecol 2012; 206(1):53.

(13) Causes of death among stillbirths. JAMA 2011; 306(22):2459-2468. 
(14) Flenady V, Middleton P, Smith GC, Duke W, Erwich JJ, Khong TY et al. Stillbirths: the way forward in high-income countries. Lancet 2011; 377(9778):1703-1717.

(15) Fretts RC. Etiology and prevention of stillbirth. Am J Obstet Gynecol 2005; 193(6):1923-1935.

(16) Froen JF, Arnestad M, Frey K, Vege A, Saugstad OD, Stray-Pedersen B. Risk factors for sudden intrauterine unexplained death: epidemiologic characteristics of singleton cases in Oslo, Norway, 1986-1995. Am J Obstet Gynecol 2001; 184(4):694-702.

(17) Petersson K, Bremme K, Bottinga R, Hofsjo A, Hulthen-Varli I, Kublickas M et al. Diagnostic evaluation of intrauterine fetal deaths in Stockholm 199899. Acta Obstet Gynecol Scand 2002; 81(4):284-292.

(18) Rasmussen S, Albrechtsen S, Irgens LM, Dalaker K, Maartmann-Moe H, Vlatkovic $L$ et al. Risk factors for unexplained antepartum fetal death in Norway 1967-1998. Early Hum Dev 2003; 71(1):39-52.

(19) Helgadottir LB, Turowski G, Skjeldestad FE, Jacobsen AF, Sandset PM, Roald $B$ et al. Classification of stillbirths and risk factors by cause of death-a case-control study. Acta Obstet Gynecol Scand 2013; 92(3):325-333.

(20) Flenady V, Froen JF, Pinar H, Torabi R, Saastad E, Guyon G et al. An evaluation of classification systems for stillbirth. BMC Pregnancy Childbirth 2009; 9:24.

(21) Yudkin PL, Wood L, Redman CW. Risk of unexplained stillbirth at different gestational ages. Lancet 1987; 1(8543):1192-1194.

(22) Fretts RC, Boyd ME, Usher RH, Usher HA. The changing pattern of fetal death, 1961-1988. Obstet Gynecol 1992; 79(1):35-39.

(23) Reddy UM, Ko CW, Willinger M. Maternal age and the risk of stillbirth throughout pregnancy in the United States. Am J Obstet Gynecol 2006; 195(3):764-770.

(24) Willinger M, Ko CW, Reddy UM. Racial disparities in stillbirth risk across gestation in the United States. Am J Obstet Gynecol 2009; 201(5):469-8.

(25) Auger N, Delezire P, Harper S, Platt RW. Maternal education and stillbirth: estimating gestational-age-specific and cause-specific associations. Epidemiology 2012; 23(2):247-254.

(26) Joseph KS, Demissie K, Kramer MS. Obstetric intervention, stillbirth, and preterm birth. Semin Perinatol 2002; 26(4):250-259.

(27) Goldenberg RL, Culhane JF, lams JD, Romero R. Epidemiology and causes of preterm birth. Lancet 2008; 371(9606):75-84. 
(28) World Health Organization. ICD-10: International Statistical Classification of Diseases and Related Health Problems - Instruction Manual. 2. Geneva, Switzerland: World Health Organization; 2004. [http://www.who.int/classifications/icd/icdonlineversions/en/index.html]. Last accessed 20.10.2012.

Ref Type: Online Source

(29) Lawn JE, Blencowe H, Pattinson R, Cousens S, Kumar R, Ibiebele I et al. Stillbirths: Where? When? Why? How to make the data count? Lancet 2011; 377(9775):1448-1463.

(30) Lawn JE, Yakoob MY, Haws RA, Soomro T, Darmstadt GL, Bhutta ZA. 3.2 million stillbirths: epidemiology and overview of the evidence review. $B M C$ Pregnancy Childbirth 2009; 9 Suppl 1:S2.

(31) Woods R. Definitions, measurement, influences. In: Death before Birth. Fetal Health \& Mortality in Historical Perspective. Oxford University Press; 2009. 14-34.

(32) Incidence, etiology and prevention of stillbirth. UpToDate. Available at: [http://www.uptodate.com/contents/incidence-etiology-and-prevention-ofstillbirth]. Last accessed 31.08.2012.

Ref Type: Online Source

(33) Lawn JE, Kerber K, Enweronu-Laryea C, Massee BO. Newborn survival in low resource settings--are we delivering? BJOG 2009; 116 Suppl 1:49-59.

(34) Yasmin S, Osrin D, Paul E, Costello A. Neonatal mortality of low-birthweight infants in Bangladesh. Bull World Health Organ 2001; 79(7):608614.

(35) Fellman V, Hellstrom-Westas L, Norman M, Westgren M, Kallen K, Lagercrantz $\mathrm{H}$ et al. One-year survival of extremely preterm infants after active perinatal care in Sweden. JAMA 2009; 301(21):2225-2233.

(36) Flenady V, Koopmans L, Middleton P, Froen JF, Smith GC, Gibbons K et al. Major risk factors for stillbirth in high-income countries: a systematic review and meta-analysis. Lancet 2011; 377(9774):1331-1340.

(37) Graafmans WC, Richardus JH, Macfarlane A, Rebagliato M, Blondel B, Verloove-Vanhorick SP et al. Comparability of published perinatal mortality rates in Western Europe: the quantitative impact of differences in gestational age and birthweight criteria. BJOG 2001; 108(12):1237-1245.

(38) Gissler M, Mohangoo AD, Blondel B, Chalmers J, Macfarlane A, Gaizauskiene A et al. Perinatal health monitoring in Europe: results from the EURO-PERISTAT project. Inform Health Soc Care 2010; 35(2):64-79.

(39) Gourbin G, Masuy-stroobant G. Registration of vital data: are live births and stillbirths comparable all over Europe? Bull World Health Organ 1995; 73(4):449-460. 
(40) World Health Organization. Perinatal mortality. A listing of available information. Family and reproducitve health. Geneva, Switzerland 1996.

Available at: [http://whqlibdoc.who.int/hq/1996/WHO FRH MSM 96.7.pdf]. Last accessed 10.10.2012.

Ref Type: Online Source

(41) World Health Organization. Neonatal and perinatal mortality. Country, regional and global estimates 2004. Department of Making Pregnancy Safer. Geneva, Switzerland: WHO;2007. Available at: [http://www.searo.who.int/LinkFiles/Publications Neonatal and Perinatal Mortality update.pdf]. Last accessed 10.10.2012.

Ref Type: Report

(42) World Health Organization. Neonatal and perinatal mortality 2000. Country, regional and global estimates. Available

at:[http://whqlibdoc.who.int/publications/2006/9241563206 eng.pdf]. Last accessed 10.10.2012.

Ref Type: Online Source

(43) European Perinatal Health Report 2008 by the EURO-PERISTAT project in collaboration with SCPE, EUROCAT \& EURONEOSTAT. Available at: [http://www.europeristat.com]. Last accessed 15.01.2014.

Ref Type: Online Source

(44) European Perinatal Health Report. Health and care of pregnant women and babies in Europe in 2010. Available at: [http://www.europeristat.com]. Last accessed 15.01.2014.

(45) de Graaf JP, Steegers EA, Bonsel GJ. Inequalities in perinatal and maternal health. Curr Opin Obstet Gynecol 2013; 25(2):98-108.

(46) The World Bank - Country classification [http://data.worldbank.org/about/country-classifications/country-andlending-groups\#High income]. Last accessed 20.7.2012.

Ref Type: Online Source

(47) Critical Appraisal Skills Programme (CASP). [http://www.sph.nhs.uk/sphfiles/casp-appraisal-tools/?searchterm=casp]. Last accessed 19.2.2014.

Ref Type: Online Source

(48) Breart G, Barros H, Wagener Y, Prati S. Characteristics of the childbearing population in Europe. Eur J Obstet Gynecol Reprod Biol 2003; 111 Suppl 1:S45-S52.

(49) Hamilton BE, Martin JA, Ventura SJ. Births: preliminary data for 2012. National Vital Statistics Reports, volume 62, number 3. Available at: [http://www.cdc.gov/nchs/data/nvsr/nvsr62/nvsr62 03.pdf]. Last acccessed 22.02.2014.

Ref Type: Online Source 
(50) Fretts RC, Schmittdiel J, McLean FH, Usher RH, Goldman MB. Increased maternal age and the risk of fetal death. N Engl $J$ Med 1995; 333(15):953957.

(51) Fretts RC, Usher RH. Causes of fetal death in women of advanced maternal age. Obstet Gynecol 1997; 89(1):40-45.

(52) Hoffman MC, Jeffers S, Carter J, Duthely L, Cotter A, Gonzalez-Quintero $\mathrm{VH}$. Pregnancy at or beyond age 40 years is associated with an increased risk of fetal death and other adverse outcomes. Am J Obstet Gynecol 2007; 196(5):e11-e13.

(53) Helgadottir LB, Skjeldestad FE, Jacobsen AF, Sandset PM, Jacobsen EM. Incidence and risk factors of fetal death in Norway: a case-control study. Acta Obstet Gynecol Scand 2011; 90(4):390-397.

(54) Bateman BT, Simpson LL. Higher rate of stillbirth at the extremes of reproductive age: a large nationwide sample of deliveries in the United States. Am J Obstet Gynecol 2006; 194(3):840-845.

(55) Canterino JC, Ananth CV, Smulian J, Harrigan JT, Vintzileos AM. Maternal age and risk of fetal death in singleton gestations: USA, 1995-2000. J Matern Fetal Neonatal Med 2004; 15(3):193-197.

(56) Jacobsson B, Ladfors L, Milsom I. Advanced maternal age and adverse perinatal outcome. Obstet Gynecol 2004; 104(4):727-733.

(57) Jolly M, Sebire N, Harris J, Robinson S, Regan L. The risks associated with pregnancy in women aged 35 years or older. Hum Reprod 2000; 15(11):2433-2437.

(58) Nybo Andersen AM, Wohlfahrt J, Christens P, Olsen J, Melbye M. Maternal age and fetal loss: population based register linkage study. BMJ 2000; 320(7251):1708-1712.

(59) O'Leary CM, Bower C, Knuiman M, Stanley FJ. Changing risks of stillbirth and neonatal mortality associated with maternal age in Western Australia 1984-2003. Paediatr Perinat Epidemiol 2007; 21(6):541-549.

(60) Raymond EG, Cnattingius S, Kiely JL. Effects of maternal age, parity, and smoking on the risk of stillbirth. Br J Obstet Gynaecol 1994; 101(4):301306.

(61) Salihu HM, Shumpert MN, Slay M, Kirby RS, Alexander GR. Childbearing beyond maternal age 50 and fetal outcomes in the United States. Obstet Gynecol 2003; 102(5 Pt 1):1006-1014.

(62) Kenny LC, Lavender T, McNamee R, O'Neill SM, Mills T, Khashan AS. Advanced maternal age and adverse pregnancy outcome: evidence from a large contemporary cohort. PLoS One 2013; 8(2):e56583. 
(63) Salihu HM, Wilson RE, Alio AP, Kirby RS. Advanced maternal age and risk of antepartum and intrapartum stillbirth. J Obstet Gynaecol Res 2008; 34(5):843-850.

(64) Page JM, Snowden JM, Cheng YW, Doss AE, Rosenstein MG, Caughey $A B$. The risk of stillbirth and infant death by each additional week of expectant management stratified by maternal age. Am J Obstet Gynecol 2013; 209(4):375-377.

(65) Lisonkova S, Pare E, Joseph KS. Does advanced maternal age confer a survival advantage to infants born at early gestation? BMC Pregnancy Childbirth 2013; 13:87.

(66) Gordon A, Raynes-Greenow C, McGeechan K, Morris J, Jeffery H. Risk factors for antepartum stillbirth and the influence of maternal age in New South Wales Australia: a population based study. BMC Pregnancy Childbirth 2013; 13:12.

(67) Balayla J, Azoulay L, Assayag J, Benjamin A, Abenhaim HA. Effect of maternal age on the risk of stillbirth: a population-based cohort study on 37 million births in the United States. Am J Perinatol 2011; 28(8):643-650.

(68) Reddy UM, Laughon SK, Sun L, Troendle J, Willinger M, Zhang J. Prepregnancy risk factors for antepartum stillbirth in the United States. Obstet Gynecol 2010; 116(5):1119-1126.

(69) Association between stillbirth and risk factors known at pregnancy confirmation. JAMA 2011; 306(22):2469-2479.

(70) Gardosi J, Madurasinghe V, Williams M, Malik A, Francis A. Maternal and fetal risk factors for stillbirth: population based study. BMJ 2013; 346:f108.

(71) Resta RG. Changing demographics of advanced maternal age (AMA) and the impact on the predicted incidence of Down syndrome in the United States: Implications for prenatal screening and genetic counseling. Am J Med Genet A 2005; 133A(1):31-36.

(72) Salihu HM, Sharma PP, Ekundayo OJ, Kristensen S, Badewa AP, Kirby RS et al. Childhood pregnancy (10-14 years old) and risk of stillbirth in singletons and twins. J Pediatr 2006; 148(4):522-526.

(73) de Vienne CM, Creveuil C, Dreyfus M. Does young maternal age increase the risk of adverse obstetric, fetal and neonatal outcomes: a cohort study. Eur J Obstet Gynecol Reprod Biol 2009; 147(2):151-156.

(74) Warshak CR, Wolfe KB, Russell KA, Habli M, Lewis DF, Defranco EA. Influence of adolescence and obesity on the rate of stillbirth. Paediatr Perinat Epidemiol 2013; 27(4):346-352.

(75) Haldre K, Rahu K, Karro H, Rahu M. Is a poor pregnancy outcome related to young maternal age? A study of teenagers in Estonia during the period 
of major socio-economic changes (from 1992 to 2002). Eur J Obstet Gynecol Reprod Biol 2007; 131(1):45-51.

(76) Jolly MC, Sebire N, Harris J, Robinson S, Regan L. Obstetric risks of pregnancy in women less than 18 years old. Obstet Gynecol 2000; 96(6):962-966.

(77) Scholl TO, Hediger ML, Schall JI. Maternal growth and fetal growth: pregnancy course and outcome in the Camden Study. Ann N Y Acad Sci 1997; 817:292-301.

(78) Jacquemyn Y, Senten L, Vellinga S, Vermeulen K, Martens G. Does practice make perfect? An age-matched study on grand multiparity in Flanders, Belgium. J Perinat Med 2006; 34(1):28-31.

(79) Little RE, Weinberg CR. Risk factors for antepartum and intrapartum stillbirth. Am J Epidemiol 1993; 137(11):1177-1189.

(80) McCowan LM, George-Haddad M, Stacey T, Thompson JM. Fetal growth restriction and other risk factors for stillbirth in a New Zealand setting. Aust N Z J Obstet Gynaecol 2007; 47(6):450-456.

(81) Aliyu MH, Salihu HM, Keith LG, Ehiri JE, Islam MA, Jolly PE. Extreme parity and the risk of stillbirth. Obstet Gynecol 2005; 106(3):446-453.

(82) Bhattacharya S, Campbell DM, Liston WA, Bhattacharya S. Effect of Body Mass Index on pregnancy outcomes in nulliparous women delivering singleton babies. BMC Public Health 2007; 7:168.

(83) Cnattingius S, Bergstrom R, Lipworth L, Kramer MS. Prepregnancy weight and the risk of adverse pregnancy outcomes. N Engl J Med 1998; 338(3):147-152.

(84) Cnattingius S, Haglund B, Kramer MS. Differences in late fetal death rates in association with determinants of small for gestational age fetuses: population based cohort study. BMJ 1998; 316(7143):1483-1487.

(85) Hilder L, Sairam S, Thilaganathan B. Influence of parity on fetal mortality in prolonged pregnancy. Eur J Obstet Gynecol Reprod Biol 2007; 132(2):167170.

(86) Skjaerven R, Wilcox AJ, Lie RT, Irgens LM. Selective fertility and the distortion of perinatal mortality. Am J Epidemiol 1988; 128(6):1352-1363.

(87) Flegal KM, Carroll MD, Ogden CL, Johnson CL. Prevalence and trends in obesity among US adults, 1999-2000. JAMA 2002; 288(14):1723-1727.

(88) Flegal KM, Carroll MD, Kit BK, Ogden CL. Prevalence of obesity and trends in the distribution of body mass index among US adults, 1999-2010. JAMA 2012; 307(5):491-497. 
(89) Stamnes Koepp UM, Frost AL, Dahl-Joergensen K, Stigum H, Nass O, Nystad W. Maternal pre-pregnant body mass index, maternal weight change and offspring birthweight. Acta Obstet Gynecol Scand 2012; 91(2):243-249.

(90) Cedergren MI. Maternal morbid obesity and the risk of adverse pregnancy outcome. Obstet Gynecol 2004; 103(2):219-224.

(91) Kristensen J, Vestergaard M, Wisborg K, Kesmodel U, Secher NJ. Prepregnancy weight and the risk of stillbirth and neonatal death. BJOG 2005; 112(4):403-408.

(92) Nohr EA, Bech BH, Davies MJ, Frydenberg M, Henriksen TB, Olsen J. Prepregnancy obesity and fetal death: a study within the Danish National Birth Cohort. Obstet Gynecol 2005; 106(2):250-259.

(93) Salihu HM, Dunlop AL, Hedayatzadeh M, Alio AP, Kirby RS, Alexander GR. Extreme obesity and risk of stillbirth among black and white gravidas. Obstet Gynecol 2007; 110(3):552-557.

(94) Sebire NJ, Jolly M, Harris JP, Wadsworth J, Joffe M, Beard RW et al. Maternal obesity and pregnancy outcome: a study of 287,213 pregnancies in London. Int J Obes Relat Metab Disord 2001; 25(8):1175-1182.

(95) Scott-Pillai R, Spence D, Cardwell CR, Hunter A, Holmes VA. The impact of body mass index on maternal and neonatal outcomes: a retrospective study in a UK obstetric population, 2004-2011. BJOG 2013; 120(8):932939.

(96) Whiteman VE, Crisan L, McIntosh C, Alio AP, Duan J, Marty PJ et al. Interpregnancy body mass index changes and risk of stillbirth. Gynecol Obstet Invest 2011; 72(3):192-195.

(97) Tennant PW, Rankin J, Bell R. Maternal body mass index and the risk of fetal and infant death: a cohort study from the North of England. Hum Reprod 2011; 26(6):1501-1511.

(98) Stephansson O, Dickman PW, Johansson A, Cnattingius S. Maternal weight, pregnancy weight gain, and the risk of antepartum stillbirth. Am J Obstet Gynecol 2001; 184(3):463-469.

(99) Khashan AS, Kenny LC. The effects of maternal body mass index on pregnancy outcome. Eur J Epidemiol 2009; 24(11):697-705.

(100) Villamor E, Cnattingius S. Interpregnancy weight change and risk of adverse pregnancy outcomes: a population-based study. Lancet 2006; 368(9542):1164-1170.

(101) Ananth CV, Savitz DA, Bowes WA, Jr. Hypertensive disorders of pregnancy and stillbirth in North Carolina, 1988 to 1991. Acta Obstet Gynecol Scand 1995; 74(10):788-793. 
(102) Basso O, Rasmussen S, Weinberg CR, Wilcox AJ, Irgens LM, Skjaerven $\mathrm{R}$. Trends in fetal and infant survival following preeclampsia. JAMA 2006; 296(11):1357-1362.

(103) Heard AR, Dekker GA, Chan A, Jacobs DJ, Vreeburg SA, Priest KR. Hypertension during pregnancy in South Australia, part 1: pregnancy outcomes. Aust N Z J Obstet Gynaecol 2004; 44(5):404-409.

(104) Roberts CL, Algert CS, Morris JM, Ford JB, Henderson-Smart DJ. Hypertensive disorders in pregnancy: a population-based study. Med $J$ Aust 2005; 182(7):332-335.

(105) Smulian JC, Ananth CV, Vintzileos AM, Scorza WE, Knuppel RA. Fetal deaths in the United States. Influence of high-risk conditions and implications for management. Obstet Gynecol 2002; 100(6):1183-1189.

(106) Roberts CL, Ford JB, Algert CS, Antonsen S, Chalmers J, Cnattingius S et al. Population-based trends in pregnancy hypertension and pre-eclampsia: an international comparative study. BMJ Open 2011; 1(1):e000101.

(107) Aagaard-Tillery KM, Holmgren C, Lacoursiere DY, Houssain S, Bloebaum L, Satterfield $R$ et al. Factors associated with nonanomalous stillbirths: the Utah Stillbirth Database 1992-2002. Am J Obstet Gynecol 2006; 194(3):849-854.

(108) Hutcheon JA, Lisonkova S, Magee LA, von DP, Woo HL, Liu S et al. Optimal timing of delivery in pregnancies with pre-existing hypertension. BJOG 2011; 118(1):49-54.

(109) Zetterstrom K, Lindeberg SN, Haglund B, Hanson U. The association of maternal chronic hypertension with perinatal death in male and female offspring: a record linkage study of 866,188 women. BJOG 2008; 115(11):1436-1442.

(110) Tuuli MG, Rampersad R, Stamilio D, Macones G, Odibo AO. Perinatal outcomes in women with preeclampsia and superimposed preeclampsia: do they differ? Am J Obstet Gynecol 2011; 204(6):508-7.

(111) Yanit KE, Snowden JM, Cheng YW, Caughey AB. The impact of chronic hypertension and pregestational diabetes on pregnancy outcomes. Am J Obstet Gynecol 2012; 207(4):333-336.

(112) Gilbert WM, Young AL, Danielsen B. Pregnancy outcomes in women with chronic hypertension: a population-based study. J Reprod Med 2007; 52(11):1046-1051.

(113) Allen VM, Joseph K, Murphy KE, Magee LA, Ohlsson A. The effect of hypertensive disorders in pregnancy on small for gestational age and stillbirth: a population based study. BMC Pregnancy Childbirth 2004; $4(1): 17$. 
(114) Klungsoyr K, Morken NH, Irgens L, Vollset SE, Skjaerven R. Secular trends in the epidemiology of pre-eclampsia throughout 40 years in Norway: prevalence, risk factors and perinatal survival. Paediatr Perinat Epidemiol 2012; 26(3):190-198.

(115) Lisonkova S, Joseph KS. Incidence of preeclampsia: risk factors and outcomes associated with early- versus late-onset disease. Am J Obstet Gynecol 2013; 209(6):544.

(116) Ananth CV, Basso O. Impact of pregnancy-induced hypertension on stillbirth and neonatal mortality. Epidemiology 2010; 21(1):118-123.

(117) Cruz MO, Gao W, Hibbard JU. Obstetrical and perinatal outcomes among women with gestational hypertension, mild preeclampsia, and mild chronic hypertension. Am J Obstet Gynecol 2011; 205(3):260-269.

(118) Shah DM. Perinatal implications of maternal hypertension. Semin Pediatr Neurol 2001; 8(2):108-119.

(119) Eidem I, Vangen S, Hanssen KF, Vollset SE, Henriksen T, Joner G et al. Perinatal and infant mortality in term and preterm births among women with type 1 diabetes. Diabetologia 2011; 54(11):2771-2778.

(120) Beyerlein A, von KR, Hummel M, Lack N, SchiessI B, Giani G et al. Improvement in pregnancy-related outcomes in the offspring of diabetic mothers in Bavaria, Germany, during 1987-2007. Diabet Med 2010; 27(12):1379-1384.

(121) Penney GC, Mair G, Pearson DW. Outcomes of pregnancies in women with type 1 diabetes in Scotland: a national population-based study. BJOG 2003; 110(3):315-318.

(122) Lauenborg J, Mathiesen E, Ovesen P, Westergaard JG, Ekbom P, Molsted-Pedersen $L$ et al. Audit on stillbirths in women with pregestational type 1 diabetes. Diabetes Care 2003; 26(5):1385-1389.

(123) Evers IM, de Valk HW, Visser GH. Risk of complications of pregnancy in women with type 1 diabetes: nationwide prospective study in the Netherlands. BMJ 2004; 328(7445):915.

(124) Macintosh MC, Fleming KM, Bailey JA, Doyle P, Modder J, Acolet D et al. Perinatal mortality and congenital anomalies in babies of women with type 1 or type 2 diabetes in England, Wales, and Northern Ireland: population based study. BMJ 2006; 333(7560):177.

(125) Persson M, Norman M, Hanson U. Obstetric and perinatal outcomes in type 1 diabetic pregnancies: A large, population-based study. Diabetes Care 2009; 32(11):2005-2009.

(126) Peticca P, Keely EJ, Walker MC, Yang Q, Bottomley J. Pregnancy outcomes in diabetes subtypes: how do they compare? A province-based study of Ontario, 2005-2006. J Obstet Gynaecol Can 2009; 31(6):487-496. 
(127) Jensen DM, Damm P, Moelsted-Pedersen L, Ovesen P, Westergaard JG, Moeller $\mathrm{M}$ et al. Outcomes in type 1 diabetic pregnancies: a nationwide, population-based study. Diabetes Care 2004; 27(12):2819-2823.

(128) Wood SL, Jick H, Sauve R. The risk of stillbirth in pregnancies before and after the onset of diabetes. Diabet Med 2003; 20(9):703-707.

(129) Dunne F, Brydon P, Smith K, Gee H. Pregnancy in women with Type 2 diabetes: 12 years outcome data 1990-2002. Diabet Med 2003; 20(9):734738.

(130) Yang J, Cummings EA, O'connell C, Jangaard K. Fetal and neonatal outcomes of diabetic pregnancies. Obstet Gynecol 2006; 108(3 Pt 1):644650.

(131) Cnattingius S, Berne C, Nordstrom ML. Pregnancy outcome and infant mortality in diabetic patients in Sweden. Diabet Med 1994; 11(7):696-700.

(132) Casson IF, Clarke CA, Howard CV, McKendrick O, Pennycook S, Pharoah $\mathrm{PO}$ et al. Outcomes of pregnancy in insulin dependent diabetic women: results of a five year population cohort study. BMJ 1997; 315(7103):275278.

(133) Silva IS, Higgins C, Swerdlow AJ, Laing SP, Slater SD, Pearson DW et al. Birthweight and other pregnancy outcomes in a cohort of women with pregestational insulin-treated diabetes mellitus, Scotland, 1979-95. Diabet Med 2005; 22(4):440-447.

(134) Rosenstein MG, Cheng YW, Snowden JM, Nicholson JM, Doss AE, Caughey $A B$. The risk of stillbirth and infant death stratified by gestational age in women with gestational diabetes. Am J Obstet Gynecol 2012; 206(4):309-7.

(135) Fadl HE, Ostlund IK, Magnuson AF, Hanson US. Maternal and neonatal outcomes and time trends of gestational diabetes mellitus in Sweden from 1991 to 2003. Diabet Med 2010; 27(4):436-441.

(136) Dudley DJ. Diabetic-associated stillbirth: incidence, pathophysiology, and prevention. Clin Perinatol 2007; 34(4):611-26, vii.

(137) Crowther CA, Hiller JE, Moss JR, McPhee AJ, Jeffries WS, Robinson JS. Effect of treatment of gestational diabetes mellitus on pregnancy outcomes. N Engl J Med 2005; 352(24):2477-2486.

(138) Kapoor N, Sankaran S, Hyer S, Shehata H. Diabetes in pregnancy: a review of current evidence. Curr Opin Obstet Gynecol 2007; 19(6):586590.

(139) Lawler J, Osman M, Shelton JA, Yeh J. Population-based analysis of hypertensive disorders in pregnancy. Hypertens Pregnancy 2007; 26(1):67-76. 
(140) Povoa AM, Costa F, Rodrigues T, Patricio B, Cardoso F. Prevalence of hypertension during pregnancy in Portugal. Hypertens Pregnancy 2008; 27(3):279-284.

(141) Ray JG, Burrows RF, Burrows EA, Vermeulen MJ. MOS HIP: McMaster outcome study of hypertension in pregnancy. Early Hum Dev 2001; 64(2):129-143.

(142) Hogberg L, Cnattingius S. The influence of maternal smoking habits on the risk of subsequent stillbirth: is there a causal relation? BJOG 2007; 114(6):699-704.

(143) Wisborg K, Kesmodel U, Henriksen TB, Olsen SF, Secher NJ. Exposure to tobacco smoke in utero and the risk of stillbirth and death in the first year of life. Am J Epidemiol 2001; 154(4):322-327.

(144) Salihu HM, Sharma PP, Getahun D, Hedayatzadeh M, Peters S, Kirby RS et al. Prenatal tobacco use and risk of stillbirth: a case-control and bidirectional case-crossover study. Nicotine Tob Res 2008; 10(1):159-166.

(145) Aliyu MH, Lynch O, Wilson RE, Alio AP, Kristensen S, Marty PJ et al. Association between tobacco use in pregnancy and placenta-associated syndromes: a population-based study. Arch Gynecol Obstet 2011; 283(4):729-734.

(146) Aliyu MH, Salihu HM, Alio AP, Wilson RE, Chakrabarty S, Clayton HB. Prenatal smoking among adolescents and risk of fetal demise before and during labor. J Pediatr Adolesc Gynecol 2010; 23(3):129-135.

(147) Gray R, Bonellie SR, Chalmers J, Greer I, Jarvis S, Kurinczuk JJ et al. Contribution of smoking during pregnancy to inequalities in stillbirth and infant death in Scotland 1994-2003: retrospective population based study using hospital maternity records. BMJ 2009; 339:b3754.

(148) Goy J, Dodds L, Rosenberg MW, King WD. Health-risk behaviours: examining social disparities in the occurrence of stillbirth. Paediatr Perinat Epidemiol 2008; 22(4):314-320.

(149) Cupul-Uicab LA, Baird DD, Skjaerven R, Saha-Chaudhuri P, Haug K, Longnecker MP. In utero exposure to maternal smoking and women's risk of fetal loss in the Norwegian Mother and Child Cohort (MoBa). Hum Reprod 2011; 26(2):458-465.

(150) Eriksson KM, Salvesen KA, Haug K, Eik-Nes SH. Smoking habits among pregnant women in a Norwegian county 1987-1994. Acta Obstet Gynecol Scand 1996; 75(4):355-359.

(151) Kvalvik LG, Skjaerven R, Haug K. Smoking during pregnancy from 1999 to 2004: a study from the Medical Birth Registry of Norway. Acta Obstet Gynecol Scand 2008; 87(3):280-285. 
(152) Faden VB, Graubard BI, Dufour M. The relationship of drinking and birth outcome in a US national sample of expectant mothers. Paediatr Perinat Epidemiol 1997; 11(2):167-180.

(153) Kesmodel U, Wisborg K, Olsen SF, Henriksen TB, Secher NJ. Moderate alcohol intake during pregnancy and the risk of stillbirth and death in the first year of life. Am J Epidemiol 2002; 155(4):305-312.

(154) Strandberg-Larsen K, Nielsen NR, Gronbaek M, Andersen PK, Olsen J, Andersen AM. Binge drinking in pregnancy and risk of fetal death. Obstet Gynecol 2008; 111(3):602-609.

(155) O'Leary C, Jacoby P, D'Antoine H, Bartu A, Bower C. Heavy prenatal alcohol exposure and increased risk of stillbirth. BJOG 2012; 119(8):945952.

(156) Andersen AM, Andersen PK, Olsen J, Gronbaek M, Strandberg-Larsen K. Moderate alcohol intake during pregnancy and risk of fetal death. Int $J$ Epidemiol 2012; 41(2):405-413.

(157) Aliyu MH, Wilson RE, Zoorob R, Chakrabarty S, Alio AP, Kirby RS et al. Alcohol consumption during pregnancy and the risk of early stillbirth among singletons. Alcohol 2008; 42(5):369-374.

(158) Wisborg K, Kesmodel U, Bech BH, Hedegaard M, Henriksen TB. Maternal consumption of coffee during pregnancy and stillbirth and infant death in first year of life: prospective study. BMJ 2003; 326(7386):420.

(159) Bech BH, Nohr EA, Vaeth M, Henriksen TB, Olsen J. Coffee and fetal death: a cohort study with prospective data. Am J Epidemiol 2005; 162(10):983-990.

(160) Copper RL, Goldenberg RL, DuBard MB, Davis RO. Risk factors for fetal death in white, black, and Hispanic women. Collaborative Group on Preterm Birth Prevention. Obstet Gynecol 1994; 84(4):490-495.

(161) Craig ED, Mantell CD, Ekeroma AJ, Stewart AW, Mitchell EA. Ethnicity and birth outcome: New Zealand trends 1980-2001. Part 1. Introduction, methods, results and overview. Aust N Z J Obstet Gynaecol 2004; 44(6):530-536.

(162) Getahun D, Ananth CV, Selvam N, Demissie K. Adverse perinatal outcomes among interracial couples in the United States. Obstet Gynecol 2005; 106(1):81-88.

(163) Guildea ZE, Fone DL, Dunstan FD, Sibert JR, Cartlidge PH. Social deprivation and the causes of stillbirth and infant mortality. Arch Dis Child 2001; 84(4):307-310.

(164) Haglund B, Cnattingius S, Nordstrom ML. Social differences in late fetal death and infant mortality in Sweden 1985-86. Paediatr Perinat Epidemiol 1993; 7(1):33-44. 
(165) Healy AJ, Malone FD, Sullivan LM, Porter TF, Luthy DA, Comstock CH et al. Early access to prenatal care: implications for racial disparity in perinatal mortality. Obstet Gynecol 2006; 107(3):625-631.

(166) Luo ZC, Wilkins R, Kramer MS. Effect of neighbourhood income and maternal education on birth outcomes: a population-based study. CMAJ 2006; 174(10):1415-1420.

(167) Saastad E, Vangen S, Froen JF. Suboptimal care in stillbirths - a retrospective audit study. Acta Obstet Gynecol Scand 2007; 86(4):444450.

(168) Stephansson O, Dickman PW, Johansson AL, Cnattingius S. The influence of socioeconomic status on stillbirth risk in Sweden. Int J Epidemiol 2001; 30(6):1296-1301.

(169) Vangen S, Stoltenberg C, Johansen RE, Sundby J, Stray-Pedersen B. Perinatal complications among ethnic Somalis in Norway. Acta Obstet Gynecol Scand 2002; 81(4):317-322.

(170) Rom AL, Mortensen LH, Cnattingius S, Arntzen A, Gissler M, Andersen AM. A comparative study of educational inequality in the risk of stillbirth in Denmark, Finland, Norway and Sweden 1981-2000. J Epidemiol Community Health 2012; 66(3):240-246.

(171) Savard N, Auger N, Park AL, Lo E, Martinez J. Educational inequality in stillbirth: temporal trends in Quebec from 1981 to 2009. Can J Public Health 2013; 104(2):e148-e153.

(172) Wood AM, Pasupathy D, Pell JP, Fleming M, Smith GC. Trends in socioeconomic inequalities in risk of sudden infant death syndrome, other causes of infant mortality, and stillbirth in Scotland: population based study. BMJ 2012; 344:e1552.

(173) Drysdale H, Ranasinha S, Kendall A, Knight M, Wallace EM. Ethnicity and the risk of late-pregnancy stillbirth. Med J Aust 2012; 197(5):278-281.

(174) Ekeus C, Cnattingius S, Essen B, Hjern A. Stillbirth among foreign-born women in Sweden. Eur J Public Health 2011; 21(6):788-792.

(175) Getahun D, Ananth CV, Kinzler WL. Risk factors for antepartum and intrapartum stillbirth: a population-based study. Am J Obstet Gynecol 2007; 196(6):499-507.

(176) Hogue CJ, Parker CB, Willinger M, Temple JR, Bann CM, Silver RM et al. A population-based case-control study of stillbirth: the relationship of significant life events to the racial disparity for African Americans. Am J Epidemiol 2013; 177(8):755-767.

(177) Lorch SA, Kroelinger CD, Ahlberg C, Barfield WD. Factors that mediate racial/ethnic disparities in US fetal death rates. Am J Public Health 2012; 102(10):1902-1910. 
(178) Luque-Fernandez MA, Franco M, Gelaye B, Schomaker M, Garitano IG, D'Este $\mathrm{C}$ et al. Unemployment and stillbirth risk among foreign-born and Spanish pregnant women in Spain, 2007-2010: a multilevel analysis study. Eur J Epidemiol 2013; 28(12):991-999.

(179) Ravelli AC, Tromp M, Eskes M, Droog JC, van der Post JA, Jager KJ et al. Ethnic differences in stillbirth and early neonatal mortality in The Netherlands. J Epidemiol Community Health 2011; 65(8):696-701.

(180) Reeske A, Kutschmann M, Razum O, Spallek J. Stillbirth differences according to regions of origin: an analysis of the German perinatal database, 2004-2007. BMC Pregnancy Childbirth 2011; 11:63.

(181) Salihu HM, Kinniburgh BA, Aliyu MH, Kirby RS, Alexander GR. Racial disparity in stillbirth among singleton, twin, and triplet gestations in the United States. Obstet Gynecol 2004; 104(4):734-740.

(182) Stacey T, Thompson JM, Mitchell EA, Ekeroma AJ, Zuccollo JM, McCowan LM. Relationship between obesity, ethnicity and risk of late stillbirth: a case control study. BMC Pregnancy Childbirth 2011; 11:3.

(183) Villadsen SF, Mortensen LH, Andersen AM. Ethnic disparity in stillbirth and infant mortality in Denmark 1981-2003. J Epidemiol Community Health 2009; 63(2):106-112.

(184) Villadsen SF, Sievers E, Andersen AM, Arntzen A, Audard-Mariller M, Martens $\mathrm{G}$ et al. Cross-country variation in stillbirth and neonatal mortality in offspring of Turkish migrants in northern Europe. Eur J Public Health 2010; 20(5):530-535.

(185) Khalil A, Rezende J, Akolekar R, Syngelaki A, Nicolaides KH. Maternal racial origin and adverse pregnancy outcome: a cohort study. Ultrasound Obstet Gynecol 2013; 41(3):278-285.

(186) Auger N, Park AL, Zoungrana H, McHugh NG, Luo ZC. Rates of stillbirth by gestational age and cause in Inuit and First Nations populations in Quebec. CMAJ 2013; 185(6):E256-E262.

(187) Clausson B, Cnattingius S, Axelsson O. Outcomes of post-term births: the role of fetal growth restriction and malformations. Obstet Gynecol 1999; 94(5 Pt 1):758-762.

(188) Clausson B, Gardosi J, Francis A, Cnattingius S. Perinatal outcome in SGA births defined by customised versus population-based birthweight standards. BJOG 2001; 108(8):830-834.

(189) Divon MY, Haglund B, Nisell H, Otterblad PO, Westgren M. Fetal and neonatal mortality in the postterm pregnancy: the impact of gestational age and fetal growth restriction. Am J Obstet Gynecol 1998; 178(4):726-731. 
(190) Froen JF, Gardosi JO, Thurmann A, Francis A, Stray-Pedersen B. Restricted fetal growth in sudden intrauterine unexplained death. Acta Obstet Gynecol Scand 2004; 83(9):801-807.

(191) Kramer MS, Olivier M, McLean FH, Willis DM, Usher RH. Impact of intrauterine growth retardation and body proportionality on fetal and neonatal outcome. Pediatrics 1990; 86(5):707-713.

(192) Zhang X, Platt RW, Cnattingius S, Joseph KS, Kramer MS. The use of customised versus population-based birthweight standards in predicting perinatal mortality. BJOG 2007; 114(4):474-477.

(193) Pilliod RA, Cheng YW, Snowden JM, Doss AE, Caughey AB. The risk of intrauterine fetal death in the small-for-gestational-age fetus. Am J Obstet Gynecol 2012; 207(4):318-6.

(194) Stacey T, Thompson JM, Mitchell EA, Zuccollo JM, Ekeroma AJ, McCowan LM. Antenatal care, identification of suboptimal fetal growth and risk of late stillbirth: findings from the Auckland Stillbirth Study. Aust N Z J Obstet Gynaecol 2012; 52(3):242-247.

(195) Trudell AS, Cahill AG, Tuuli MG, Macones GA, Odibo AO. Risk of stillbirth after 37 weeks in pregnancies complicated by small-for-gestational-age fetuses. Am J Obstet Gynecol 2013; 208(5):376-377.

(196) Baschat AA, Galan H, Ross M, Gabbe SG. Intrauterine Growth Restriction. In: Gabbe SG, Niebyl JR, Simpson JL, editors. In: Obstetrics. Normal and problem pregnancies. 5th edition ed. Churchill Livingstone Elsevier; 2007. 771-814.

(197) Caughey AB, Musci TJ. Complications of term pregnancies beyond 37 weeks of gestation. Obstet Gynecol 2004; 103(1):57-62.

(198) Cotzias CS, Paterson-Brown S, Fisk NM. Prospective risk of unexplained stillbirth in singleton pregnancies at term: population based analysis. BMJ 1999; 319(7205):287-288.

(199) Heimstad R, Romundstad PR, Eik-Nes SH, Salvesen KA. Outcomes of pregnancy beyond 37 weeks of gestation. Obstet Gynecol 2006; 108(3 Pt 1):500-508.

(200) Smith GC. Life-table analysis of the risk of perinatal death at term and post term in singleton pregnancies. Am J Obstet Gynecol 2001; 184(3):489-496.

(201) Rosenstein MG, Cheng YW, Snowden JM, Nicholson JM, Caughey AB. Risk of stillbirth and infant death stratified by gestational age. Obstet Gynecol 2012; 120(1):76-82.

(202) Mandujano A, Waters TP, Myers SA. The risk of fetal death: current concepts of best gestational age for delivery. Am J Obstet Gynecol 2013; 208(3):207-208. 
(203) Samueloff A, Xenakis EM, Berkus MD, Huff RW, Langer O. Recurrent stillbirth. Significance and characteristics. J Reprod Med 1993; 38(11):883886.

(204) Sharma PP, Salihu HM, Kirby RS. Stillbirth recurrence in a population of relatively low-risk mothers. Paediatr Perinat Epidemiol 2007; 21 Suppl 1:24-30.

(205) Bhattacharya S, Prescott GJ, Black M, Shetty A. Recurrence risk of stillbirth in a second pregnancy. BJOG 2010; 117(10):1243-1247.

(206) Melve KK, Skjaerven R, Rasmussen S, Irgens LM. Recurrence of stillbirth in sibships: Population-based cohort study. Am J Epidemiol 2010; 172(10):1123-1130.

(207) Gordon A, Raynes-Greenow C, McGeechan K, Morris J, Jeffery H. Stillbirth risk in a second pregnancy. Obstet Gynecol 2012; 119(3):509-517.

(208) Salihu HM, Sharma PP, Aliyu MH, Kristensen S, Grimes-Dennis J, Kirby RS et al. Is small for gestational age a marker of future fetal survival in utero? Obstet Gynecol 2006; 107(4):851-856.

(209) Smith GC, Shah I, White IR, Pell JP, Dobbie R. Previous preeclampsia, preterm delivery, and delivery of a small for gestational age infant and the risk of unexplained stillbirth in the second pregnancy: a retrospective cohort study, Scotland, 1992-2001. Am J Epidemiol 2007; 165(2):194-202.

(210) Surkan PJ, Stephansson O, Dickman PW, Cnattingius S. Previous preterm and small-for-gestational-age births and the subsequent risk of stillbirth. $N$ Engl J Med 2004; 350(8):777-785.

(211) BAIRD D, WALKER J, THOMSON AM. The causes and prevention of stillbirths and first week deaths. III. A classification of deaths by clinical cause; the effect of age, parity and length of gestation on death rates by cause. J Obstet Gynaecol Br Emp 1954; 61(4):433-448.

(212) Hey EN, Lloyd DJ, Wigglesworth JS. Classifying perinatal death: fetal and neonatal factors. Br J Obstet Gynaecol 1986; 93(12):1213-1223.

(213) Korteweg FJ, Gordijn SJ, Timmer A, Erwich JJ, Bergman KA, Bouman K et al. The Tulip classification of perinatal mortality: introduction and multidisciplinary inter-rater agreement. BJOG 2006; 113(4):393-401.

(214) Ahlenius I, Floberg J, Thomassen P. Sixty-six cases of intrauterine fetal death. A prospective study with an extensive test protocol. Acta Obstet Gynecol Scand 1995; 74(2):109-117.

(215) Pauli RM, Reiser CA. Wisconsin Stillbirth Service Program: II. Analysis of diagnoses and diagnostic categories in the first 1,000 referrals. Am J Med Genet 1994; 50(2):135-153. 
(216) Liu S, Joseph KS, Wen SW, Kramer MS, Marcoux S, Ohlsson A et al. Secular trends in congenital anomaly-related fetal and infant mortality in Canada, 1985-1996. Am J Med Genet 2001; 104(1):7-13.

(217) Goldenberg RL, McClure EM, Saleem S, Reddy UM. Infection-related stillbirths. Lancet 2010; 375(9724):1482-1490.

(218) Prospective study of human parvovirus (B19) infection in pregnancy. Public Health Laboratory Service Working Party on Fifth Disease. BMJ 1990; 300(6733):1166-1170.

(219) Enders M, Weidner A, Zoellner I, Searle K, Enders G. Fetal morbidity and mortality after acute human parvovirus B19 infection in pregnancy: prospective evaluation of 1018 cases. Prenat Diagn 2004; 24(7):513-518.

(220) Norbeck O, Papadogiannakis N, Petersson K, Hirbod T, Broliden K, Tolfvenstam T. Revised clinical presentation of parvovirus B19-associated intrauterine fetal death. Clin Infect Dis 2002; 35(9):1032-1038.

(221) Petersson K, Norbeck O, Westgren M, Broliden K. Detection of parvovirus B19, cytomegalovirus and enterovirus infections in cases of intrauterine fetal death. J Perinat Med 2004; 32(6):516-521.

(222) Skjoldebrand-Sparre L, Fridell E, Nyman M, Wahren B. A prospective study of antibodies against parvovirus B19 in pregnancy. Acta Obstet Gynecol Scand 1996; 75(4):336-339.

(223) Skjoldebrand-Sparre L, Tolfvenstam T, Papadogiannakis N, Wahren B, Broliden K, Nyman M. Parvovirus B19 infection: association with thirdtrimester intrauterine fetal death. BJOG 2000; 107(4):476-480.

(224) Tolfvenstam T, Papadogiannakis N, Norbeck O, Petersson K, Broliden K. Frequency of human parvovirus B19 infection in intrauterine fetal death. Lancet 2001; 357(9267):1494-1497.

(225) Korteweg FJ, Erwich JJ, Holm JP, Ravise JM, van der Meer J, Veeger NJ et al. Diverse placental pathologies as the main causes of fetal death. Obstet Gynecol 2009; 114(4):809-817.

(226) Radestad I, Steineck G, Nordin C, Sjogren B. Psychological complications after stillbirth--influence of memories and immediate management: population based study. BMJ 1996; 312(7045):1505-1508.

(227) Hughes PM, Turton P, Evans CD. Stillbirth as risk factor for depression and anxiety in the subsequent pregnancy: cohort study. BMJ 1999; 318(7200):1721-1724.

(228) Turton P, Evans C, Hughes P. Long-term psychosocial sequelae of stillbirth: phase II of a nested case-control cohort study. Arch Womens Ment Health 2009; 12(1):35-41. 
(229) Calderon-Margalit R, Friedlander Y, Yanetz R, Deutsch L, Manor O, Harlap $S$ et al. Late stillbirths and long-term mortality of mothers. Obstet Gynecol 2007; 109(6):1301-1308.

(230) Ranthe MF, Andersen EA, Wohlfahrt J, Bundgaard H, Melbye M, Boyd HA. Pregnancy loss and later risk of atherosclerotic disease. Circulation 2013; 127(17):1775-1782.

(231) Kharazmi E, Dossus L, Rohrmann S, Kaaks R. Pregnancy loss and risk of cardiovascular disease: a prospective population-based cohort study (EPIC-Heidelberg). Heart 2011; 97(1):49-54.

(232) Bech BH, Obel C, Henriksen TB, Olsen J. Effect of reducing caffeine intake on birth weight and length of gestation: randomised controlled trial. BMJ 2007; 334(7590):409.

(233) Woods R. Long-term trends in fetal mortality: implications for developing countries. Bull World Health Organ 2008; 86(6):460-466.

(234) Elsheikh A, Malik A, Gardosi J. West Midlands Perinatal \& Infant Mortality 2008/9. Available at: [http://www.perinatal.nhs.uk/pnm/KHD 2008-9.pdf]. Last accessed 24.03.2014.

Ref Type: Online Source

(235) Alfirevic Z, Stampalija T, Gyte GM. Fetal and umbilical Doppler ultrasound in high-risk pregnancies. Cochrane Database Syst Rev 2010;(1):CD007529.

(236) Alfirevic Z, Stampalija T, Gyte GM. Fetal and umbilical Doppler ultrasound in normal pregnancy. Cochrane Database Syst Rev 2010;(8):CD001450.

(237) Vintzileos AM. Evidence-based compared with reality-based medicine in obstetrics. Obstet Gynecol 2009; 113(6):1335-1340.

(238) Duke CW, Correa A, Romitti PA, Martin J, Kirby RS. Challenges and priorities for surveillance of stillbirths: a report on two workshops. Public Health Rep 2009; 124(5):652-659.

(239) Martin JA, Hoyert DL. The national fetal death file. Semin Perinatol 2002; 26(1):3-11.

(240) Rothman KJ. Using secondary data. In: Modern Epidemiology. 3rd edition ed. Lippincott Williams \& Wilkins; 2008. 481-491.

(241) Embleton ND. Fetal and neonatal death from maternally acquired infection. Paediatr Perinat Epidemiol 2001; 15(1):54-60.

(242) Jenum PA, Stray-Pedersen B, Melby KK, Kapperud G, Whitelaw A, Eskild A et al. Incidence of Toxoplasma gondii infection in 35,940 pregnant women in Norway and pregnancy outcome for infected women. $J$ Clin Microbiol 1998; 36(10):2900-2906. 
(243) Lamont RF, Sobel JD, Vaisbuch E, Kusanovic JP, Mazaki-Tovi S, Kim SK et al. Parvovirus B19 infection in human pregnancy. BJOG 2011; 118(2):175-186.

(244) Valeur-Jensen AK, Pedersen CB, Westergaard T, Jensen IP, Lebech M, Andersen $\mathrm{PK}$ et al. Risk factors for parvovirus B19 infection in pregnancy. JAMA 1999; 281(12):1099-1105.

(245) Nybo Andersen AM, Hansen KD, Andersen PK, Davey SG. Advanced paternal age and risk of fetal death: a cohort study. Am J Epidemiol 2004; 160(12):1214-1222.

(246) Klungsoyr K, Morken NH, Irgens L, Vollset SE, Skjaerven R. Secular trends in the epidemiology of pre-eclampsia throughout 40 years in Norway: prevalence, risk factors and perinatal survival. Paediatr Perinat Epidemiol 2012; 26(3):190-198.

(247) Blondel B, Kaminski M. Trends in the occurrence, determinants, and consequences of multiple births. Semin Perinatol 2002; 26(4):239-249.

(248) Hutcheon JA, Lisonkova S, Joseph KS. Epidemiology of pre-eclampsia and the other hypertensive disorders of pregnancy. Best Pract Res Clin Obstet Gynaecol 2011; 25(4):391-403.

(249) Kramer MS, Liu S, Luo Z, Yuan H, Platt RW, Joseph KS. Analysis of perinatal mortality and its components: time for a change? Am J Epidemiol 2002; 156(6):493-497.

(250) Cheung YB. On the definition of gestational-age-specific mortality. Am J Epidemiol 2004; 160(3):207-210.

(251) Joseph KS. Theory of obstetrics: an epidemiologic framework for justifying medically indicated early delivery. BMC Pregnancy Childbirth 2007; 7:4.

(252) Wilcox AJ. Stillbirth and infant mortality. In: Fertility and Pregnancy. 1st edition ed. Oxford University Press; 2010. 164-182.

(253) Kramer MS, Zhang X, Platt RW. Analyzing risks of adverse pregnancy outcomes. Am J Epidemiol 2014; 179(3):361-367.

(254) Platt RW, Joseph KS, Ananth CV, Grondines J, Abrahamowicz M, Kramer MS. A proportional hazards model with time-dependent covariates and time-varying effects for analysis of fetal and infant death. Am J Epidemiol 2004; 160(3):199-206.

(255) Rothman KJ. Dealing with biases. In: Epidemiology: An introduction. 2nd edition ed. Oxford University Press, Inc.; 2012. 124-147.

(256) Woodward M. Sample size determination. In: Epidemiology Study Design and Data Analysis. 2nd edition ed. Chapman \& Hall; 2005. 381-426. 
(257) Sample Size Calculator for Unmatched Case Control Studies. Available at: [http://www.stat.ubc.ca/ rollin/stats/ssize/caco.html]. Last accessed 20.02.2014.

Ref Type: Online Source

(258) Greb AE, Pauli RM, Kirby RS. Accuracy of fetal death reports: comparison with data from an independent stillbirth assessment program. Am J Public Health 1987; 77(9):1202-1206.

(259) Joseph KS, Allen A, Kramer MS, Cyr M, Fair M. Changes in the registration of stillbirths < $500 \mathrm{~g}$ in Canada, 1985-95. Fetal-Infant Mortality Study Group of the Canadian Perinatal Surveillance System. Paediatr Perinat Epidemiol 1999; 13(3):278-287.

(260) de Jong EP, de Haan TR, Kroes AC, Beersma MF, Oepkes D, Walther FJ. Parvovirus B19 infection in pregnancy. J Clin Virol 2006; 36(1):1-7.

(261) Eskild A, Nesheim BI, Berglund T, Totlandsdal JK, Andresen JF. [Geographical variation in the occurrence of induced late abortions in Norway 1996-97]. Tidsskr Nor Laegeforen 2001; 121(1):24-27.

(262) Eskild A, Jeansson S, Stray-Pedersen B, Jenum PA. Herpes simplex virus type-2 infection in pregnancy: no risk of fetal death: results from a nested case-control study within 35,940 women. BJOG 2002; 109(9):1030-1035.

(263) Rasmussen S, Albrechtsen S, Irgens LM, Dalaker K, Maartmann-Moe H, Vlatkovic L et al. Unexplained antepartum fetal death in Norway, 1985-97: diagnostic validation and some epidemiologic aspects. Acta Obstet Gynecol Scand 2003; 82(2):109-115.

(264) Baghestan E, Bordahl PE, Rasmussen SA, Sande AK, Lyslo I, Solvang I. A validation of the diagnosis of obstetric sphincter tears in two Norwegian databases, the Medical Birth Registry and the Patient Administration System. Acta Obstet Gynecol Scand 2007; 86(2):205-209.

(265) Engeland A, Bjorge T, Daltveit AK, Vollset SE, Furu K. Validation of disease registration in pregnant women in the Medical Birth Registry of Norway. Acta Obstet Gynecol Scand 2009; 88(10):1083-1089.

(266) Kubon C, Sivertsen A, Vindenes HA, Abyholm F, Wilcox A, Lie RT. Completeness of registration of oral clefts in a medical birth registry: a population-based study. Acta Obstet Gynecol Scand 2007; 86(12):14531457.

(267) Melve KK, Lie RT, Skjaerven R, Van Der Hagen CB, Gradek GA, Jonsrud $\mathrm{C}$ et al. Registration of Down syndrome in the Medical Birth Registry of Norway: validity and time trends. Acta Obstet Gynecol Scand 2008; 87(8):824-830.

(268) Skomsvoll J, Ostensen M, Baste V, Irgens L. Validity of a rheumatic disease diagnosis in the Medical Birth Registry of Norway. Acta Obstet Gynecol Scand 2002; 81(9):831-834. 
(269) Stene LC, Eidem I, Vangen S, Joner G, Irgens LM, Moe N. The validity of the diabetes mellitus diagnosis in th eMedical Birth Registry of Norway. Norsk Epidemiologi 2007; 17(2):165-174.

(270) Haglund B. Birthweight distributions by gestational age: comparison of LMP-based and ultrasound-based estimates of gestational age using data from the Swedish Birth Registry. Paediatr Perinat Epidemiol 2007; 21 Suppl 2:72-78.

(271) Tunon K, Eik-Nes SH, Grottum P. A comparison between ultrasound and a reliable last menstrual period as predictors of the day of delivery in 15,000 examinations. Ultrasound Obstet Gynecol 1996; 8(3):178-185.

(272) Thomsen LC, Klungsoyr K, Roten LT, Tappert C, Araya E, Baerheim G et al. Validity of the diagnosis of pre-eclampsia in the Medical Birth Registry of Norway. Acta Obstet Gynecol Scand 2013; 92(8):943-950.

(273) [Definisjonsrapporter for variabler i Medisinsk fødselsregister Del 2.] In Norwegian. Available at: [http://www.fhi.no/dokumenter/ef6810b3dd.pdf]. 2009.

Ref Type: Report

(274) [Definisjonsrapporter for variabler i Medisinsk fødselsregister Del 1.] In Norwegian. Available at: [http://www.fhi.no/dokumenter/0a3d4061ec.pdf]. 2009.

Ref Type: Report

(275) Rothman KJ. Controlling confounding by straifying data. In: Epidemiology: An introduction. 2nd edition ed. Oxford University Press, Inc.; 2012. 176197.

(276) Jensen IP, Thorsen P, Jeune B, Moller BR, Vestergaard BF. An epidemic of parvovirus B19 in a population of 3,596 pregnant women: a study of sociodemographic and medical risk factors. BJOG 2000; 107(5):637-643.

(277) Laszlo KD, Svensson T, Li J, Obel C, Vestergaard M, Olsen J et al. Maternal bereavement during pregnancy and the risk of stillbirth: a nationwide cohort study in Sweden. Am J Epidemiol 2013; 177(3):219-227.

(278) Ananth CV, Chauhan SP. Epidemiology of twinning in developed countries. Semin Perinatol 2012; 36(3):156-161.

(279) Ulset E, Undheim R, Malterud K. [Has the obesity epidemic reached Norway?]. Tidsskr Nor Laegeforen 2007; 127(1):34-37.

(280) Droyvold WB, Nilsen TI, Kruger O, Holmen TL, Krokstad S, Midthjell K et al. Change in height, weight and body mass index: Longitudinal data from the HUNT Study in Norway. Int J Obes (Lond) 2006; 30(6):935-939.

(281) Callaway LK, O'Callaghan M, McIntyre HD. Obesity and the hypertensive disorders of pregnancy. Hypertens Pregnancy 2009; 28(4):473-493. 
(282) Brown T, Anand A, Ritchie LD, Clewley JP, Reid TM. Intrauterine parvovirus infection associated with hydrops fetalis. Lancet 1984; 2(8410):1033-1034.

(283) Miller E, Fairley CK, Cohen BJ, Seng C. Immediate and long term outcome of human parvovirus B19 infection in pregnancy. Br J Obstet Gynaecol 1998; 105(2):174-178.

(284) Rodis JF, Quinn DL, Gary GW, Jr., Anderson LJ, Rosengren S, Cartter ML et al. Management and outcomes of pregnancies complicated by human B19 parvovirus infection: a prospective study. Am J Obstet Gynecol 1990; 163(4 Pt 1):1168-1171.

(285) Harger JH, Adler SP, Koch WC, Harger GF. Prospective evaluation of 618 pregnant women exposed to parvovirus B19: risks and symptoms. Obstet Gynecol 1998; 91(3):413-420.

(286) Kinney JS, Anderson LJ, Farrar J, Strikas RA, Kumar ML, Kliegman RM et al. Risk of adverse outcomes of pregnancy after human parvovirus B19 infection. J Infect Dis 1988; 157(4):663-667.

(287) Bonvicini F, Puccetti C, Salfi NC, Guerra B, Gallinella G, Rizzo N et al. Gestational and fetal outcomes in B19 maternal infection: a problem of diagnosis. J Clin Microbiol 2011; 49(10):3514-3518.

(288) Kerr JR, O'Neill HJ, Coyle PV, Thompson W. An outbreak of parvovirus B19 infection; a study of clinical manifestations and the incidence of fetal loss. Ir J Med Sci 1994; 163(2):65-67.

(289) Mossong J, Hens N, Friederichs V, Davidkin I, Broman M, Litwinska B et al. Parvovirus B19 infection in five European countries: seroepidemiology, force of infection and maternal risk of infection. Epidemiol Infect 2008; 136(8):1059-1068.

(290) van Gessel PH, Gaytant MA, Vossen AC, Galama JM, Ursem NT, Steegers EA et al. Incidence of parvovirus B19 infection among an unselected population of pregnant women in the Netherlands: $A$ prospective study. Eur J Obstet Gynecol Reprod Biol 2006; 128(1-2):4649.

(291) Lassen J, Jensen AK, Bager P, Pedersen CB, Panum I, NorgaardPedersen B et al. Parvovirus B19 infection in the first trimester of pregnancy and risk of fetal loss: a population-based case-control study. Am J Epidemiol 2012; 176(9):803-807.

(292) Weiffenbach J, Bald R, Gloning KP, Minderer S, Gartner BC, Weidner A et al. Serological and virological analysis of maternal and fetal blood samples in prenatal human parvovirus b19 infection. J Infect Dis 2012; 205(5):782788.

(293) Broliden K, Tolfvenstam T, Norbeck O. Clinical aspects of parvovirus B19 infection. J Intern Med 2006; 260(4):285-304. 
(294) Enders M, Klingel K, Weidner A, Baisch C, Kandolf R, Schalasta G et al. Risk of fetal hydrops and non-hydropic late intrauterine fetal death after gestational parvovirus B19 infection. J Clin Virol 2010; 49(3):163-168.

(295) Riipinen A, Vaisanen E, Nuutila M, Sallmen M, Karikoski R, Lindbohm ML et al. Parvovirus b19 infection in fetal deaths. Clin Infect Dis 2008; 47(12):1519-1525.

(296) Enders M, Weidner A, Rosenthal T, Baisch C, Hedman L, SoderlundVenermo $M$ et al. Improved diagnosis of gestational parvovirus B19 infection at the time of nonimmune fetal hydrops. J Infect Dis 2008; 197(1):58-62.

(297) US Department of Health and Human Services, Center for Disease Control and Prevention, National Center for Health Statistics. Health, United States, 2010. Available at: [http://www.cdc.gov/nchs/data/hus/hus10.pdf]. Last accessed 20.2.2014.

Ref Type: Online Source

(298) Backe B. [Antenatal care in Norway--many unnecessary check ups]. Tidsskr Nor Laegeforen 2002; 122(20):1989-1992.

(299) Mohangoo AD, Buitendijk SE, Szamotulska K, Chalmers J, Irgens LM, Bolumar $\mathrm{F}$ et al. Gestational age patterns of fetal and neonatal mortality in Europe: results from the Euro-Peristat project. PLoS One 2011; 6(11):e24727.

(300) Yuan H, Platt RW, Morin L, Joseph KS, Kramer MS. Fetal deaths in the United States, 1997 vs 1991. Am J Obstet Gynecol 2005; 193(2):489-495.

(301) Martin JA, Hamilton BE, Sutton PD, Ventura SJ, Menacker F, Kirmeyer S et al. Births: final data for 2005. Natl Vital Stat Rep 2007; 56(6):1-103.

(302) Carlsen F, Grytten J, Eskild A. Maternal education and risk of offspring death; changing patterns from 16 weeks of gestation until one year after birth. Eur J Public Health 2014; 24(1):157-162.

(303) Sjoborg KD, Vistad I, Myhr SS, Svenningsen R, Herzog C, Kloster-Jensen A et al. Pregnancy outcome after cervical cone excision: a case-control study. Acta Obstet Gynecol Scand 2007; 86(4):423-428.

(304) Albrechtsen S, Rasmussen S, Thoresen S, Irgens LM, Iversen OE. Pregnancy outcome in women before and after cervical conisation: population based cohort study. BMJ 2008; 337:a1343.

(305) Carolan M, Frankowska D. Advanced maternal age and adverse perinatal outcome: a review of the evidence. Midwifery 2011; 27(6):793-801.

(306) Miller DA. Is advanced maternal age an independent risk factor for uteroplacental insufficiency? Am J Obstet Gynecol 2005; 192(6):19741980. 
(307) Facchinetti F, Alberico S, Benedetto C, Cetin I, Cozzolino S, Di Renzo GC et al. A multicenter, case-control study on risk factors for antepartum stillbirth. J Matern Fetal Neonatal Med 2011; 24(3):407-410.

(308) Cleary-Goldman J, Malone FD, Vidaver J, Ball RH, Nyberg DA, Comstock $\mathrm{CH}$ et al. Impact of maternal age on obstetric outcome. Obstet Gynecol 2005; 105(5 Pt 1):983-990.

(309) Arbyn M, Kyrgiou M, Simoens C, Raifu AO, Koliopoulos G, Martin-Hirsch P et al. Perinatal mortality and other severe adverse pregnancy outcomes associated with treatment of cervical intraepithelial neoplasia: metaanalysis. BMJ 2008; 337:a1284.

(310) Herstad L, Klungsoyr K, Skjaerven R, Tanbo T, Eidem I, Forsen L et al. Maternal age and elective cesarean section in a low-risk population. Acta Obstet Gynecol Scand 2012; 91(7):816-823.

(311) Anthony S, Jacobusse GW, van der Pal-de Bruin KM, Buitendijk S, Zeitlin $J$. Do differences in maternal age, parity and multiple births explain variations in fetal and neonatal mortality rates in Europe?--Results from the EURO-PERISTAT project. Paediatr Perinat Epidemiol 2009; 23(4):292300.

(312) Harden A, Brunton G, Fletcher A, Oakley A. Teenage pregnancy and social disadvantage: systematic review integrating controlled trials and qualitative studies. BMJ 2009; 339:b4254.

(313) Chen XK, Wen SW, Smith G, Yang Q, Walker M. Pregnancy-induced hypertension is associated with lower infant mortality in preterm singletons. BJOG 2006; 113(5):544-551.

(314) Wilcox AJ, Weinberg CR, Basso O. On the pitfalls of adjusting for gestational age at birth. Am J Epidemiol 2011; 174(9):1062-1068.

(315) Abalos E, Duley L, Steyn DW, Henderson-Smart DJ. Antihypertensive drug therapy for mild to moderate hypertension during pregnancy. Cochrane Database Syst Rev 2007;(1):CD002252.

(316) The Lancet Stillbirth series. Available at: [http://www.thelancet.com/series/stillbirth]. Last accessed 15.03.2014.

Ref Type: Online Source

(317) Rowland Hogue CJ, Silver RM. Racial and ethnic disparities in United States: stillbirth rates: trends, risk factors, and research needs. Semin Perinatol 2011; 35(4):221-233.

(318) Jorgensen T, Mortensen LH, Andersen AM. Social inequality in fetal and perinatal mortality in the Nordic countries. Scand J Public Health 2008; 36(6):635-649. 


\section{APPENDIX I.}

Table A. Adjusted hazard ratio with $95 \% \mathrm{Cl}$ of fetal death in gestational weeks $16-43$ according to maternal age in the period 1999 to 2006 (corresponding to Table 2 in Paper III, but limited to the year 1999 to 2006).

\section{Year of delivery 1999-2006}

\section{Gestational week 16-22}

\begin{tabular}{cc}
\hline Maternal age & Adjusted $\mathrm{HR}^{*}(95 \% \mathrm{CI})$ \\
\hline$<20$ & $1.41(1.03-1.92)$ \\
$20-24$ & 1 \\
$25-29$ & $0.99(0.83-1.18)$ \\
$30-34$ & $1.15(0.96-1.39)$ \\
$35-39$ & $1.29(1.04-1.59)$ \\
$40-44$ & $1.44(1.06-1.95)$ \\
$\geq 45$ & $1.71(0.63-4.66)$ \\
\hline
\end{tabular}

\section{Gestational week 23-29}

\begin{tabular}{cc}
\hline Maternal age & Adjusted HR* $(95 \%$ \\
\hline$<20$ & $1.27(0.81-2.00)$ \\
$20-24$ & 1 \\
$25-29$ & $1.03(0.80-1.33)$ \\
$30-34$ & $1.07(0.80-1.41)$ \\
$35-39$ & $1.11(0.80-1.55)$ \\
$40-44$ & $1.20(0.71-2.04)$ \\
$\geq 45$ & \\
\hline
\end{tabular}

\section{Gestational week 30-36}

\begin{tabular}{cc}
\hline Maternal age & Adjusted $\mathrm{HR}^{*}(95 \% \mathrm{CI})$ \\
\hline$<20$ & $0.95(0.51-1.75)$ \\
$20-24$ & 1 \\
$25-29$ & $1.06(0.79-1.43)$ \\
$30-34$ & $1.41(1.03-1.93)$ \\
$35-39$ & $1.62(1.12-2.34)$ \\
$40-44$ & $2.42(1.43-4.12)$ \\
$\geq 45$ & $2.50(0.34-18.38)$ \\
\hline
\end{tabular}

\section{Gestational week 37-43}

\begin{tabular}{cc}
\hline Maternal age & Adjusted $\mathrm{HR}^{*}(95 \% \mathrm{CI})$ \\
\hline$<20$ & $1.74(1.12-2.72)$ \\
$20-24$ & 1 \\
$25-29$ & $1.41(1.09-1.83)$ \\
$30-34$ & $1.53(1.16-2.03)$ \\
$35-39$ & $2.19(1.60-3.00)$ \\
$40-44$ & $2.24(1.38-3.65)$ \\
$>45$ &
\end{tabular}

\footnotetext{
* Adjusted for period of delivery, paternal age, parity and pre-eclampsia. At 16-22 weeks pre-eclampsia is not adjusted for.
} 
Table B. Adjusted hazard ratio with $95 \% \mathrm{Cl}$ of fetal death in gestational weeks $16-43$ according to year of delivery among singletons (corresponding to Table 2 in Paper II, but limited to singletons).

\begin{tabular}{cc}
\multicolumn{2}{l}{ Gestational week 16-22 } \\
\hline Year & Adjusted HR* $(95 \% \mathrm{CI})$ \\
\hline $1967-1971$ & 1 \\
$1972-1976$ & $1.14(1.00-1.30)$ \\
$1977-1981$ & $1.26(1.10-1.43)$ \\
$1982-1986$ & $1.43(1.26-1.63)$ \\
$1987-1991$ & $2.03(1.81-2.28)$ \\
$1992-1996$ & $2.68(2.41-3.00)$ \\
$1997-2001$ & $2.35(2.10-2.63)$ \\
$2002-2006$ & $1.92(1.71-2.16)$ \\
\hline
\end{tabular}

Gestational week 23-29

\begin{tabular}{cc}
\hline Year & Adjusted HR* $(95 \% \mathrm{CI})$ \\
\hline $1967-1971$ & 1 \\
$1972-1976$ & $1.10(1.00-1.22)$ \\
$1977-1981$ & $1.06(0.95-1.18)$ \\
$1982-1986$ & $0.91(0.82-1.02)$ \\
$1987-1991$ & $0.79(0.70-0.88)$ \\
$1992-1996$ & $0.72(0.64-0.81)$ \\
$1997-2001$ & $0 . .57(0.50-0.64)$ \\
$2002-2006$ & $0.44(0.39-0.50)$ \\
\hline
\end{tabular}

\section{Gestational week 30-36}

\begin{tabular}{cc}
\hline Year & Adjusted HR* $(95 \% \mathrm{CI})$ \\
\hline $1967-1971$ & 1 \\
$1972-1976$ & $0.82(0.75-0.89)$ \\
$1977-1981$ & $0.67(0.62-0.74)$ \\
$1982-1986$ & $0.48(0.43-0.53)$ \\
$1987-1991$ & $0.38(0.34-0.43)$ \\
$1992-1996$ & $0.30(0.26-0.33)$ \\
$1997-2001$ & $0.26(0.22-0.30)$ \\
$2002-2006$ & $0.19(0.16-0.21)$ \\
\hline
\end{tabular}

\section{Gestational week 37-43}

\begin{tabular}{cc}
\hline Year & Adjusted HR* $(95 \% \mathrm{CI})$ \\
\hline $1967-1971$ & 1 \\
$1972-1976$ & $0.79(0.74-0.86)$ \\
$1977-1981$ & $0.58(0.53-0.64)$ \\
$1982-1986$ & $0.44(0.40-0.49)$ \\
$1987-1991$ & $0.36(0.32-0.39)$ \\
$1992-1996$ & $0.35(0.31-0.39)$ \\
$1997-2001$ & $0.37(0.34-0.41)$ \\
$2002-2006$ & $0.30(0.26-0.33)$ \\
\hline
\end{tabular}

* Adjusted for maternal age, paternal age, parity and pre-eclampsia. At 16-22 weeks preeclampsia is not adjusted for. 
Table C. Adjusted hazard ratio with $95 \% \mathrm{Cl}$ of fetal death in gestational weeks $16-43$ according to maternal age among singletons (corresponding to Table 2 in Paper III, but limited to singletons).

\begin{tabular}{cc}
\multicolumn{2}{l}{ Gestational week 16-22 } \\
\hline Maternal age & Adjusted HR* $(95 \% \mathrm{CI})$ \\
\hline$<20$ & $1.10(0.97-1.26)$ \\
$20-24$ & 1 \\
$25-29$ & $1.05(0.97-1.15)$ \\
$30-34$ & $1.22(1.10-1.34)$ \\
$35-39$ & $1.52(1.36-1.70)$ \\
$40-44$ & $2.06(1.74-2.43)$ \\
$\geq 45$ & $1.22(0.58-2.58)$ \\
\hline
\end{tabular}

Gestational week 23-29

\begin{tabular}{cc}
\hline Maternal age & Adjusted $\mathrm{HR}^{*}(95 \% \mathrm{CI})$ \\
\hline$<20$ & $1.08(0.96-1.22)$ \\
$20-24$ & 1 \\
$25-29$ & $1.03(0.95-1.13)$ \\
$30-34$ & $1.17(1.05-1.30)$ \\
$35-39$ & $1.32(1.15-1.52)$ \\
$40-44$ & $1.43(1.14-1.80)$ \\
$\geq 45$ & $2.14(1.14-4.04)$ \\
\hline
\end{tabular}

Gestational week 30-36

\begin{tabular}{cc}
\hline Maternal age & Adjusted $\mathrm{HR}^{*}(95 \% \mathrm{CI})$ \\
\hline$<20$ & $0.85(0.76-0.96)$ \\
$20-24$ & 1 \\
$25-29$ & $1.10(1.01-1.19)$ \\
$30-34$ & $1.34(1.21-1.48)$ \\
$35-39$ & $1.70(1.49-1.93)$ \\
$40-44$ & $2.23(1.85-2.70)$ \\
$\geq 45$ & $2.68(1.56-4.60)$ \\
\hline
\end{tabular}

Gestational week 37-43

\begin{tabular}{cc}
\hline Maternal age & Adjusted $\mathrm{HR}^{*}(95 \% \mathrm{CI})$ \\
\hline$<20$ & $0.78(0.70-0.88)$ \\
$20-24$ & 1 \\
$25-29$ & $1.24(1.15-1.33)$ \\
$30-34$ & $1.49(1.35-1.63)$ \\
$35-39$ & $1.98(1.76-2.23)$ \\
$40-44$ & $2.76(2.32-3.29)$ \\
$\geq 45$ & $3.42(2.06-5.67)$ \\
\hline
\end{tabular}

* Adjusted for period of delivery, paternal age, parity and pre-eclampsia. At 16-22 weeks preeclampsia is not adjusted for. 
Table D. Hazard ratio with $95 \% \mathrm{Cl}$ of fetal death in gestational weeks $16-43$ according to maternal age, stratified by parity (corresponding to Table 2 in Paper III, but stratified by parity to check for interaction). The P-value was obtained by incorporating an interaction term between maternal age and parity into the regression model. Nulliparous women 35 years and older had increased risk of fetal death compared to multiparous women.

\section{Gestational week 16-22}

\begin{tabular}{cccc} 
Maternal age & 0 & Parity* & \multicolumn{1}{c}{2} \\
\hline$<20$ & $1.38(1.20-1.57)$ & $1.52(1.06-2.16)$ & $1.63(0.40-6.60)$ \\
$20-24$ & 1 & 1 & 1 \\
$25-29$ & $1.22(1.09-1.35)$ & $1.00(0.88-1.13)$ & $0.96(0.77-1.21)$ \\
$30-34$ & $1.52(1.34-1.74)$ & $1.31(1.15-1.45)$ & $1.23(0.99-1.52)$ \\
$35-39$ & $2.38(1.98-2.85)$ & $2.01(1.71-2.37)$ & $1.50(1.12-1.90)$ \\
$40-44$ & $4.08(2.90-5.75)$ & $3.36(2.49-4.53)$ & $2.26(1.63-3.14)$ \\
$\geq 45$ & $2.70(0.38-19.18)$ & $2.56(0.36-18.18)$ & $1.25(0.17-8.93)$ \\
\hline * P-value for interaction term in regression analysis $\mathrm{p}=0.008$
\end{tabular}

\section{Gestational week 23-29}

\begin{tabular}{cccr} 
Maternal age & 0 & Parity** & \multicolumn{1}{c}{2} \\
\hline$<20$ & $1.50(1.33-1.70)$ & $1.79(1.29-2.49)$ & $4.32(1.76-10.64)$ \\
$20-24$ & 1 & 1 & 1 \\
$25-29$ & $0.85(0.76-0.95)$ & $0.77(0.67-0.87)$ & $0.84(0.67-1.06)$ \\
$30-34$ & $0.98(0.85-1.13)$ & $0.76(0.66-0.89)$ & $0.67(0.53-0.85)$ \\
$35-39$ & $1.34(1.07-1.66)$ & $0.79(0.62-0.99)$ & $0.83(0.63-1.08)$ \\
$40-44$ & $1.64(1.00-2.68)$ & $1.19(0.73-1.93)$ & $0.85(0.53-1.39)$ \\
$\geq 45$ & $2.28(0.32-16.19)$ & $2.56(0.36-18.22)$ & $1.31(0.18-9.40)$ \\
\hline$* *$ P-value for interaction term in regression analysis $\mathrm{p}=0.032$
\end{tabular}

\section{Gestational week 30-36}

\begin{tabular}{cccc} 
Maternal age & 0 & Parity*** & \multicolumn{1}{c}{2} \\
\hline$<20$ & $1.26(1.12-1.439$ & $1.04(0.69-1.57)$ & $0.92(0.13-6.59)$ \\
$20-24$ & 1 & 1 & 1 \\
$25-29$ & $0.83(0.75-0.92)$ & $0.81(0.72-0.92)$ & $0.83(0.65-1.05)$ \\
$30-34$ & $0.98(0.86-1.12)$ & $0.82(0.71-0.94)$ & $0.77(0.61-0.98)$ \\
$35-39$ & $1.41(1.15-1.72)$ & $1.30(1.08-1.56)$ & $0.91(0.70-1.18)$ \\
$40-44$ & $1.90(1.22-2.96)$ & $1.64(1.09-2.45)$ & $1.87(1.29-2.69)$ \\
$\geq 45$ & $13.20(5.91-29.5)$ & $4.91(1.22-19.68)$ & $1.36(0.19-9.75)$ \\
\hline$* * *$ P-value for interaction term in regression analysis $\mathrm{p}=0.160$
\end{tabular}

\section{Gestational week 37-43}

\begin{tabular}{cccr} 
Maternal age & 0 & 1 & 2 \\
\hline$<20$ & $1.06(0.95-1.19)$ & $1.08(0.71-1.64)$ & 0 \\
$20-24$ & 1 & 1 & 1 \\
$25-29$ & $0.92(0.84-1.01)$ & $1.04(0.92-1.18)$ & $0.92(0.74-1.15)$ \\
$30-34$ & $1.15(1.02-1.29)$ & $1.03(0.90-1.19)$ & $0.92(0.74-1.15)$ \\
$35-39$ & $2.14(1.81-2.52)$ & $1.70(1.14-2.05)$ & $1.08(0.84-1.38)$ \\
$40-44$ & $2.57(1.74-3.79)$ & $2.05(2.15-4.33)$ & $1.76(1.12-2.57)$ \\
$\geq 45$ & & & $1.54(0.21-11.02)$ \\
\hline$* * * *$ P-value for interaction term in regression analysis $\mathrm{p}=0.031$
\end{tabular}





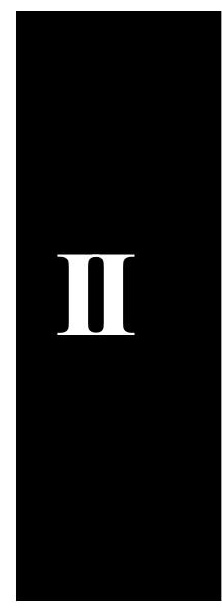





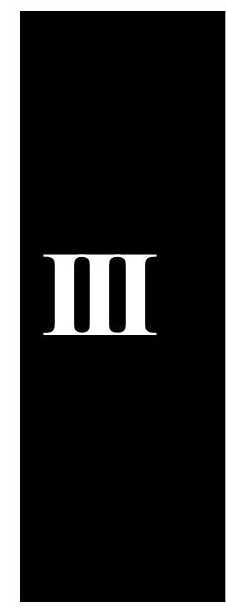





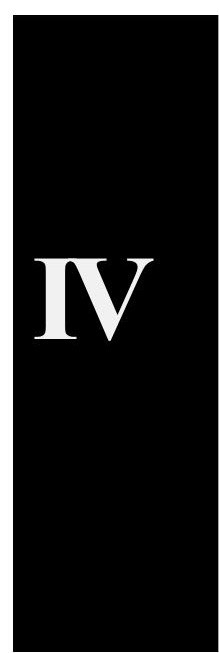







\section{Registreringsskjema fra 1967-1998}

STATENS HELSETILSYN Postboks 8128 Dep. 0032 OSLO

\section{Medisinsk registrering av fødsel}

Sendes 9. dag etter fodselen til tylkeslegen (stadsfysikus) i det fylket der moren er bosatt.

Merk: Det skal fylles ut blankett for hvert barn (foster). Dør barnet etter fødselen, skal det også fylles ut legeerklæring om dødsfall, og/eller dødsfallet meldes til skifteretten (lensmannen).

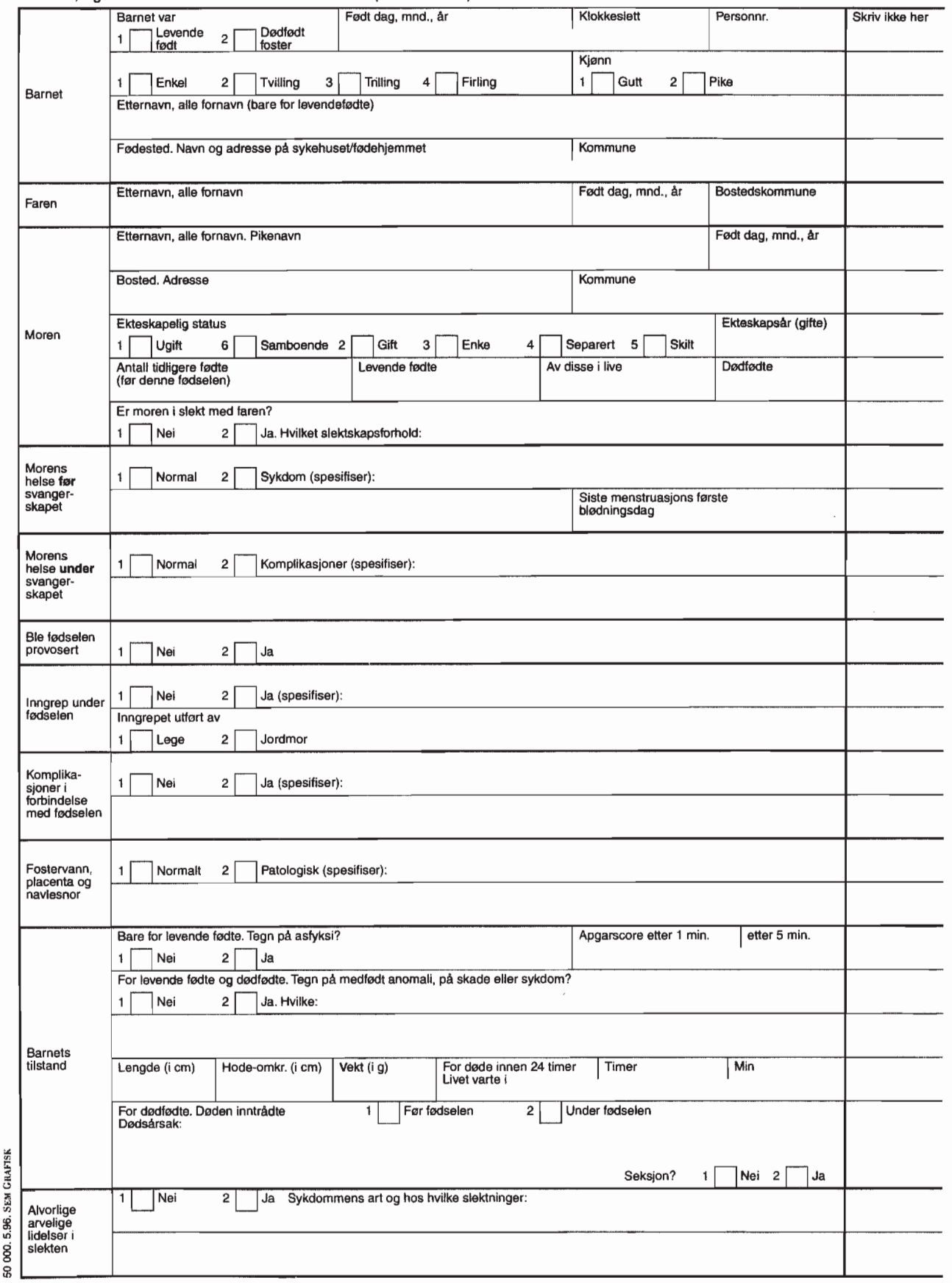





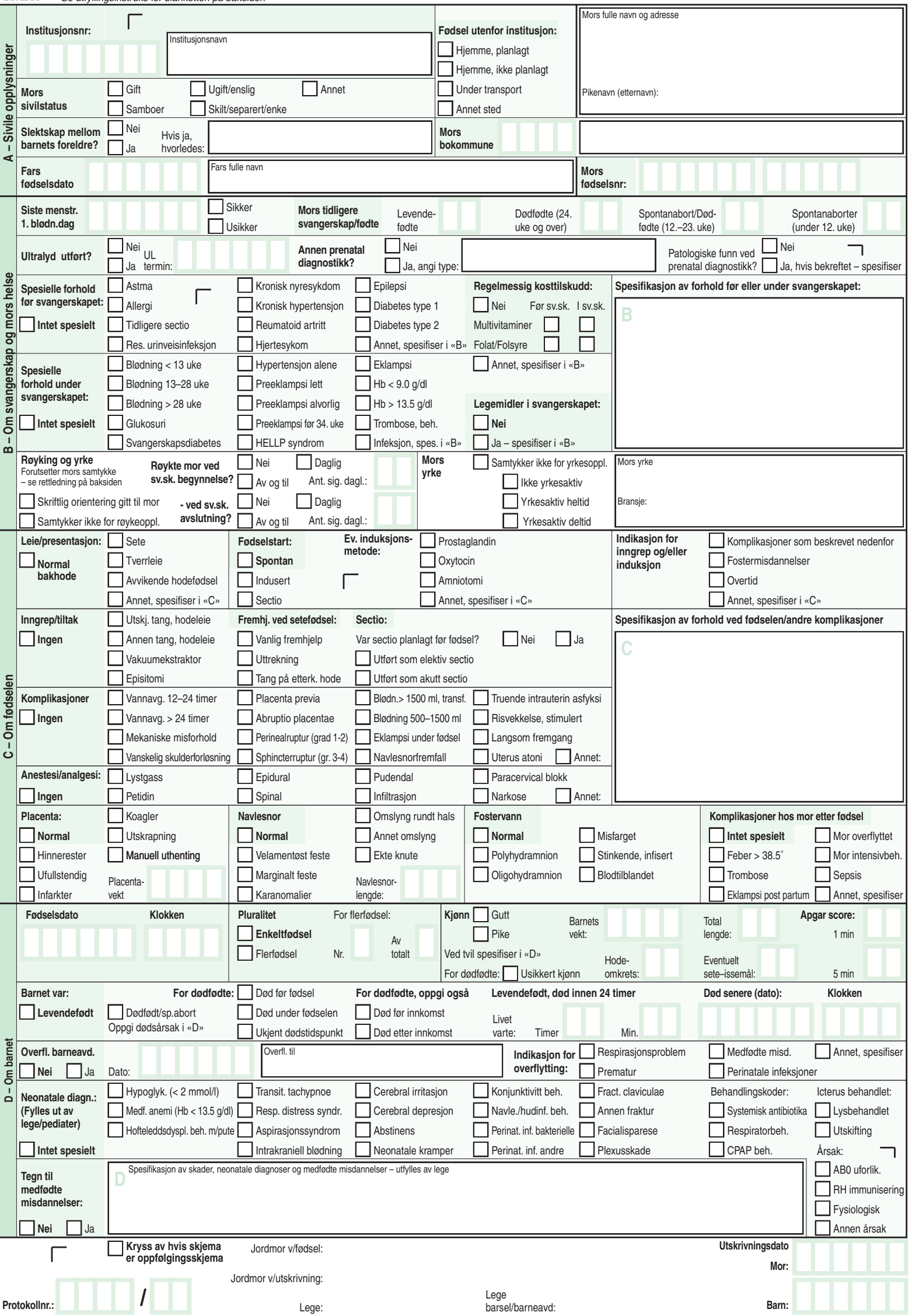


